Viviane Monteiro Silva Kupriyanov

Análise de conteúdo estomacal de aves Furnariida (Passeriformes)

São Paulo 
Viviane Monteiro Silva Kupriyanov

\title{
Análise de conteúdo estomacal de aves Furnariida (Passeriformes)
}

\author{
Exemplar corrigido.
}

O original encontra-se disponível no Instituto de Biociências da Usp.

Dissertação apresentada ao Instituto de Biociências da Universidade de São Paulo, para a obtenção de Título de Mestre em Ciências, na Área de Zoologia.

Orientadora: Profa. Dra. Elizabeth Höfling

São Paulo 
Ficha Catalográfica

Kupriyanov, Viviane Monteiro Silva

Análise de conteúdo estomacal de aves Furnariida (Passeriformes)

$95 \mathrm{Pp}$.

Dissertação (Mestrado) - Instituto de Biociências da Universidade de São Paulo. Departamento de Zoologia.

1.Furnariida. 2. aves. 3.conteúdo estomacal. 4. artrópodes. 5.vertebrados.

Universidade de São Paulo. Instituto de Biociências.

Departamento de Zoologia.

Comissão Julgadora:

Prof.(a) Dr.(a)

Prof.(a) Dr.(a)

Profa.Dra. Elizabeth Höfling

Orientadora 
Dedicatória

À minha pequena Sofia 


\section{Agradecimentos}

À Profa. Dra. Elizabeth Höfling pela orientação, confiança, paciência e valorosa contribuição na minha formação profissional.

Ao Juan D. Daza, pela colaboração frutífera e considerável auxílio na identificação dos vertebrados.

Ao Renato Gaban Lima, pela ideia original do trabalho executado e por parte das amostras coletadas.

Ao Guilherme Renzo Rocha Brito, pela colaboração e amostras coletadas.

Ao Prof. Dr. Sérgio Antonio Vanin pela constante ajuda na identificação dos invertebrados.

Aos curadores e responsáveis pelas coleções por cederem o material para estudo e pela atenção e disposição demonstradas: Prof. Dr. Carlos José Einicker Lamas (Diptera) e Prof. Dr. Ricardo Pinto da Rocha (Arachnida) - Museu de Zoologia da Universidade de São Paulo; Prof. Dr. Sérgio Antonio Vanin, por disponibilizar a Coleção Didática do Departamento de Zoologia - Instituto de Biociências da Universidade de São Paulo; Prof. Dr Flávio Henrique Caetano (Universidade Estadual Paulista " Júlio de Mesquita Filho" - Câmpus Rio Claro) e Fernando José Zara (Universidade Estadual Paulista "Júlio de Mesquita Filho" - Câmpus Jaboticabal) por ceder material de Hymenoptera (Formicidae) proveniente da Amazônia.

Aos professores das disciplinas de pós-graduação que contribuíram com a minha formação Prof. Dr. Sérgio Antonio Vanin, Prof. Dr. Marcelo Duarte da Silva, Profa. Dra. Sônia Aparecida Casari, Profa Dra. Elizabeth Höfling, Prof. Dr. Dante Martins Teixeira, Prof. Dr. José Carlos Motta Júnior.

Aos técnicos do Depto. de Zoologia, Ênio Mattos e Phillip Lenktaitis, e à técnica do Museu de Zoologia Ana Maria Vasques, pela atenção e disposição em ajudar.

Ao Professor Peter Gibbs do Plant Sciences Laboratory School of Biology da University of St. Andrews, Escócia, Reino Unido, pela revisão do Abstract. 
À Fernanda Porcari, pelo auxílio na formatação e organização da dissertação.

À Lívia Pinheiro e Andrea Ferrari pelas críticas e sugestões na finalização deste trabalho.

À Coordenadoria de Aperfeiçoamento de Pessoal de Ensino Superior (CAPES) pelo apoio financeiro por intermédio do curso de Pós-graduação, do Instituto de Biociências da Universidade de São Paulo.

Aos amigos da pós-graduação: Andrea Paixão, Andrea Ferrari, Fernanda Porcari, Thiago Alves, Rafael Migotto, Talitha Pires e Catapa (Vanderson); amigos do IB: Alice, Aline, Angela, Maíra, Mariana, Leda, Roggero, Gustavo e amigos - veteranos de Ribeirão Preto, lepidopteristas - Lívia e Simeão.

Aos meus queridos pais, José Francisco e Zilda, pelo amor, incentivo e paciência, sempre dispostos a oferecer ajuda; às minhas irmãs, Cibele e Letícia, e aos cunhados, Hugo e André, pelo carinho, confiança e permanente apoio.

Ao meu querido esposo pelo incentivo e força que me deu ao longo deste trabalho, pela compreensão e apoio nos momentos mais difíceis, suprindo as necessidades emergentes e zelando por nossa filha Sofia. Por todo seu amor e carinho. 


\section{Sumário}

1. Introdução

.01

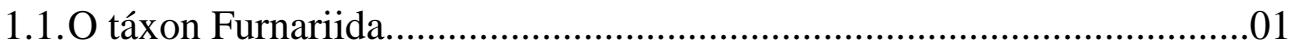

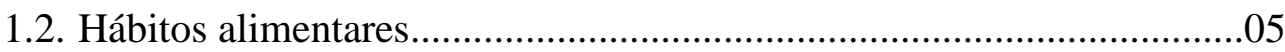

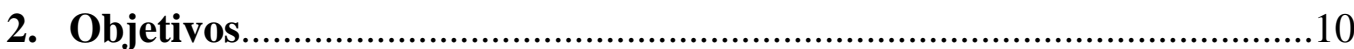

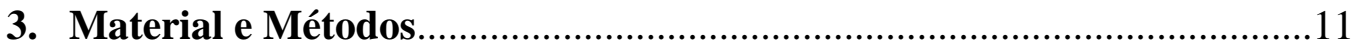

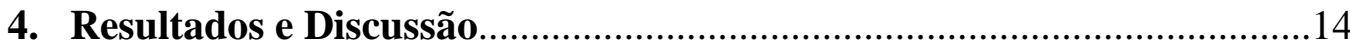

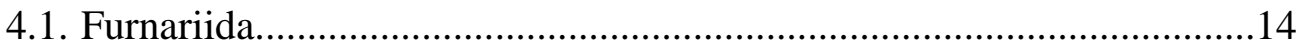

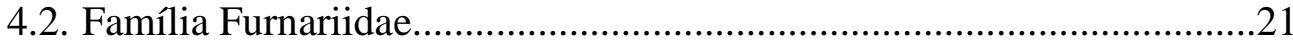

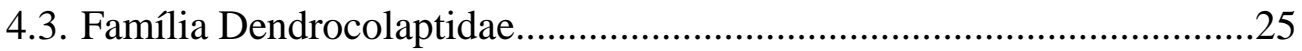

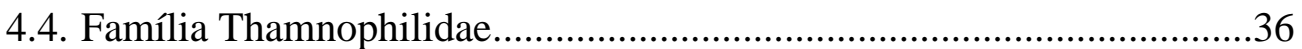

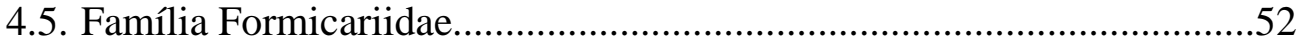

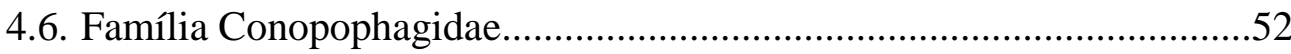

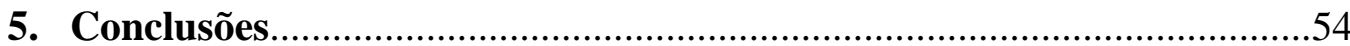

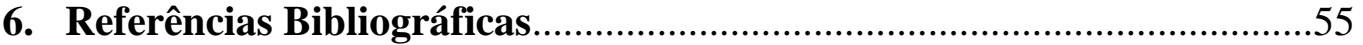

7. Resumo

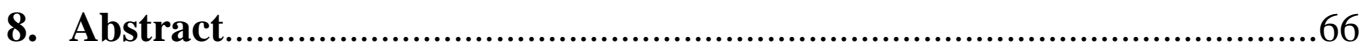

Anexo 1 - Relação dos espécimes amostrados............................................67

Anexo 2 - Frequência de ocorrência (FO) de itens alimentares consumidos por espécies de Furnariida .88 
Figura 1. Hemiptera (Auchenorrhyncha).

Figura 2. Cabeça de Coleoptera (Curculionidae) ......................................................... 15

Figura 3. Par de asas e cabeça de Hemiptera (Heteroptera).........................................16

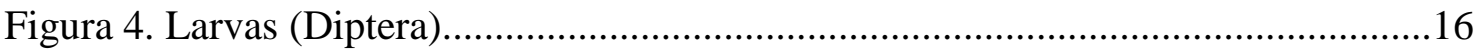

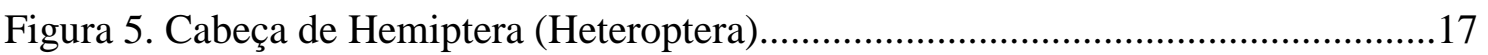

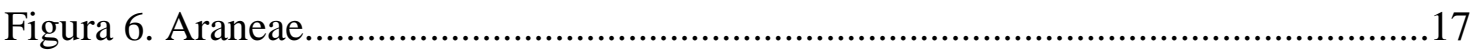

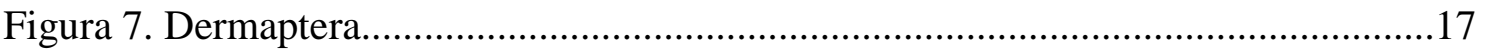

Figura 8. Úmeros e fêmures de Gonatodes humeralis...................................................18

Figura 9. Dentário direito de Gonatodes humeralis..................................................18

Figura 10. Itens alimentares consumidos por Automolus ochrolaemus $(\mathrm{n}=14) \ldots \ldots \ldots \ldots . . .23$

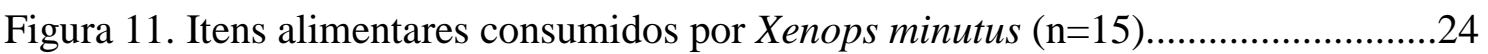

Figura 12. Biomassa consumida por representantes de Dendrocolaptidae...................29

Figura 13. Itens alimentares consumidos por Dendrocincla fuliginosa $(\mathrm{n}=20) \ldots \ldots \ldots \ldots . . .30$

Figura 14. Itens alimentares consumidos por Dendrocincla merula $(\mathrm{n}=12) \ldots \ldots \ldots \ldots \ldots . . . . .30$

Figura 15. Itens alimentares consumidos por Glyphorhynchus spirurus $(\mathrm{n}=50) \ldots \ldots \ldots . . .32$

Figura 16. Itens alimentares consumidos por Xiphorhynchus spixii $(\mathrm{n}=10) \ldots \ldots \ldots \ldots \ldots \ldots . . . .35$

Figura 17. Itens alimentares consumidos por Xiphorhynchus guttatus $(\mathrm{n}=15) \ldots \ldots \ldots \ldots . . . . .35$

Figura 18. Itens alimentares consumidos por Thamnophilus schistaceus $(\mathrm{n}=15) \ldots \ldots \ldots . . .38$

Figura 19. Itens alimentares consumidos por Thamnomanes saturninus $(\mathrm{n}=29) \ldots \ldots \ldots \ldots . .39$

Figura 20. Itens alimentares consumidos por Thamnomanes caesius $(\mathrm{n}=18) \ldots \ldots \ldots \ldots . . . .40$ 
Figura 21. Itens alimentares consumidos por Myrmotherula hauxwelli $(\mathrm{n}=16)$.

Figura 22. Itens alimentares consumidos por Myrmotherula leucophthama $(\mathrm{n}=10) \ldots . . .43$

Figura 23. Itens alimentares consumidos por Myrmotherula axillaris $(\mathrm{n}=34) \ldots \ldots \ldots \ldots \ldots . . . .44$

Figura 24. Itens alimentares consumidos por Myrmoborus myotherinus $(\mathrm{n}=10) \ldots \ldots \ldots \ldots . . .46$

Figura 25. Itens alimentares consumidos por Hypocnemis cantator $(\mathrm{n}=22) \ldots \ldots \ldots \ldots \ldots \ldots . . . . .47$

Figura 26. Itens alimentares consumidos por Hylophylax poecilinotus $(\mathrm{n}=24) \ldots \ldots \ldots \ldots . . .50$

Figura 27. Itens alimentares consumidos por Phlegopsis nigromaculata $(\mathrm{n}=10) \ldots \ldots \ldots . .52$ 


\section{Introdução}

\subsection{O táxon Furnariida}

São consideradas 9.895 espécies de aves no mundo (del Hoyo et al., 2010) e, entre elas, a ordem dos Passeriformes representa mais da metade da riqueza de espécies atuais (Sibley e Monroe, 1990). Dois grandes grupos são identificados entre os Passeriformes: os Oscines, numericamente dominantes e distribuídos mundialmente, e os Suboscines, com poucas espécies no Velho Mundo e maior diversidade na América do Sul (Sick, 1997).

No Brasil estima-se que mais de 1.000 espécies pertençam à ordem Passeriformes (CBRO, 2011), sendo que 35\% delas faz parte do clado Furnariida (Sibley et al., 1988 e Irestedt et al., 2002), reconhecido já há muito tempo por outros nomes (e.g.: Furnarioidea, Tracheophonae) (Marantz et al., 2003). Todas as famílias desta linhagem, que incluem Furnariidae, Dendrocolaptidae, Thamnophilidae, Formicariidae, Conopophagidae e Rhinocryptidae, compartilham morfologia única da siringe (Ames, 1971; King, 1989) - monofilia que também é suportada por hipóteses filogenéticas moleculares (Irestedt et al., 2002). O clado dos Furnariida é endêmico da região Neotropical e extremamente diverso em termos de especialização ecológica (Irested et al., 2002), representado por cerca de 623 espécies distribuídas em 134 gêneros (del Hoyo et al., 2003).

A família Furnariidae (56 gêneros e 236 espécies), representada pelas aves conhecidas popularmente como joão-de-barro e joão-teneném é, tradicionalmente, reconhecida como um grupo natural (e.g., Pinto 1978; Meyer de Schauensee, 1982; Ridgely e Tudor, 1994; Sick, 1997; Remsen, 2003). No entanto, de acordo com resultados apresentados por Irestedt et al. (2002) e Chesser (2004), o táxon Dendrocolaptidae (arapaçus) é considerado grupo inclusivo no clado dos Furnariidae.

De maneira geral, os furnariídeos são aves de coloração apagada, com predominância de tons de marrom, ferrugem ou cinza e não registram dimorfismo sexual externo (Ridgely e Tudor, 1994). São exclusivamente Neotropicais, distribuídas desde as mais altas altitudes nos Andes até as planícies da Amazônia - abrigando a mais rica comunidade de aves do mundo. Seus hábitos estendem-se de florestas 
permanentemente úmidas, desertos secos, dunas de areias litorâneas e até a zona rochosa entre marés (Remsen, 2003).

A família Dendrocolaptidae é representada por 13 gêneros e 52 espécies. Ela constitui um grupo uniforme de aves Passeriformes de porte pequeno a médio, conhecidas como arapaçus. Todos os integrantes desta família compartilham um padrão exclusivo da pterilose, e calcificação extensa dos tendões dos membros posteriores adaptação relacionada ao seu hábito escansorial (Marantz et al., 2003). As aves desta família possuem coloração marrom (em várias tonalidades), havendo frequentemente a invasão de ferrugem, branco e preto (Ridgely e Tudor, 1994).

A maioria dos dendrocolaptídeos ocorre, principalmente, em florestas úmidas, alcançando máxima diversidade na Amazônia, entre as florestas de terra firme e áreas inundáveis como várzeas e igapós (Marantz et al., 2003). Algumas espécies ocorrem no cerrado e outras em áreas semiabertas. Um número menor de arapaçus vive em florestas de pinheiros nas montanhas da América Central.

Os dendrocolaptídeos apresentam semelhanças morfológicas análogas às dos pica-paus (Picidae) e, como eles, também escalam troncos de árvores. Porém, apesar das similaridades, os arapaçus exibem uma variedade de comportamentos de forrageamento e não se limitam à captura de alimento em troncos (Chapman e Rosenberg, 1991).

A família Thamnophilidae (papa-formigas, chocas etc.) é representada por 45 gêneros e 209 espécies. Originalmente, esta família estava inserida no táxon dos Formicariidae (Ridgely e Tudor, 1994), mas análises siringeais (Ames, 1971), combinadas com resultados obtidos de hibridação de DNA, apontam que os dois táxons fazem parte de linhagens distintas (Sibley e Ahlquist, 1990).

As características da siringe, forma do esterno, escutelação do tarsometatarso, conexão dos artelhos e detalhes da estrutura da maxila superior são características estruturais que definem esta família. Os representantes deste táxon apresentam um entalhe tomial subterminal na maxila superior - uma adaptação que os auxilia a explorar e esmagar artrópodes. Em espécies maiores, o bico é forte o suficiente para apreender e macerar pequenos vertebrados (Zimmer e Isler, 2003). 
Vários tamnofilídeos têm áreas desprovidas de penas, particularmente ao redor dos olhos, que contrastam com a pele também nua da face. Isto é, principalmente, proeminente entre os seguidores - regulares e obrigatórios - de formigas de correição. Todos os membros do gênero Rhegmatorhina apresentam essas "manchas" periorbitais evidentes. Willis (1969) especulou que estes "olhos" proeminentes funcionam como uma grande íris, afugentando potenciais predadores ou competidores assustados da mesma ou de outras espécies.

A plumagem da maioria dos representantes desta família não é muito colorida. No entanto, muitos apresentam um padrão chamativo em tons de preto, branco, vários tons de ferrugem, castanho ou amarelo. Na maioria das espécies há dimorfismo sexual externo. Em geral, os machos possuem combinações de cinza, preto e branco, enquanto que as fêmeas tendem para castanho e ferrugem. Nem todas as aves deste táxon exibem forte dimorfismo sexual externo, cujo padrão é particularmente observado entre as seguidoras de formigas de correição (Zimmer e Isler, 2003).

Os representantes da família Thamnophilidae estão totalmente distribuídos na região Neotropical, e em algumas ilhas próximas da costa continental. A grande maioria deles habita as planícies de florestas úmidas, e atinge sua maior diversidade na bacia amazônica. A diversidade de espécies diminui conforme há um aumento da altitude nas regiões montanhosas. Muitos membros da família são arborícolas, que vão do subbosque até o dossel, porém alguns são terrícolas (como é o caso do gênero Myrmeciza) (Zimmer e Isler, 2003).

A família Formicariidae (tovacas, mãe-de-taoca e afins) é representada por sete gêneros e 63 espécies. Mesmo depois da separação dos tamnofilídeos do clado Formicariidae (Ames, 1971; Sibley e Ahlquist, 1990), ainda há controvérsias quanto à monofilia do grupo. Dois estudos sugerem que esta família seja parafilética (Irested et al., 2002; Chesser, 2004).

Os formicariídeos habitam florestas úmidas, com apenas uma espécie limitada a ambientes secos (Grallaria watkinsi). Eles forrageiam, principalmente, sobre o solo, bem escondidos no sub-bosque (Krabe e Schulenberg, 2003a), e a maioria é claramente colorida (Rice, 2005). Apresentam cabeça larga, olhos grandes e cauda curta. Não são bons voadores, apenas as espécies de Formicarius são capazes de um forte voo, no 
entanto elas raramente usam suas asas exceto quando deixam o ninho, ou quando pressionadas por um predador. Não apresentam dimorfismo sexual externo, exceto alguns gêneros (Pittasoma e Grallaricula). As fêmeas tendem a ser um pouco menor do que os machos da mesma espécie, mas no caso de Formicarius e, possivelmente, também Chamaeza, o inverso também pode acontecer (Krabe e Schulenberg, 2003a).

A família Conopophagidae (popularmente conhecidos como chupa-dentes e cuspidores), representada por um gênero com oito espécies, é tradicionalmente considerada um grupo próximo aos formicariídeos e tapaculos (Rhinocryptidae) (Sibley e Ahlquist, 1990). Tal relacionamento é suportado por dados morfológicos e moleculares recentes, porém o status como uma família separada das demais é bastante controverso (Whitney, 2003).

Os representantes desta família formam um grupo morfologicamente conservado, mostrando pouca variação na forma básica e característica. Todos são pequenos, com cauda curta e asas arredondadas e curtas. Eles têm pernas proporcionalmente longas, e bico achatado com um gancho sutil na ponta. A maioria apresenta uma listra pós-ocular branca e conspícua (Whitney, 2003).

Os conopofagídeos são encontrados primordialmente em hábitats úmidos de florestas baixas. Todos são habitantes de sub-bosque e são, frequentemente, vistos próximos ou no chão. Também, empoleiram em galhos horizontais, cipós e troncos (Sick, 1997; Whitney, 2003).

Os representantes da famíla Rhinocryptidae (popularmente conhecidos como tapaculos) são aves terrícolas de porte pequeno a médio, com 12 gêneros e 55 espécies. Esta família mostra-se polifilética, de acordo com as evidências moleculares (Irestedt $e t$ al., 2002), pois apresenta duas linhagens distintas: o gênero Melanopareia, com quatro espécies, que não aparece associado aos demais gêneros reconhecidos nessa família, e os demais rinocriptídeos. Irestedt et al. (2002) recomendam o reconhecimento de uma nova família, Melanopareiidae. Com essa nova proposta, a família Rhinocryptidae manter-se-ia agrupada aos demais Furnariida.

Os tapaculos têm, geralmente, bico reto, fraco e fino, mas em algumas espécies a base do bico é elevada para adicionar mais força. Os opérculos táteis que cobrem as 
narinas de todos os tapaculos, deram origem ao nome Rhinocryptidae, que literalmente significa "nariz escondido" (Krabbe e Schulenberg, 2003b).

Como observado em outras aves que voam pouco, a quilha mediana do esterno está ausente. Com exceção de Melanopareia, os membros desta família têm a columela do ouvido médio distinta. Outra característica que os une é a presença do osso lacrimal fusionado ao etmoide. Já nos tamnofilídeos, formicariídeos e conopofagídeos não ocorre osso lacrimal (Krabbe e Schulenberg, 2003b).

\subsection{Hábitos alimentares}

Os primeiros registros sobre a alimentação de aves no Brasil foram publicados por Wied (1830-1833) e o zoólogo Burmeister (1856: apud Mallet-Rodrigues et al., 1997). Moojen et al. (1941) publicaram um trabalho referente à dieta de 189 espécies de aves, provenientes dos estados de Minas Gerais e do Mato Grosso. Em 1949, Hempel, em um trabalho publicado postumamente, apresentou a análise de 61 espécies de aves. Jimbo (1957) analisou a dieta dos Tinamidae. Schubart et al. (1965), a partir de 1900 espécimes, apresentaram os resultados da análise de cerca de 600 espécies e subespécies de aves brasileiras, sendo esse o estudo disponível mais abrangente. Aguirre (1973, 1974, 1975) descreveu, nesta série de trabalhos, a dieta de representantes da família Columbidae.

Todos os trabalhos citados acima são, essencialmente, descritivos, e a análise de conteúdo estomacal foi o método utilizado para a determinação da dieta das aves. Além do procedimento referido, outros métodos também são utilizados, tais como a análise de fezes (Pineschi, 1990; Hasui e Höfling, 1998) e de pelotas regurgitadas (Motta-Júnior e Talamoni, 1996), a observação direta no campo (Brandt e Machado, 1990; Sick, 1997; Hasui e Höfling, 1998) ou, ainda, pela análise do regurgito induzido pela ingestão forçada de tártaro emético (Mallet-Rodrigues et al., 1997).

Segundo Mills (1996), os diferentes métodos para amostragem de itens alimentares apresentam vantagens e desvantagens para uma fiel análise da composição da dieta de animais. Considerações éticas e/ou dificuldades na coleta de grande número de espécimes, por vezes, inviabilizam estudos baseados em análises do conteúdo gástrico (Mallet-Rodrigues et al.,1997). Bisbal e Ojasti (1980) consideram que a análise 
de conteúdo estomacal tem certas limitações como um método quantitativo, já que para obter um resultado mais próximo do real, depende do avanço da digestão (o tempo transcorrido desde a captura da presa). Entretanto, de acordo com Durães e Marini (2003) o método de análise de conteúdo estomacal permite maior precisão nos resultados.

A identificação dos itens alimentares, além de melhorar o conhecimento da dieta de aves neotropicais, é fundamental para entender o uso de recursos alimentares pelos animais, as interações entre espécies e, consequentemente, a estrutura de comunidades. Apesar disso, o conhecimento detalhado dos hábitos alimentares de espécies de florestas neotropicais permanece limitado (e.g. Poulin et al., 1994a; Poulin e Lefebvre, 1996; Rougés e Blake, 2001).

O estudo da dieta permite compreender tendências ecológicas, fisiológicas e comportamentais do grupo, tais como adaptações em relação à amplitude do nicho trófico (generalistas e especialistas) e à competição (moldando a forma e o tamanho dos nichos). Além disso, auxilia na elaboração de estratégias de manejo e conservação da fauna silvestre e seus respectivos hábitats (Bisbal e Ojasti, 1980; Rosenberg, 1993; Cueto e Casenave, 2002).

O hábito alimentar das aves é influenciado pelas suas características anatômicas, tais como especializações na forma do bico, língua, pernas, pés, estômagos e intestino, bem como pela disponibilidade de alimento, que varia espacial e temporalmente. Por esta razão as aves apresentam diferentes respostas às variações espaciais e/ou sazonais (Gill, 1994) ao selecionar os locais de forrageamento com base na oferta de recursos alimentares (Naranjo e Ulloa, 1997; Develey e Peres, 2000), desenvolvendo estratégias específicas para a captura de suas presas (Rosenberg, 1993) e regulam o tamanho do território, a massa corpórea (Kruuk e Parish, 1982) e, também, o sucesso reprodutivo (Orians, 1969).

O forrageamento de bandos mistos de espécies é um dos fenômenos mais conspícuos das aves de florestas tropicais (Munn e Terborgh, 1979). Estes grupos formam-se logo após o amanhecer e persistem até o entardecer, dia após dia, durante o ano (Davis, 1946; Jones, 1978). Cada bando contém espécies nucleares, que promovem a formação e a manutenção destes grupos mistos, por meio das vocalizações, coloração e comportamento (Munn e Terborgh, 1979). Entre os Passeriformes destacam-se os 
tamnofilídeos como componentes-chave de bandos mistos de sub-bosque e, em um grau menor, dos que se situam no dossel das árvores. Munn e Terborgh (1979) sugerem que as aves, membros dos bandos mistos, beneficiam-se do comportamento cooperativo antipredador e, por apresentarem técnicas de forrageamento semelhantes, os bandos têm importante papel na regulação da competição intra e interespecífica.

Em muitas florestas tropicais, as folhas que caem do dossel podem ficar presas a trepadeiras e outras plantas de estratos baixos, formando uma serrapilheira aérea. Estas folhas mortas suspensas funcionam como esconderijos diurnos de artrópodes noturnos. Gradwohl e Greenberg (1982) encontraram que 68\% dos artrópodes em folhas mortas, no Panamá, eram Blattodea, Orthoptera e Araneae e sugeriram que as espécies envolvidas eram únicas na serrapilheira aérea. Além disso, a frequência e o tamanho das presas encontradas em folhas mortas são maiores do que as encontradas na folhagem viva (Gradwohl e Greenberg, 1982; Rosenberg, 1990).

Algumas espécies de aves forrageiam procurando artrópodes, exclusivamente, em folhas mortas (Remsen e Parker, 1984; Rosenberg, 1990, 1993) e a grande maioria dessas aves especialistas pertence às famílias Furnariidae e Thamnophilidae. A maior parte desses forrageadores de serrapilheira aérea parece ser dependente de bandos mistos de espécies. Provavelmente, esses forrageadores de folhas mortas podem se beneficiar diretamente do aumento da vigilância fornecido pelos membros dos bandos mistos (Rosenberg, 1997).

Outra estratégia de forrageamento, peculiar das regiões tropicais, é a de seguir as formigas de correição. Ao afugentar artrópodes e pequenos vertebrados seus seguidores (aves, sapos, lagartos, vespas parasitas etc.) aproveitam para predar animais afugentados, ou atacar hospedeiros em potencial (Willis e Oniki, 1978; Brumfield et al., 2007).

As formigas de correição neotropicais são representadas pela tribo Ecitonini, cujas principais espécies são Eciton burchelli, de cor marrom na parte anterior e laranja clara no abdômen, com cerca de $10 \mathrm{~mm}$ de comprimento e Labidus praedator, uma espécie de formiga preta e pequena. Eciton burchelli forma enxames diurnos que contêm centenas de milhares de vorazes formigas carnívoras, que espantam grande número de artrópodes e pequenos vertebrados, muitos dos quais estão, normalmente, 
escondidos na serrapilheira. Labidus praedator tem ninhos subterrâneos e as trilhas são cobertas de terra desde o ninho até a frente de caçada, que ocorre, principalmente, à noite ou após a chuva e, por esta razão, representam um recurso menos confiável (Willis e Oniki, 1978).

As correições de formigas fornecem um importante auxílio que aumenta a eficiência de forrageamento das aves. Muitas espécies de aves seguidoras de formigas de correição evoluíram em especialistas deste tipo de forrageamento. As seguidoras ocasionais são espécies que apenas seguem as colunas de formigas, oportunisticamente, em seu território; as seguidoras regulares, rotineiramente buscam as correições além de seus territórios, mas, frequentemente, são encontradas forrageando independentemente das agregações de formigas; e as espécies obrigatórias, são incapazes de forragear independentemente das colunas de formigas ou outros agitadores de presas (Willis e Oniki, 1978; Zimmer e Isler, 2003). A maioria dos seguidores obrigatórios, ou "profissionais", são membros da família Thamnophilidae, embora alguns pertencem à família dos arapaçus (Dendrocolaptidae) (Zimmer e Isler, 2003).

Os representantes de Furnariida são considerados insetívoros (Sick, 1997), embora este termo refira-se à preferência alimentar por artrópodes, em geral, e não apenas a insetos (Mestre, 2002). Esses pássaros podem, ainda, consumir ocasionalmente uma pequena quantidade de frutos ou sementes (Lopes et al., 2003) e, esporadicamente, pequenos vertebrados (Lopes et al., 2005).

Grande parte dos furnariídeos é membro característico de bandos mistos de espécies, dentro dos quais eles são encontrados em pequenos grupos familiares (Sick, 1997). Por outro lado, eles não são bem representados em agregações de aves que seguem formigas de correição (Willis e Oniki, 1978).

Análises quantitativas da dieta de furnariídeos são quase ausentes. Apresentam dietas restritas a invertebrados, principalmente artrópodes. As ordens de insetos mais comumente detectadas em análises de conteúdos estomacais são, em geral, Orthoptera, Blattodea, Coleoptera e larvas de Lepidoptera (Schubart et al., 1965; Delarmelina e Alves, 2009; Vasconcelos et al., 2007; Remsen, 2003). Diptera e Hymenoptera (não Formicidae) parecem ser particularmente incomuns, o que não é surpresa diante da 
ausência de forrageamento aéreo entre representantes dessa família. Vertebrados são registrados na dieta de furnariídeos de grande porte (Remsen, 2003).

Muitas espécies de arapaçus associam-se a bandos mistos (Munn, 1985), enquanto outras seguem formigas de correição para se alimentarem dos animais espantados por elas (Willis e Oniki, 1978). Representantes desta família consomem artrópodes e, ocasionalmente, capturam pequenos vertebrados (Marantz et al., 2003). Além disso, com exceção do tamanho das presas, a dieta difere pouco entre as espécies (Chapman e Rosenberg, 1991; Rocha e Peñaranda, 1992; Poulin et al.,1994 a e b). Os itens de alimento mais comuns são gafanhotos e grilos (Orthoptera), besouros (Coleoptera), baratas (Blattodea), formigas (Formicidae), aranhas (Araneae) (Chapman e Rosenberg, 1991; Marantz et al., 2003). Há registros, para algumas espécies, quanto ao consumo de lagartos, especialmente do gênero Anolis (Poulin et al., 2001). Os dendrocolaptídeos consomem pequenas quantidades de cigarras e cigarrinhas (Auchenorrhyncha), percevejos (Heteroptera), cupins (Isoptera), tesourinhas (Dermaptera), formiga-leão (Neuroptera), abelhas e vespas (Hymenoptera), moscas (Diptera), mariposas (Lepidoptera), lagartas e larvas de outros insetos, libélulas (Odonata), centopeias (Chilopoda), piolhos-de-cobra (Diplopoda), escorpiões (Scorpiones), Pseudoscorpiones, e até pequenas lesmas (Mollusca) e caranguejos (Decapoda). Frutos e pequenas sementes foram encontrados em estômagos de poucos arapaçus (Poulin et al. 1994a; Lopes et al., 2005), mas é pouco provável que algum arapaçu consuma matéria vegetal com frequência (Marantz et al., 2003).

Todos os tamnofilídeos alimentam-se, principalmente, de uma ampla variedade de insetos e outros artrópodes, incluindo Araneae, Scorpiones, Chilopoda e Isopoda. Orthoptera, juntamente com Blattodea, Mantidae e Phasmida, parecem ser presas preferidas por muitas espécies, assim como larvas de Lepidoptera, besouros e aranhas (Zimmer e Isler, 2003). Algumas espécies alimentam-se de pequenos vertebrados, ao menos ocasionalmente. Tais presas consistem principalmente de pequenos lagartos, em geral, espécies do gênero Anolis (Poulin et al., 2001), embora também ocorram lagartixas, sapos e serpentes (Zimmer e Isler, 2003).

A grande maioria dos Thamnophilidae é seguidora obrigatória, ou "profissional" de formigas de correição (Willis e Oniki, 1978; Brumfield et al., 2007). Os membros 
desta família também formam bandos mistos de sub-bosque e, em um grau menor, que ficam no dossel das árvores. Munn e Terborgh (1979) encontraram duas espécies de Thamnomanes que servem como espécies nucleares de bandos mistos de sub-bosque.

Os Formicariidae, em geral, alimentam-se sozinhos, apesar de serem, frequentemente, encontrados aos pares. Em geral, não seguem bandos mistos, mas Formicarius, Chamaeza, Pittasoma, Hylopezus e Myrmothera forrageiam próximo de agregações de formigas de correição. $\mathrm{O}$ alimento ingerido pelos representantes desta família inclui uma grande variedade de invertebrados. Além disso, ossos de vertebrados, presumivelmente de sapos, são encontrados nos estômagos das espécies maiores (Poulin et al., 2001), e as espécies de Formicarius são conhecidas por predarem pequenas serpentes (Krabe e Schulenberg, 2003a).

A maior parte do alimento consumido pelos conopofagídeos provém da vegetação do solo. Eles ingerem, principalmente, artrópodes e a maioria das presas é, aparentemente, muito pequena, ou seja, menores do que $5 \mathrm{~mm}$. Uma ampla variedade de itens foi registrada e incluem aranhas, larvas, adultos de Coleoptera, Acrididae e outros Orthoptera, formigas e outros Hymenoptera, baratas, vermes e mariposas (Whitney, 2003).

Os tapaculos alimentam-se de uma variedade de artrópodes, principalmente insetos e aranhas. No entanto, podem ingerir também Chilopoda e Isopoda. Alguns rinocriptídeos podem consumir pequenos frutos e sementes. Forrageiam exclusivamente em estratos baixos da floresta, principalmente no chão (Krabbe e Schulenberg, 2003b). Andam ou correm rapidamente, antes de parar para procurar no chão com um pé, ou “ saltar-coçar" com ambos os pés, no qual a ave joga terra e folhas para trás a procura de alimento. Alguns tapaculos pegam presas de musgos, areia, terra e vegetação em decomposição (Scytalopus), outros em bambuzais e folhas caídas de bambus (Myornis) (Krabbe e Schulenberg, 2003b) .

\section{Objetivos}

Mesmo reconhecendo que as aves Furnariida são insetívoras, poucos são os trabalhos que descrevem em detalhes quais os grupos de artrópodes que são mais frequentemente consumidos e se, porventura, existe algum tipo de especialização em relação à preferência alimentar. Os estudos existentes sobre alimentação desses 
passeriformes são restritos a descrições qualitativas, enquanto que análises minuciosas sobre número de presas, estimativa da biomassa bruta consumida, podem acrescentar detalhes desconhecidos acerca dos representantes das diferentes famílias.

A partir desse contexto, o presente trabalho teve como objetivo geral descrever a dieta de espécies representantes dos Furnariida que ocorrem em diferentes regiões da Amazônia, sob o ponto de vista quali e quantitativo, procurando responder às seguintes perguntas:

Quais itens alimentares são encontrados frequentemente?

Qual a contribuição, em números e biomassa, destes itens alimentares?

\section{Material e Métodos}

As aves que foram utilizadas neste estudo são provenientes de diferentes campanhas de inventários em regiões da Amazônia e do seu contato com o Cerrado. Uma parte dos espécimes foi coletada - entre outubro e novembro de 2007 - em expedição às cabeceiras do Rio Madeira, nas regiões de Jauru - MT $\left(15,03^{\circ} \mathrm{S} / 59,03^{\circ} \mathrm{W}\right.$ e $\left.14,00^{\circ} \mathrm{S} / 59,02^{\circ} \mathrm{W}\right)$, Nova Lacerda - MT $\left(12,83^{\circ} \mathrm{S} / 60,15^{\circ} \mathrm{W}\right)$ e Vilhena - RO $\left(12,83^{\circ} \mathrm{S} / 60,15^{\circ} \mathrm{W}\right)$, coleção esta depositada no Setor de Ornitologia do Museu Nacional - UFRJ (registro de campo - GBN). Outra parte da amostra estudada, depositada também no setor de Ornitologia do Museu Nacional - UFRJ ( registros de campo -GBN e SM), foi coletada no Rio Teles Pires, em sua margem esquerda (Paranaíta - MT $9,31^{\circ} \mathrm{S} / 56,76^{\circ} \mathrm{W}$ ) e direita (Jacareacanga - PA 9,30S/56,76 ${ }^{\circ} \mathrm{W}$ ), nos meses de março, junho, setembro/outubro de 2008, fevereiro, maio/junho e setembro de 2009. Uma terceira coleção amostrada, pertencente à coleção de Aves do Museu Paraense Emílio Goeldi (MPEG) (registro de campo - AMZ), é fruto de expedição realizada em novembro e dezembro de 2007, ao baixo Rio Tapajós, em sua margem esquerda (próximo a Aveiro - PA 03,423S/55,355W) e ao Rio Arapiúns, em sua margem direita (próximo ao município de Santarém - PA $-2.5360^{\circ} \mathrm{S} / 55.3220^{\circ} \mathrm{W}$ ).

Foi analisado o conteúdo estomacal de 65 espécies de aves Furnariida $(n=476)$, sendo que 14 pertencem à família Furnariidae (n=51), 16 à Dendrocolaptidae $(n=139)$, 32 à Thamnophilidae $(n=280), 1$ à Formicariidae $(n=3)$ e 2 à Conopophagidae $(n=3)$ (Anexo 1 - Relação dos espécimes amostrados). 
As aves estudadas foram fixadas com formol $4 \% \mathrm{v} / \mathrm{v}$ injetado na cavidade abdominal e torácica, bem como no interior do tubo digestivo logo após a coleta e sexagem, para a preparação das peles. As carcaças dos animais permaneceram nessa solução por cerca de 20 dias. Depois desse período elas foram transferidas para álcool etílico $70 \%$ v/v. Após a separação dos espécimes, os estômagos (moela e proventrículo) foram retirados e transferidos para frascos individualizados, contendo álcool etílico $70 \%$ v/v e identificados com a etiqueta correspondente.

A fase de triagem dos itens alimentares iniciou-se com a abertura dos estômagos e deposição do conteúdo em placa de Petri onde os conteúdos foram examinados com o auxílio de estereomicroscópio Nikon (modelo SMZ800). Os fragmentos encontrados, passíveis de identificação, foram identificados de acordo com os respectivos grupos taxonômicos, por meio de bibliografia adequada: Costa et al. (1988), Stehr (1991), CSIRO (1991), Borror e Delong (1969), Daly (1998), Brusca e Brusca (2003), e com o auxílio de especialistas.

Foi calculada, para cada categoria de itens identificados, a sua frequência de ocorrência (FO) nas diferentes espécies de Furnariida estudadas. Essa frequência é a proporção de cada item alimentar $i$, em relação ao total de itens alimentares analisados. Ela é expressa em porcentagem e é calculada pela seguinte fórmula: $\mathbf{F O}=\mathbf{p} \times \mathbf{1 0 0} / \mathbf{P}$, onde $\mathbf{p}$ é o número de amostras em que a categoria alimentar $i$ ocorreu; $\mathbf{P}$ é o número total de itens alimentares coletados para cada espécie de ave.

A estimativa do número de presas foi feita a partir de peças, que delimitam um indivíduo, tais como: cabeças, número de mandíbulas de Insecta e quelíceras de Arachnida, evitando-se dessa maneira subestimar ou superestimar o número de presas (Emmons, 1987).

Para complementar a análise, foi calculada a biomassa bruta consumida, estimada para cada item alimentar, utilizando o número de presas e multiplicando-os pela massa média de cada item (Belentani, 2001). A massa média foi obtida a partir de exemplares depositados em coleções do Museu de Zoologia (Araneae, larvas e adultos de Diptera), do Departamento de Biologia da Universidade Estadual Paulista de Rio Claro (Hymenoptera, Formicidae) e da Coleção Didática do Departamento de Zoologia do Instituto de Biociências da Universidade de São Paulo (Pseudoscorpiones, Odonata, 
Orthoptera, Hemiptera (Heteroptera e Auchenorrhyncha), Dermaptera, Blattodea, Isoptera, Coleoptera (larvas e adultos), Lepidoptera (larvas e adultos), ou por especialistas (Vertebrata) e ainda por meio de literatura (Azevedo e Ramalho, 1999; Santos et al., 2003; Nunes et al., 2005; Zonta-de-Carvalho e Moscardi, 1994), sendo que os dados dos táxons Chilopoda e Diplopoda foram obtidos apenas por meio desses trabalhos científicos. Como a variação entre os invertebrados é muito ampla considerouse $35 \mathrm{~mm}$ de comprimento como o tamanho máximo medido entre os exemplares das coleções, visto que não foram encontrados itens alimentares maiores do que esta dimensão.

Para os espécimes de Dendrocolaptidae também foi empregado outro método de estimativa da biomassa. Cada item alimentar, encontrado nos estômagos, foi separado e colocado em frascos, previamente pesados em balança digital com precisão de 0,001 g. Em seguida essas amostras foram para estufa a $58{ }^{\circ} \mathrm{C}$ por 48 horas. Após este procedimento, os frascos ficaram em temperatura ambiente por cerca de 2 horas para diminuição da temperatura e estabilização do peso. Desta maneira obteve-se o peso da massa seca das diferentes categorias alimentares (biomassa parcial) (Pinkas et al., 1971).

Para estimar o nível de especialização da dieta das espécies amostradas foi utilizado o índice de amplitude do nicho trófico (medida de Levins), que mede a uniformidade da distribuição quantitativa de cada presa (Krebs, 1999). O índice é calculado pela seguinte fórmula: $\mathbf{B}=\mathbf{1} / \sum \mathbf{p}^{2}$, onde $\mathbf{B}$ é a medida de Levins da amplitude do nicho; $\mathbf{p}_{i}$ é a proporção de itens na dieta que são da categoria alimentar $i$ (estimada pelo número de ocorrência de categoria alimentar $i$ / número total de itens consumidos). Este índice apresenta valores que variam de 1 (especialista) até n, ou número total de categorias alimentares (generalista). Se apenas um ou poucos itens têm alta proporção na dieta, o índice tende a ser menor. No caso de vários itens apresentarem representatividade similar, o valor do índice tende a ser maior. Para facilitar a interpretação e compreensão dos dados foi utilizado o índice de Levins padronizado, que minimiza o efeito de números amostrais diferentes, e é representado como: $\mathrm{B}_{\mathrm{A}}=(\mathrm{B}-1) /(\mathrm{n}-1)$, onde $\mathrm{B}_{\mathrm{A}}$ é o índice padronizado de amplitude de nicho de Levins; B é a amplitude de nicho de Levins; $\mathrm{n}$ é o número total de categorias alimentares consumidas. Este índice padronizado varia de 0 a 1, onde valores próximos 
a um indicam maior amplitude de nicho trófico (generalista), e valores que tendem a zero indicam que poucos itens são consumidos em altas proporções (especialista).

\section{Resultados e Discussão}

\subsection{Furnariida}

Entre os exemplares de Furnariida analisados, 22 estômagos encontravam-se vazios ou não foi possível a identificação, devido à elevada fragmentação dos itens encontrados. Naqueles que continham itens alimentares foram identificadas 24 categorias, apresentadas a seguir com suas respectivas frequências de ocorrência (FO): 20,9\% de Coleoptera (Fig. 2); 17,2\% de Orthoptera; 14,7\% de Araneae (Fig. 6); 9,2 de Hymenoptera (Formicidae); 8,6\% Hemiptera (Heteroptera) (Figs. 3 e 5); 5,7\% de ovos; 5,2\% de Isoptera; 5,2\% de larvas (Fig. 4); 3,2\% de Hymenoptera (não Formicidae); 1,6\% de Pseudoscorpiones; 1,6\% de Diptera; 1,4\% de Hemiptera (Auchenorrhyncha) (Fig. 1); 1,1\% de material não identificado; 0,9\% de Vertebrata (Figs. 8 e 9); 0,7\% de Hemiptera (não identificado); 0,5\% de Dermaptera (Fig. 7); 0,4\% de Mollusca; 0,3\% de Chilopoda; 0,2\% de Blattodea; 0,07\% Hemiptera (Sternorrhyncha); 0,07\% de Lepidoptera; 0,07\% de Archaeognatha; 0,07\% de Diplopoda; 0,07 de Odonata. Apesar da alta frequência de Coleoptera, Orthoptera foi o item que contribuiu com a maior biomassa ingerida, seguido de Coleoptera e Vertebrata (44,2\%, 26,3\% e 9,2\%, respectivamente). A alta frequência de Coleoptera pode estar relacionada com a digestibilidade destes itens que, por conterem partes mais queratinizadas em relação a outros (Isoptera, por exemplo), permanecem no trato digestivo por mais tempo (Willis e Oniki, 1978). Poulin et al. (1994a) afirmaram que, provavelmente, a predominância de Coleoptera, na Venezuela, pode refletir oportunismo alimentar, já que amostras de artrópodes, revelaram que Coleoptera era o item mais abundante em armadilhas luminosas e de solo.

Algumas espécies, com elevado número de amostras, consumiram em grande quantidade Orthoptera (Automolus ochrolaemus, Hylophylax poecilinotus), o que poderia ter inflacionado este valor. O método utilizado para estimar a biomassa das

presas, pode ter superestimado este item alimentar, já que a média das variáveis analisadas (peso, tamanho) desconsidera as variações existentes na natureza. No entanto, a alta biomassa de Orthoptera no ambiente poderia explicar o maior consumo, 
ou preferência, dos insetívoros por este item (Chapman e Rosenberg, 1991, Chesser, 1995; Rosenberg, 1993).

Fig. 1
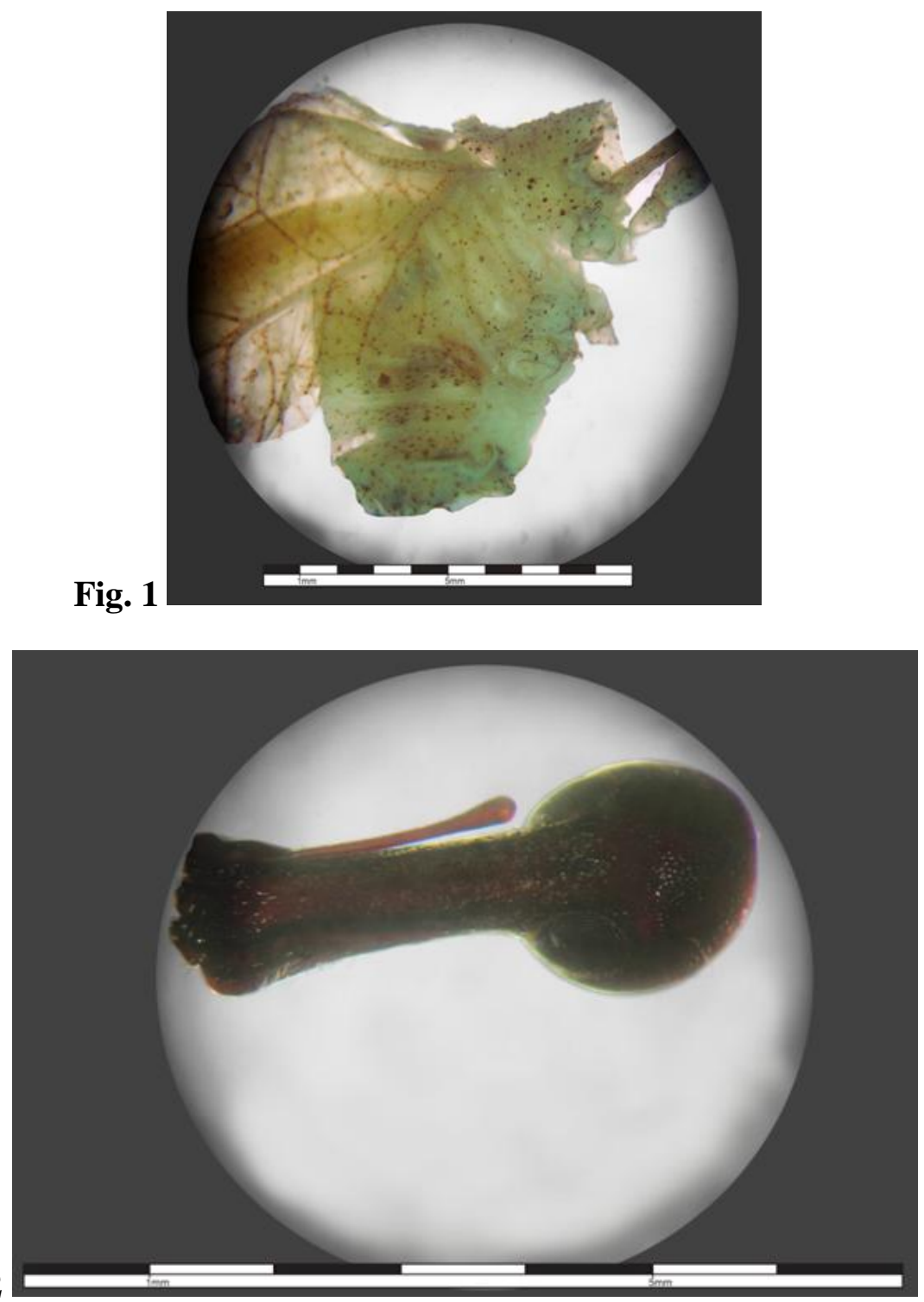

Fig. 2 


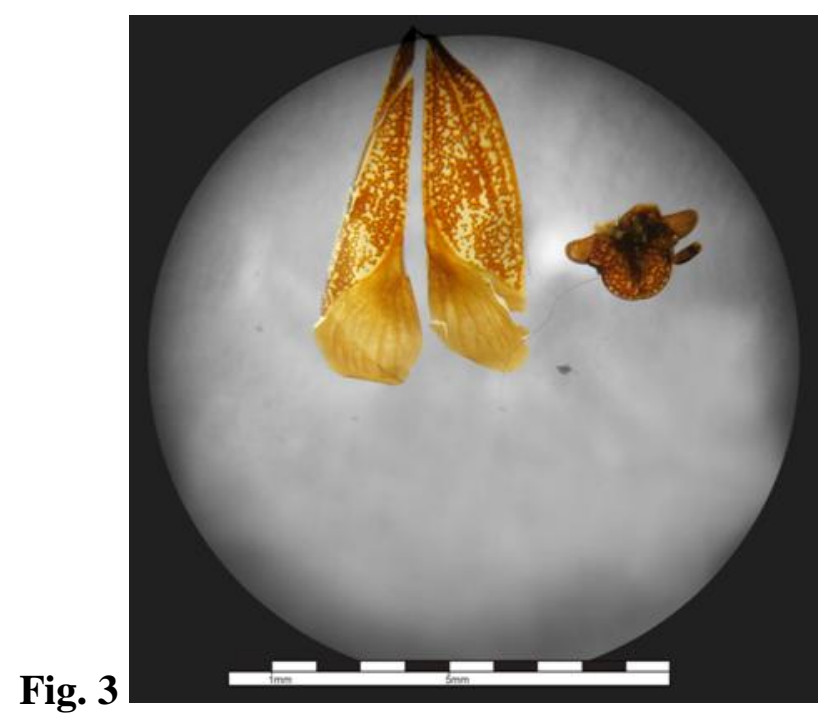

Figuras 1 - 3: 1. Hemiptera (Auchenorrhyncha); 2. Cabeça de Coleoptera (Curculionidae); 3. Par de asas e cabeça de Hemiptera (Heteroptera). Escala $1 \mathrm{~mm}$.

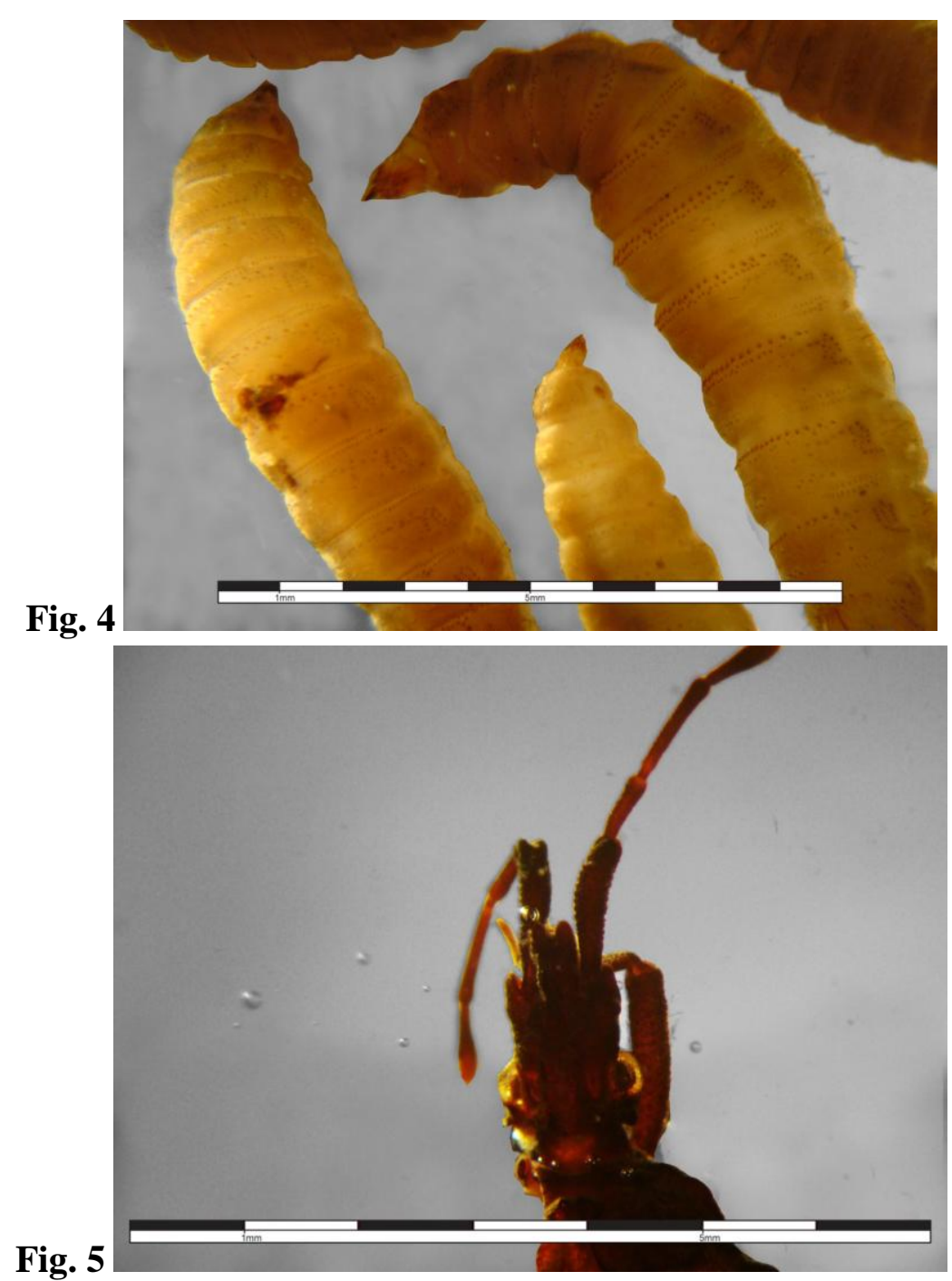




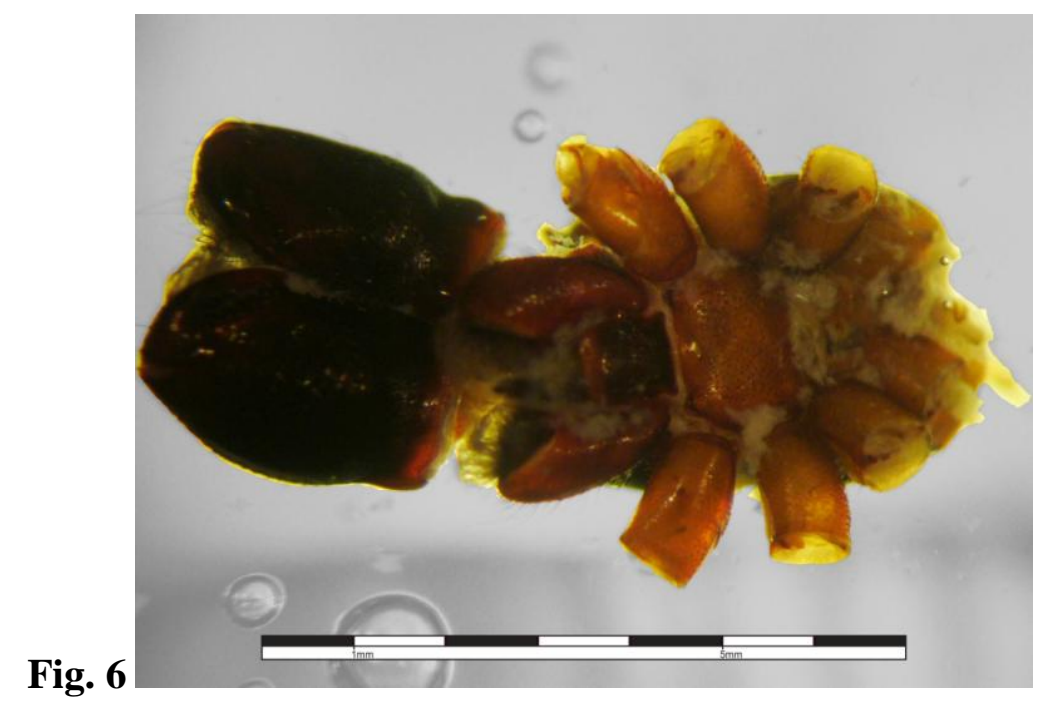

Figuras 4-6: 4. larvas (Diptera); 5. cabeça de Hemiptera (Heteroptera); 6. Araneae. Escala 1mm.

Fig. 7
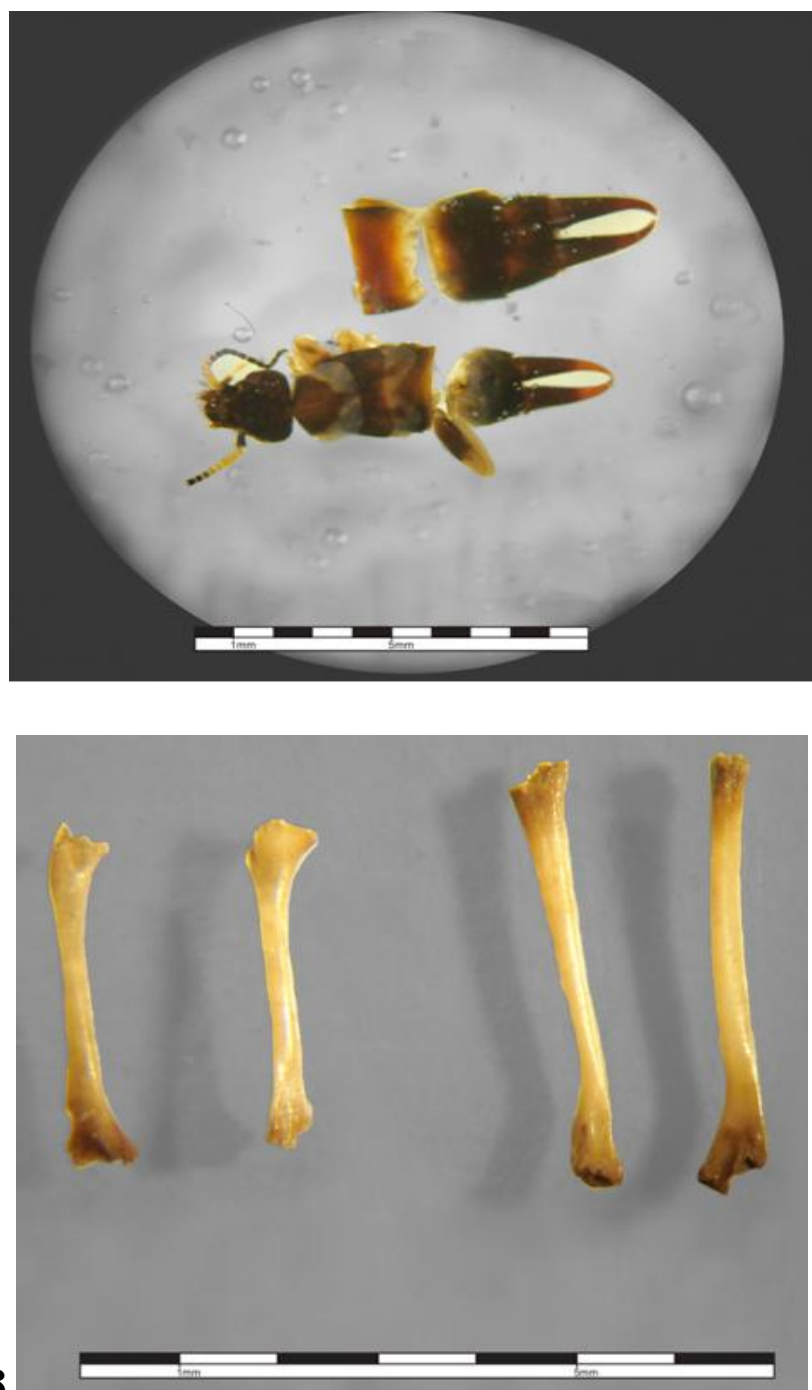

Fig. 8 


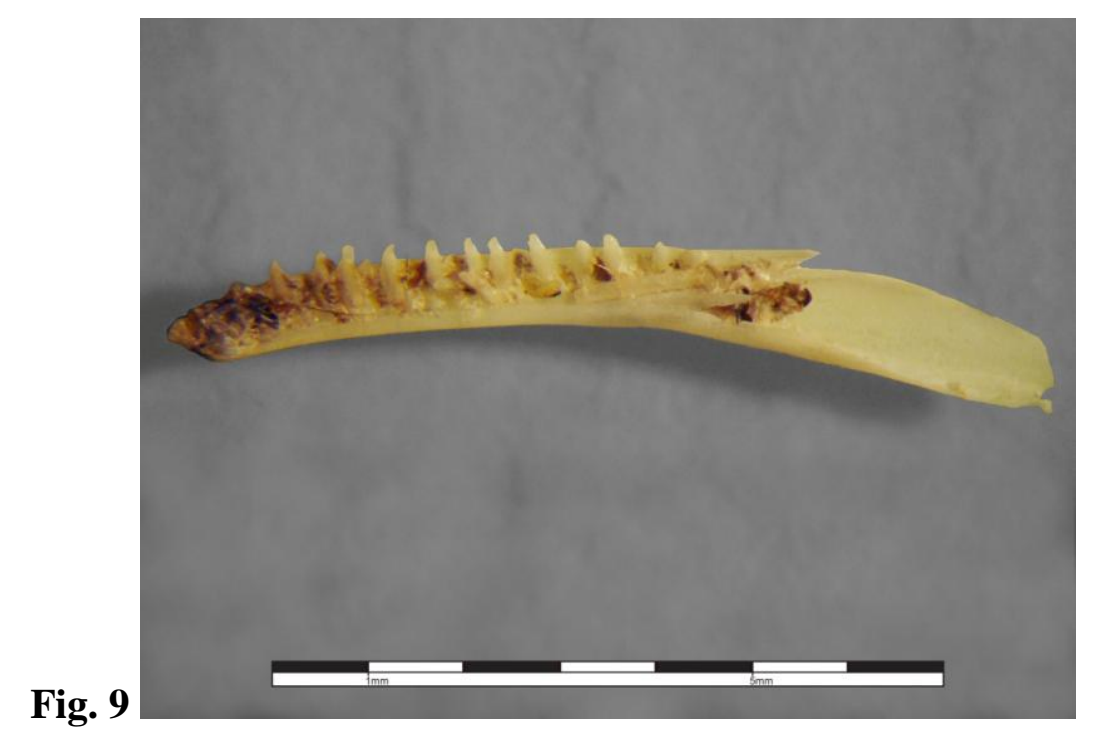

Figuras 7-9: 7. Dermaptera; 8. Úmeros e fêmures de Gonatodes humeralis; 9. Dentário direito de Gonatodes humeralis. Escala $1 \mathrm{~mm}$.

Análises de seleção de presas, relacionada com a sua disponibilidade, são necessárias, nas localidades estudadas, para avaliar se há oportunismo ou preferência pelas presas mais consumidas (Coleoptera e Orthoptera). Entretanto, como as amostras obtidas são provenientes de coletas de inventários de museus, não foi possível fazer coletas de disponibilidade de artrópodes ou ter acesso a esses dados.

Os vertebrados foram consumidos por algumas espécies de Dendrocolaptidae (Dendrocincla fuliginosa, Dendrocincla merula, Deconychura stictolaema, Xiphocolaptes promerorpirhynchus, Xiphorhynchus elegans e Xiphorhynchus guttatus) e duas de Thamnophilidae (Percnostola leucostigma e Hylophylax poecilinotus), porém os dados da biomassa referem-se apenas às presas, que foram identificadas, consumidas por Dendrocolaptidae e, por isso, provavelmente a contribuição da biomassa de vertebrados deve ser maior, entre os resultados. A maior parte do material ingerido pelos dendrocolaptídeos corresponde a Gonatodes humeralis (Kupriyanov et al., 2012), um pequeno lagarto escansorial; os vertebrados consumidos pelos tamnofilídeos não foram identificados, e a identificação dos anuros, consumidos por arapaçus, também não foi possível ao nível de espécie, mas foram encontradas evidências de que um dos sapos pertence à família Hylidae (Kupriyanov et al., 2012). A alimentação dos arapaçus e dos tamnofilídeos é baseada principalmente no consumo de artrópodes (Zimmer e Isler, 2003; Marantz et al., 2003; Lopes, 2003). Os resultados de Lopes et al. (2005) sugerem que o consumo de vertebrados por aves passeriformes neotropicais é raro, e que 
nenhuma família apresentou qualquer tendência a especialização no consumo dessas presas. Outros trabalhos afirmam que a predação de vertebrados pode ser ocasional e, geralmente, é considerada oportunística, especialmente por representantes de famílias de seguidores de formigas de correição (Willis e Oniki, 1978; Chapman e Rosenberg, 1991; Chesser, 1995; Poulin et al., 2001). A baixa frequência de lagartos e sapos consumidos por esses pássaros suporta a hipótese de oportunismo na predação de vertebrados.

O índice de Levins foi calculado entre as espécies com maior representividade $(n>10)$. Entre os resultados, não foi observado nenhum padrão geral para o táxon Furnariida. Algumas espécies tiveram uma dieta mais ampla (Xiphorhynchus spixii, 0,63; Thamnophilus schistaceus, 0,66; Myrmotherula leucophthalma, 0,67 e Phlegopsis nigromaculata, 0,70); a maioria apresentou uma diversidade média em relação aos recursos alimentares (Automolus ochrolaemus, 0,54; Xenops minutus, 0,46; Dendrocincla fuliginosa, 0,55; Dendrocincla merula, 0,53; Glyphorhynchus spirurus, 0,45; Xiphorhynchus guttatus, 0,52; Thamnomanes saturninus, 0,48; Thamnomanes caesius, 0,47; Myrmotherula axillaris, 0,50; Myrmoborus myotherinus, 0,52; Hypocnemis cantator, 0,57), enquanto que em apenas uma observou-se uma dieta mais restrita (Hylophylax poecilinotus, 0,38). A amplitude da dieta ainda pode ser analisada em diferentes épocas, para verificar se há diferenças na dieta sazonalmente e, concomitantemente, prováveis especializações. No entanto, neste estudo não foi possível verificar a sazonalidade da dieta devido ao baixo número de espécimes, de uma mesma espécie, em diferentes épocas do ano. Se a identificação das presas fosse feita de forma mais acurada (família, gênero, espécie) poderia melhorar, provavelmente, na determinação de algum tipo de especificidade na captura de presas, como observado por Queirolo (2001), porém o estado de conservação dos itens encontrados não permite que tal análise seja feita.

As categorias alimentares Archaeognatha, Hemiptera (Sternorrhyncha), Mollusca, ovos e não identificados não possuem medidas da biomassa bruta média. Com a baixa frequência de Archaeognatha e Hemiptera (Sternorrhyncha) e a falta de informação na literatura, optou-se por não incluir esses dados na biomassa bruta estimada. Como as coleções de Mollusca estão em via úmida, não seria viável comparar com os demais itens alimentares, em peso seco. Além disso, seria difícil uma massa 
média para este item, já que foram encontrados apenas pequenos vestígios que identificavam este táxon. Ovos/ooteca, apesar de serem abundantes nas análises, são raros de se encontrar em coleções e em publicações. Em relação a "ovos" não se sabe se foram consumidos deliberadamente ou se sua presença deve-se ao consumo de outros animais em estágio fértil e carregando ovos. Ootecas podem ser encontradas em fendas, com detritos aderidos na superfície externa, ou retidas pelas fêmeas pouco tempo antes dos ovos eclodirem (Daly et al., 1998). Comparando amostras que continham ovos, em bom estado de conservação, pelo método de biomassa parcial, este item contribuiu pouco para a biomassa ingerida, e ainda é geralmente consumido, em grande número, por poucas aves, não sendo, provavelmente, um item alimentar determinante na dieta das espécies analisadas. O item "não-identificado" foi estabelecido apenas para se ter uma ideia do material fragmentado que não foi possível de identificar, apresentado em porcentagem (frequência de ocorrência e frequência relativa).

A presença de Pseudoscorpiones pode estar relacionada ao consumo de outros artrópodes, pois estes aracnídeos além de serem encontrados embaixo de pedras, no solo e sob cascas de árvores, podem frequentemente utilizar "hospedeiros" temporários para a dispersão por forésia. Entre os possíveis "hospedeiros", foram encontrados besouros carregando esses pequenos aracnídeos (Muchmore, 1971; Aguiar e Bührnheim, 1990), também em galerias de Passalidae (Coleoptera, Insecta) pseudoescorpiões ocorrem comumente (Aguiar e Bührnheim, 2011), e ainda em colméias de abelhas (Gonzalez et al., 2007).

Para as espécies de Furnariida com amostras representadas por poucos indivíduos, os dados da frequência de ocorrência estão computados no Anexo 2. As figuras 10,11, $13 \square 27$ referem-se apenas às espécies com número maior de espécimes $(n>10)$.

\subsection{Família Furnariidae}

Entre os espécimes de Furnariidae 64,5\% forrageiam principalmente em folhas mortas suspensas, sendo que as espécies de Automolus são consideradas especialistas nesse tipo de forrageamento; $33,3 \%$ forrageiam em cascas de árvores e madeira morta; e $2 \%$ forrageiam em pequenas frestas e na folhagem (Remsen, 2003). Nas amostras que continham itens alimentares $(n=48)$, Orthoptera e Araneae foram os itens com maior 
frequência de ocorrência $(18,8 \%$ e $18,1 \%$, respectivamente) e também com maior frequência relativa $(15,0 \%$ e $14,4 \%$, respectivamente). No entanto, Orthoptera foi responsável por mais de $60 \%$ da biomassa consumida, seguido de Coleoptera (14,2\%). A presença de Blattodea foi muito baixa, comparada com os dados citados na literatura (Remsen, 2003; Rosenberg, 1997), mas as baixas frequências de Diptera e Lepidoptera podem ser explicadas pela ausência de forrageamento aéreo entre os representantes desta família (Remsen, 2003). A alta frequência de Orthoptera nos resultados deve-se, provavelmente, ao alto consumo deste item por Automolus ochrolaemus, que é uma espécie com elevado número de amostras $(\mathrm{n}=14)$, em relação às demais espécies. A alta frequência de Orthoptera e Araneae pode estar relacionada com o hábito alimentar melhor representado neste estudo: forrageadores de folhas mortas suspensas. No Peru e na Bolívia, a maior parte da composição da dieta de forrageadores de folhas mortas foi representada por Orthoptera, Blattodea, Coleoptera e Araneae (Rosenberg, 1997).

A presença de Isoptera, Araneae e larvas entre os itens alimentares de Sclerurus rufigularis também são descritos por Mestre (2002). Além destes, ovos e Hymenoptera (Formicidae) foram itens significativos na alimentação deste furnariídeo. Mestre (2002) e Schubart et al. (1965) descrevem ainda Isoptera (Termitidae) como presentes na sua alimentação. De acordo com Mestre (2002), S. rufigularis seleciona larvas, provavelmente devido ao modo de forragear, pois vira folhas e procura presas ao introduzir o bico no solo (Ridgely e Tudor, 1994). O único espécime de S. mexicanus consumiu apenas Araneae. As espécies de Sclerurus são terrícolas e saltam sobre o chão, capturando artrópodes do solo e da serrapilheira.

Os itens alimentares Araneae e larvas foram encontrados em todas as espécies de Synallaxis, o que concorda com os dados da literatura (Shubart et al., 1965; Remsen, 2003). Coleoptera, Hymenoptera (Formicidae), Araneae e larvas foram comuns entre $S$. rutilans e S. gujanensis. Para S. cherriei ainda é citado Diptera como item alimentar (Oren e Silva, 1987). Essas espécies, geralmente, forrageiam aos pares, porém $S$. rutilans pode ser encontrada, ocasionalmente, em bandos mistos. Os representantes de Synallaxis são encontrados no solo ou a poucos metros acima do chão, capturando artrópodes em folhas mortas, pequenos ramos e na folhagem. 
Coleoptera, Orthoptera e Araneae foram os itens mais frequentes em $P$. erythrocercum. Orthoptera foi o item mais frequente para $P$. pirrhodes e $P$. erythropterum. Shubart et al. (1965) encontraram alta frequência de Coleoptera e Araneae entre os principais itens consumidos por $P$. erythrocercum lyra, $P$. lichtensteini e $P$. rufus. Mallet-Rodrigues (2001) também encontrou alta frequência na dieta de $P$. atricapillus para os mesmos itens, enquanto que Rosenberg (1997), verificou alta preferência por Orthoptera. A análise de conteúdo estomacal de aves especialistas de folhas mortas demonstrou que a dieta deste grupo é composta por ortópteros, baratas, besouros e aranhas (Rosenberg, 1990; Mallet-Rodrigues, 2001). Mallet-Rodrigues (2001) afirma que ooteca e Lepidoptera foram itens altamente selecionados por $P$. atricapillus, enquanto Hymenoptera (Formicidae) eram itens evitados por esta espécie. P. erythrocercum é considerada especialista de folhas mortas em bandos de dossel, enquanto as demais espécies ( $P$. erythropterum, $P$. pirrhodes) podem procurar presas em folhas mortas regularmente. Ao forragearem sobre esse substrato essas espécies fazem manobras acrobáticas para capturar e puxar presas de folhas mortas suspensas e detritos, às vezes, também, em folhas vivas e em pequenos ramos. Forrageiam sozinhas ou aos pares e, ocasionalmente, juntam-se a bandos mistos (Remsen, 2003) Entretanto, Rosenberg (1993) afirma que especialistas de folhas mortas não selecionam suas presas, tampouco apresentam uma tendência a evitar presas comuns na natureza, esta especialização é considerada o resultado de uma mudança de comportamento de busca e não é acompanhada por uma preferência de presas.

Orthoptera, Hymenoptera (Formicidae) e Araneae estão entre os itens alimentares mais frequentes de Automolus paraensis. Na dieta de A. ochrolaemus (Fig. 10) Orthoptera foi o item alimentar com maior frequência $(31,7 \%)$ e também contribuiu com a maior parte da biomassa $(75,1 \%)$ entre os itens consumidos. Araneae e Coleoptera foram presas que contribuíram na alimentação desta espécie secundariamente. Remsen (2003) também cita Dermaptera, pequenos sapos e lagartos para A. ochrolaemus. No único espécime representante de A. infuscatus foram encontrados Coleoptera, Hymenoptera (Formicidae) e ovos. Schubart et al. (1965) encontraram ainda, Hemiptera, Lepidoptera (larva e pupa), e Remsen (2003) cita Orthoptera, Araneae e pequenos lagartos para esta espécie. As espécies do gênero Automolus forrageiam sozinhas ou aos pares, no sub-bosque e, ocasionalmente no chão; 
frequentemente associam-se a bandos mistos, escalam ao longo de galhos, pegam e puxam acrobaticamente artrópodes e pequenos vertebrados de folhas mortas, epífitas e detritos. As espécies de Automolus analisadas são consideradas especialistas de folhas mortas suspensas.

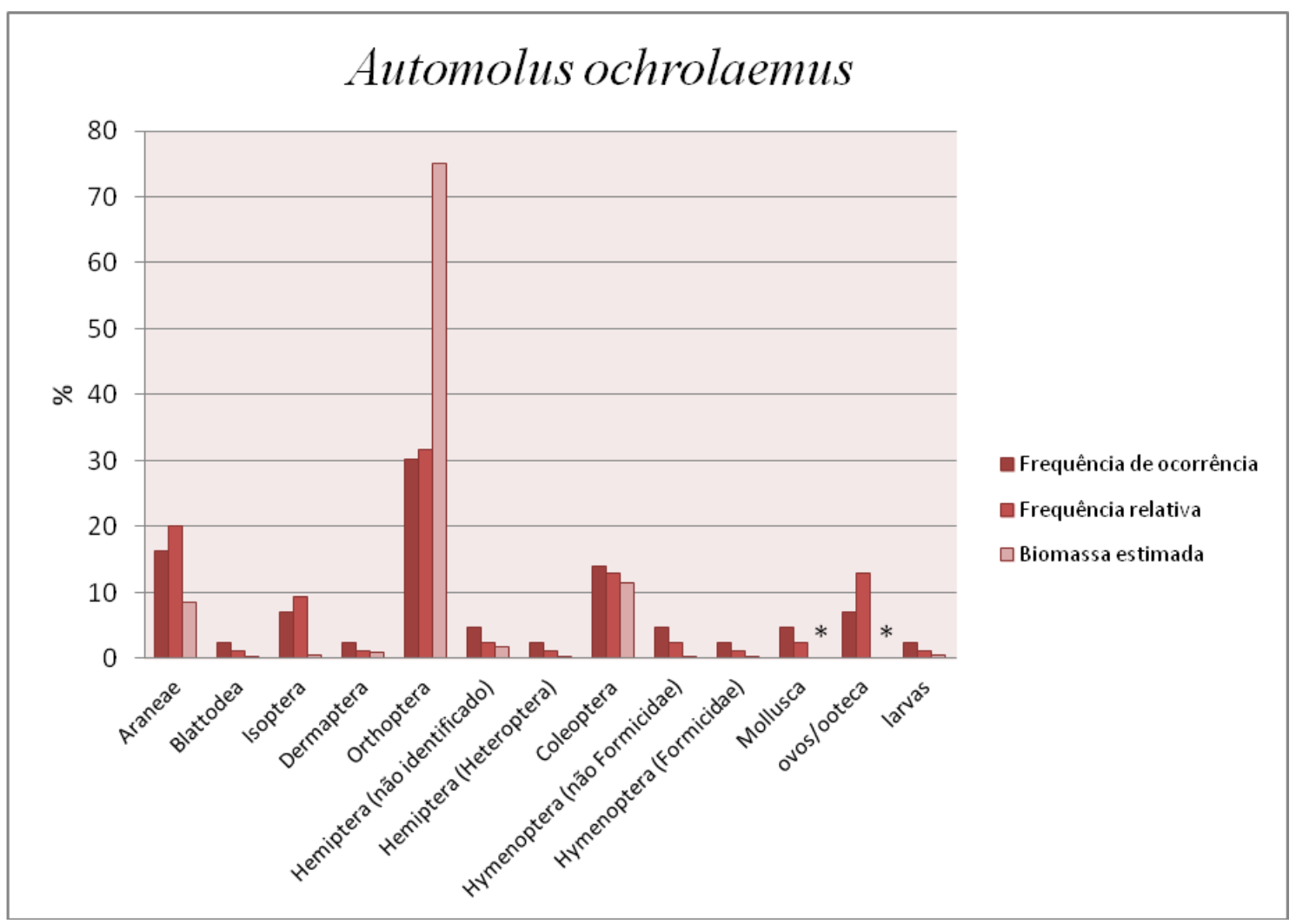

Figura 10: Itens alimentares consumidos por Automolus ochrolaemus $(\mathrm{n}=14) . *$ Biomassa estimada ausente. 


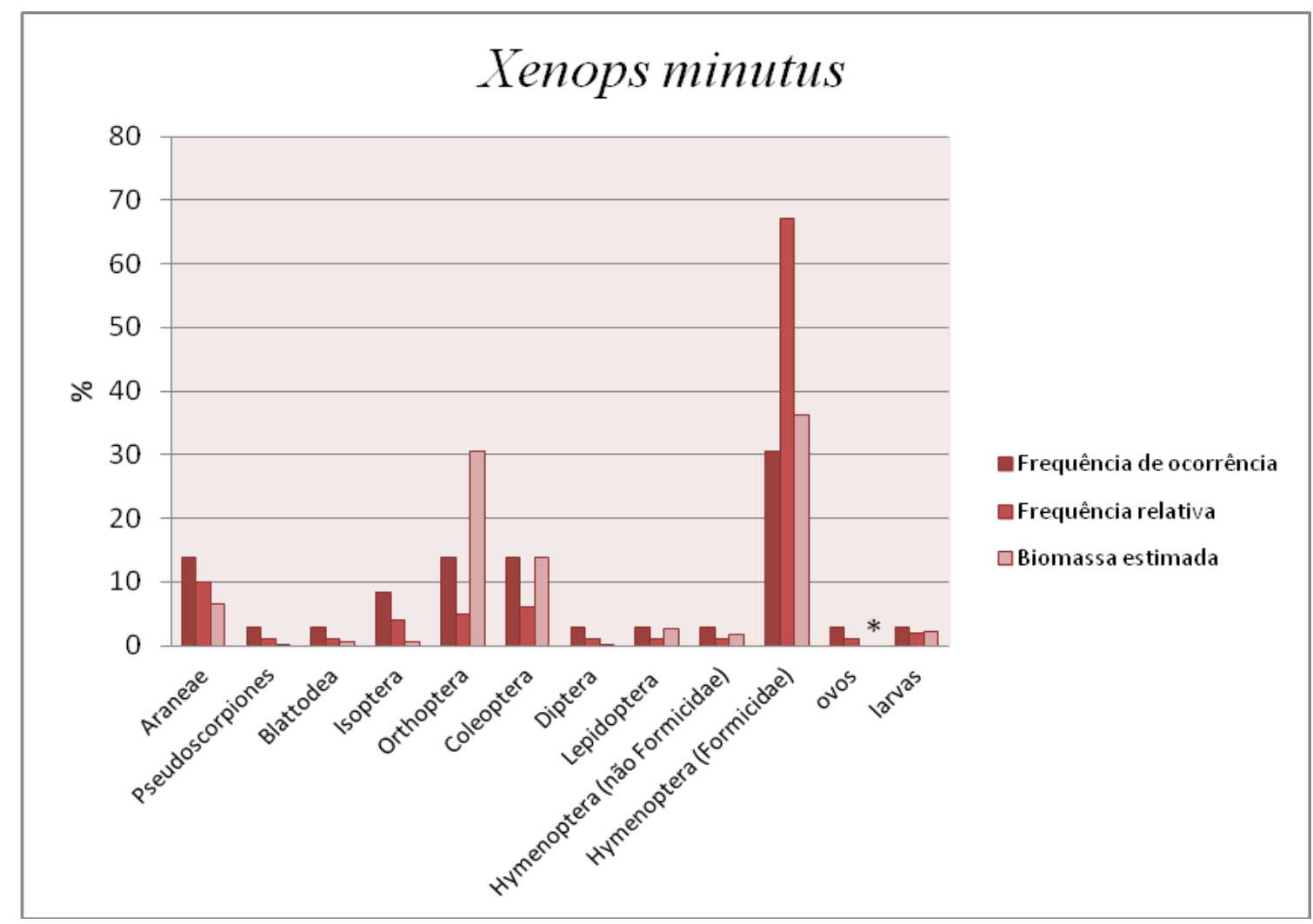

Figura 11: Itens alimentares consumidos por Xenops minutus $(\mathrm{n}=15) .{ }^{*}$ Biomassa estimada ausente.

Xenops tenuirostris consumiu Pseudoscorpiones, Isoptera, Hymenoptera (Formicidae) e ooteca de Blattodea. Hymenoptera (Formicidae) foi o item em maior frequência relativa $(67 \%)$ e maior biomassa $(38,4 \%)$ encontrados em X. minutus (Fig. 11), seguido de Orthoptera (32,2\%). Os itens consumidos por X. minutus correspondem aos dados encontrados na literatura (Schubart et al., 1965; Remsen, 2003), sendo que alguns itens com baixa representatividade [Diplopoda, pupa de Hymenoptera (Formicidae) e Dermaptera] ainda foram citados por tais autores. As espécies de Xenops forrageiam, geralmente, sozinhas, às vezes aos pares, frequentemente em bandos mistos, em estratos baixos e intermediários da floresta. Saltam e escalam ao longo de galhos finos, frequentemente com apoio nas rectrizes e capturam presas de cascas de árvores e de madeira morta.

Certhiaxis cinnamomeus, representada por apenas um espécime, consumiu Coleoptera, Hemiptera (Heteroptera), Isoptera, Diptera e Araneae. Além destes itens, Remsen (2003) cita Hemiptera, Odonata, Orthoptera, Hymenoptera e Decapoda. Esta espécie forrageia sozinha ou aos pares, geralmente a poucos metros do chão, e captura artrópodes em pequenas frestas e folhagem, ocasionalmente na água ou no chão. 


\subsection{Família Dendrocolaptidae}

Foram utilizados dois métodos diferentes para avaliar a contribuição da biomassa de itens consumidos por representantes da família Dendrocolaptidae (Fig. 12). Os resultados mostram que para alguns itens alimentares houve pouca variação entre os dois métodos [Araneae, Hemiptera (Heteroptera) e Orthoptera]. A diferença da biomassa correspondente a Hemiptera (Auchenorrhyncha) é devido, provavelmente, ao consumo de dois insetos, pouco fragmentados, por Dendrocolaptes certhia. No entanto, as maiores diferenças observadas entre a biomassa estimada e a biomassa parcial referem-se a Coleoptera e, principalmente, Vertebrata.

O método da biomassa parcial apresentou-se muito instável, já que o resultado obtido depende do estado de conservação dos itens alimentares nos estômagos. Para um mesmo item consumido pela mesma espécie pode haver uma diferença de massa de três vezes, por exemplo, há grande variação na massa de Gonatodes humeralis consumidos por três espécimes de Dendrocincla fuliginosa, pois neste caso são pesados os ossos que foram conservados no trato digestivo, já que os outros tecidos da presa foram digeridos; também o consumo de Coleoptera por Xiphorhynchus spixii mostra uma ampla variação. O método da biomassa estimada acaba excluindo as variações que existem entre as presas capturadas, já que algumas espécies podem selecionar presas de determinado tamanho (Chapman e Rosenberg, 1991) e, também, acaba omitindo a ampla diversidade que há quanto ao tamanho e à biomassa, principalmente entre os artrópodes, o que torna muito difícil de estabelecer a média para cada um dos itens. Ainda assim, neste estudo considerou-se a biomassa estimada, para a discussão, como o método mais confiável para comparar o número total de itens e a sua biomassa correspondente.

Os resultados gerais de Dendrocolaptidae mostram que Coleoptera foi o item alimentar com a maior frequência de ocorrência (20,3\%), seguido de Araneae (13,6\%) e Orthoptera (12,9\%). Em relação à biomassa ingerida, Orthoptera foi o item que mais contribuiu $(28,4 \%)$, seguido de Coleoptera 25,6\%, entretanto, Vertebrata, com frequência de ocorrência de 1,5\%, teve uma biomassa correspondente a 24,3\%.

De acordo com Marantz et al. (2003), a maior diferença interespecífica na dieta dos arapaçus é aquela entre espécies que forrageiam próximo ao solo, durante a 
correição de formigas, e espécies que procuram presas em troncos ou outros substratos arbóreos. As aves seguidoras de formigas de correição consomem uma proporção maior de presas terrícolas, tais como gafanhotos, grilos, baratas, aranhas e vertebrados, enquanto que arapaçus arborícolas alimentam-se, proporcionalmente, mais de besouros, hemípteros e larvas. Entre os arapaçus analisados, a grande maioria forrageia em troncos e trepadeiras e captura presas na superfície destes troncos e em fendas de cascas de árvores $(81,2 \%)$. Coleoptera foi a categoria alimentar mais frequente entre os dendrocolaptídeos, concordando com a hipótese de dieta dos arapaçus arborícolas (Marantz et al., 2003). Diferentemente do que foi citado por Marantz et al. (2003), exceto Xiphocolaptes promeropirrhynchus, que forrageia em vários tipos de hábitats, a maioria das aves que consumiram vertebrados forrageia, principalmente, sobre troncos, pegando presas na superfície dos troncos ou galhos e, raramente, seguem formigas de correição; entre as espécies seguidoras de formigas, Dendrocincla fuliginosa, seguidora regular, e D. merula, seguidora obrigatória, apenas a última espécie forrageia estritamente no, ou próximo do solo, enquanto que $D$. fuliginosa procura presas nos troncos, como os demais arapaçus que analisados.

O material contendo vertebrados, ingerido por alguns espécimes de arapaçus [Dendrocincla fuliginosa $(\mathrm{n}=3)$, Dendrocincla merula $(\mathrm{n}=1)$, Deconychura stictolaema $(\mathrm{n}=1)$ e Xiphorhynchus elegans $(\mathrm{n}=1)]$ corresponde a Gonatodes humeralis (Sphaerodactylidae) um pequeno lagarto escansorial (Vitt et al., 1997, 2000), que seleciona árvores com troncos largos (Miranda et al., 2010). A identificação foi feita a partir de ossos marginais com dentição isodonte e coroas contundentes, frontais tubulares fundidos dorsal e ventralmente, e com os ossos dentários fundidos no canal de Meckel (Kupriyanov et al., 2012). Dos 52 ossos encontrados, pode-se identificar pelo menos nove indivíduos, cujos ossos eram úmeros (17,3\%), maxilas superiores e dentários $(13,4 \%)$ e fêmures e ossos diversos $(11,5 \%)$.

Xiphocolaptes promeropirrhynchus e Xiphorhynchus guttatus consumiram também pequenos vertebrados (sapos). Não foi possível a identificação dos anuros ao nível de espécie, mas foram encontradas evidências de que um dos sapos pertence à família Hylidae. Os caracteres observados foram: oito vertebras pré-sacrais, vértebras pré-sacrais I e II não fusionadas, cótila cervical do atlas amplamente separada, sacro com diapófises dilatadas, articulação bicondilar com uróstilo, dentes presentes no 
maxilar e pré-maxilar, fronto-parietal coossificado, como indicado pela ornamentação substancial (Kupriyanov et al., 2012).

É provável que Dendrocincla fuliginosa, Deconychura stictolaema e Xiphorhynchus elegans consumiram presas de G. humeralis pois ocorrem juntos no mesmo hábitat. Todavia, a presença desta mesma presa em estômago de um espécime de Dendrocincla merula é curiosa, já que este arapaçu é restrito ao forrageamento no chão. Provavelmente, devido ao hábito mais restrito a troncos e trepadeiras (Chapman e Rosenberg, 1991) D. fuliginosa consumiu este vertebrado em maior número em relação a D. merula. Poulin et al. (2001) descrevem que D. fuliginosa consumiu um lagarto também escansorial (Anolis limifrons) no Panamá. A presença de pequenos vertebrados como presas de X. elegans também é conhecida (Chapman e Rosenberg, 1991; Marantz et al., 2003). No entanto, a dieta de D. stictolaema consiste de pequenos artrópodes (Marantz et al., 2003), e a presença de vertebrado é descrita pela primeira vez (Kupriyanov et al., 2012).

Comparando o tamanho dos ossos das presas desses arapaçus observa-se que os sapos são maiores do que os lagartos (Kupriyanov et al., 2012). Os grandes bicos de Xiphocolaptes promeropirrhynchus e Xiphorhynchus guttatus conferem a estes pássaros a capacidade de preparar e desarticular presas maiores, ou comer pequenos sapos de uma só vez. Poulin et al. (2001), a partir de correlação entre variáveis como o comprimento do bico de aves insetívoras e tamanho da presa, afirmam que aves com longos bicos são mais propensas a se alimentarem de sapos. X. promeropirhynchus consumiu um sapo da família Hylidae, e ainda há um registro de Hyla myotympanum para esta mesma espécie (Marantz et al., 2003).

Pode-se observar na dieta das duas espécies de Dendrocincla uma diferença na constituição dos principais itens consumidos por elas: D. fuliginosa (Fig. 13), que, em geral, forrageia em troncos e, ocasionalmente, em trepadeiras, consumiu principalmente Coleoptera (27,1\%), item característico de arapaçus arborícolas (Marantz et al., 2003) e em menores frequências Orthoptera, Hymenoptera e Araneae. Os dados citados na literatura estão de acordo com os itens encontrados nesta espécie (Schubart et al., 1965; Haverschmidt, 1968), porém Schubart et al. (1965) ainda encontraram Odonata e Neuroptera como itens consumidos. D. merula (Fig. 14) consumiu principalmente 
Orthoptera $(31,2 \%)$ e Araneae $(31,2 \%)$. Os itens encontrados por Schubart et al. (1965) incluem Blattodea e Odonata, que não foram encontrados no presente estudo, Chesser (1995) também cita que esta espécie consumiu Araneae em abundância. Entre as duas espécies de Dendrocincla, a segregação quase total quanto ao tipo de forrageamento pode ter resultado em uma troca quanto às proporções das principais categorias alimentares, com mais aranhas na dieta associada ao forrageamento no solo (D. merula) e mais besouros associados ao forrageio em troncos (D. fuliginosa) (Chapman e Rosenberg, 1991). Além disso, ambas as espécies consumiram Gonatodes humeralis (Kupriyanov et al., 2012), um pequeno lagarto, que tem o hábito de ficar sobre os troncos, havendo registros que ambos arapaçus podem, ocasionalmente, consumir pequenos vertebrados (Marantz et al., 2003; Lopes, 2005). 


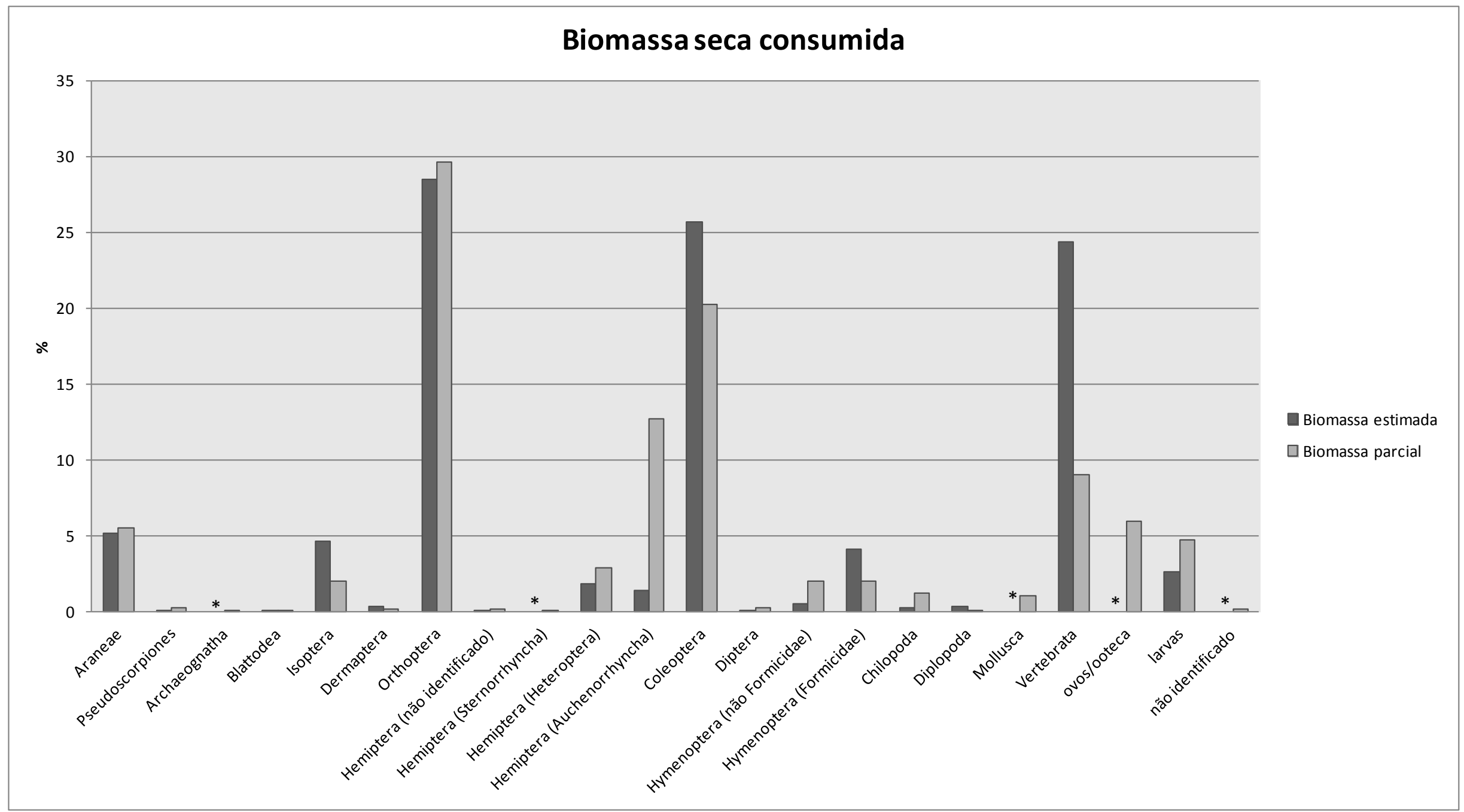

Figura12: Biomassa seca consumida por representantes de Dendrocolaptidae. 


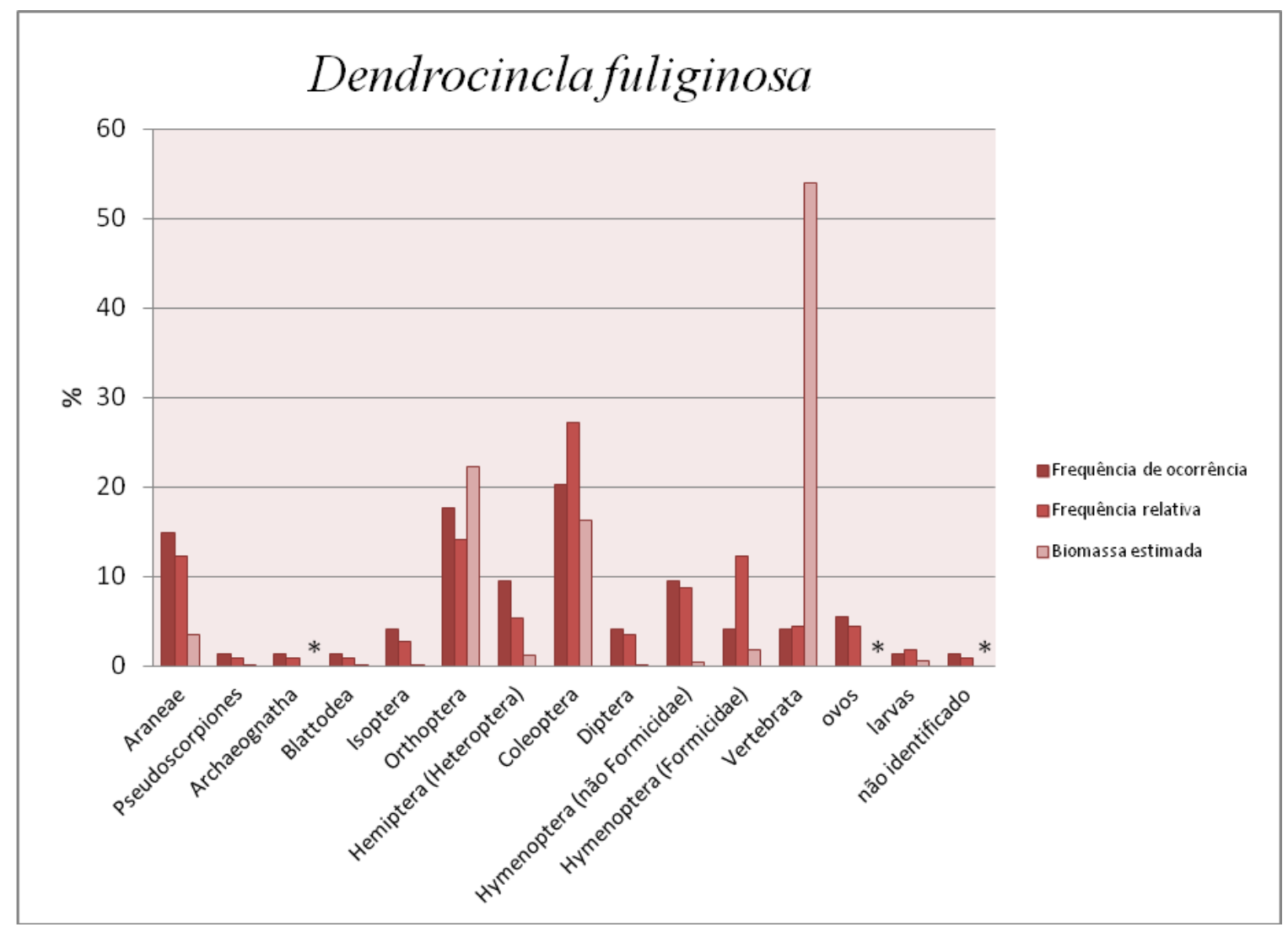

Figura 13: Itens alimentares consumidos por Dendrocincla fuliginosa $(\mathrm{n}=20) . *$ Biomassa estimada ausente.

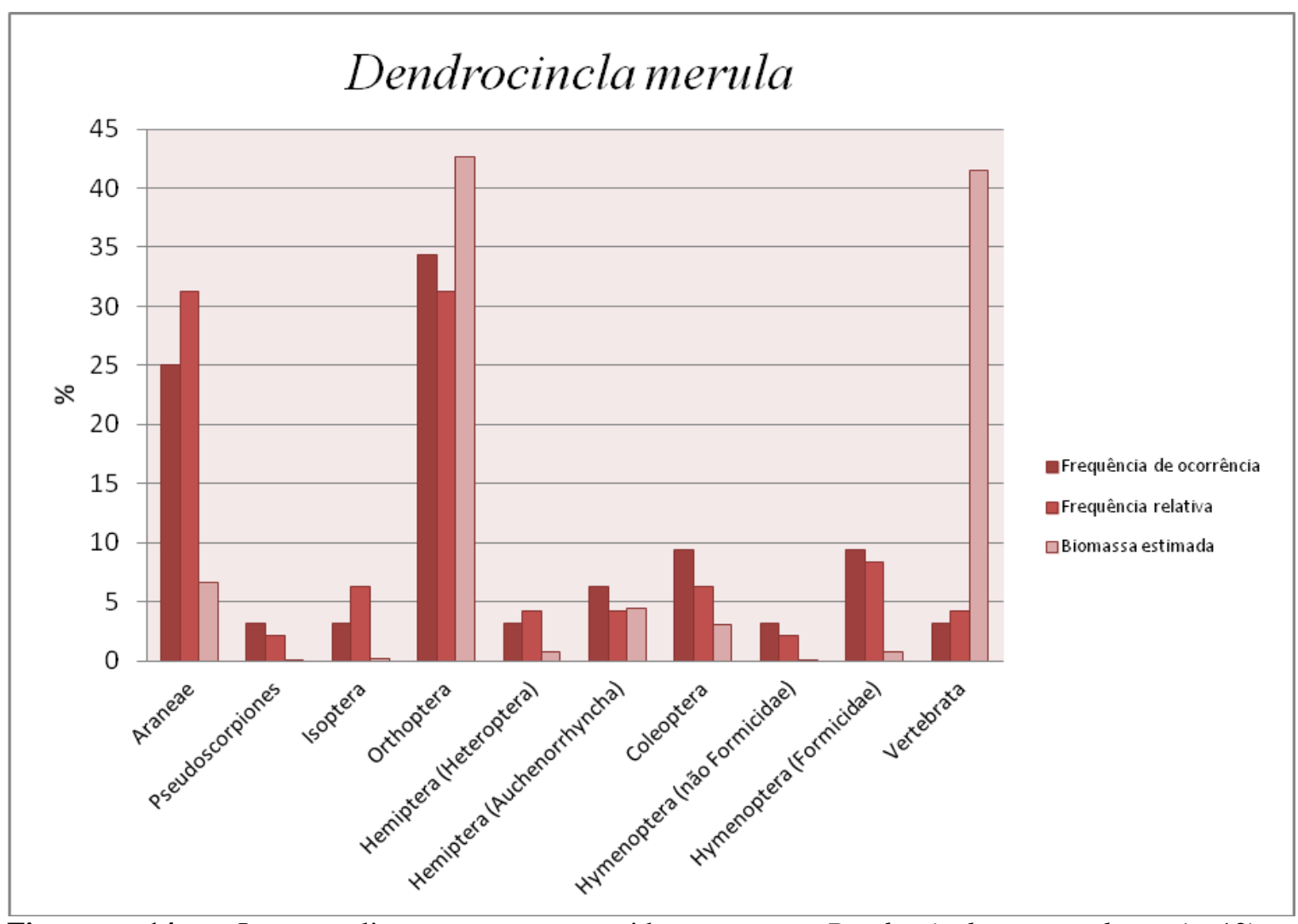

Figura 14: Itens alimentares consumidos por Dendrocincla merula $(\mathrm{n}=12)$. 
Os representantes do gênero Deconychura que, em geral, forrageiam sobre troncos, capturando presas na superfície das cascas de árvores, tiveram Coleoptera como o item alimentar em maior frequência $(81,9 \%)$. Esses itens concordam com os dados fornecidos na literatura (Marantz et al., 2003), mas esses autores citam ainda Hymenoptera (Formicidae) como um dos itens principais. D. longicauda consumiu ainda Orthoptera, Hemiptera (Auchenorrhyncha) e Araneae. D. stictolaema também consumiu um pequeno lagarto (G. humeralis) (Kupriyanov et al., 2012). Esta espécie é considerada membro obrigatório de bandos mistos e D. longicauda juntam-se ocasionalmente a esses bandos. As espécies de Deconychura raramente seguem formigas de correição, embora D. stictolaema seja atraída pelas aves seguidoras, e não pela correição de formigas.

Os itens alimentares [Coleoptera, Hemiptera (não identificado), Araneae e ovos] encontrados no estômago do único espécime de Sittasomus griseicapillus correspondem aos dados citados por Schubart et al. (1965), porém ainda é citada uma ampla variedade de itens consumidos por esta espécie [Hemiptera (Auchenorrhyncha), Pseudoscorpiones, Blattodea, Isoptera, Lepidoptera, sementes, Hymenoptera (Formicidae), Mollusca], e Haverschmidt (1968) acrescenta Diptera como outro item alimentar. Regularmente S. griseicapillus, associa-se a bandos mistos e bandos de macacos (Leontopithecus chrysopygus), principalmente no sub-bosque, forrageando em troncos e galhos. Segue formigas de correição em algumas localidades, no sul do México (Coates-Estrada e Estrada, 1989), sudoeste do Panamá (Roberts et al., 2000), e sudeste do Brasil (Faria e Rodrigues, 2009), porém este fenômeno não ocorre na Amazônia (Marantz et al., 2003).

O principal item consumido por Glyphorhynchus spirurus (Fig. 15) foi Isoptera (69,5\%), seguido de Hymenoptera (Formicidae), Coleoptera e Pseudoscorpiones. No entanto, Coleoptera e Isoptera foram os itens com maior biomassa consumida (31,4 e $28,1 \%$, respectivamente). No estômago de um espécime de G. spirurus foi ainda encontrado fragmento de osso, possivelmente consumido acidentalmente. As informações sobre a dieta desta espécie concordam com os itens encontrados neste estudo (Schubart et al., 1965; Haverschmidt, 1968). Schubart et al. (1965) acrescentam Hemiptera (Auchenorrhyncha) e, no Peru, o item principal consumido foi Coleoptera e no México foi Hymenoptera (Formicidae) (Marantz et al., 2003). O alto consumo de 
Isoptera por G. spirurus pode ser uma estratégia para diminuir a sobreposição de nichos com outras espécies, favorecendo a coexistência entre as espécies (Poulin e Levebvre, 1996). De acordo com esses autores, cupins (Isoptera) são consumidos por poucas aves, provavelmente porque estes insetos produzem substâncias não palatáveis, embora formas reprodutivas sejam atraídas por muitas aves (Eisenmann, 1961). Esses pequenos pássaros, em geral, escalam galhos e troncos, principalmente em estratos baixo e médio da floresta, para procurar presas na superfície ou nas fendas dos troncos. Frequentemente, associam-se a bandos mistos, que passam pelo seu território, principalmente aqueles bandos liderados por Thamnomanes; raramente seguem formigas de correição.

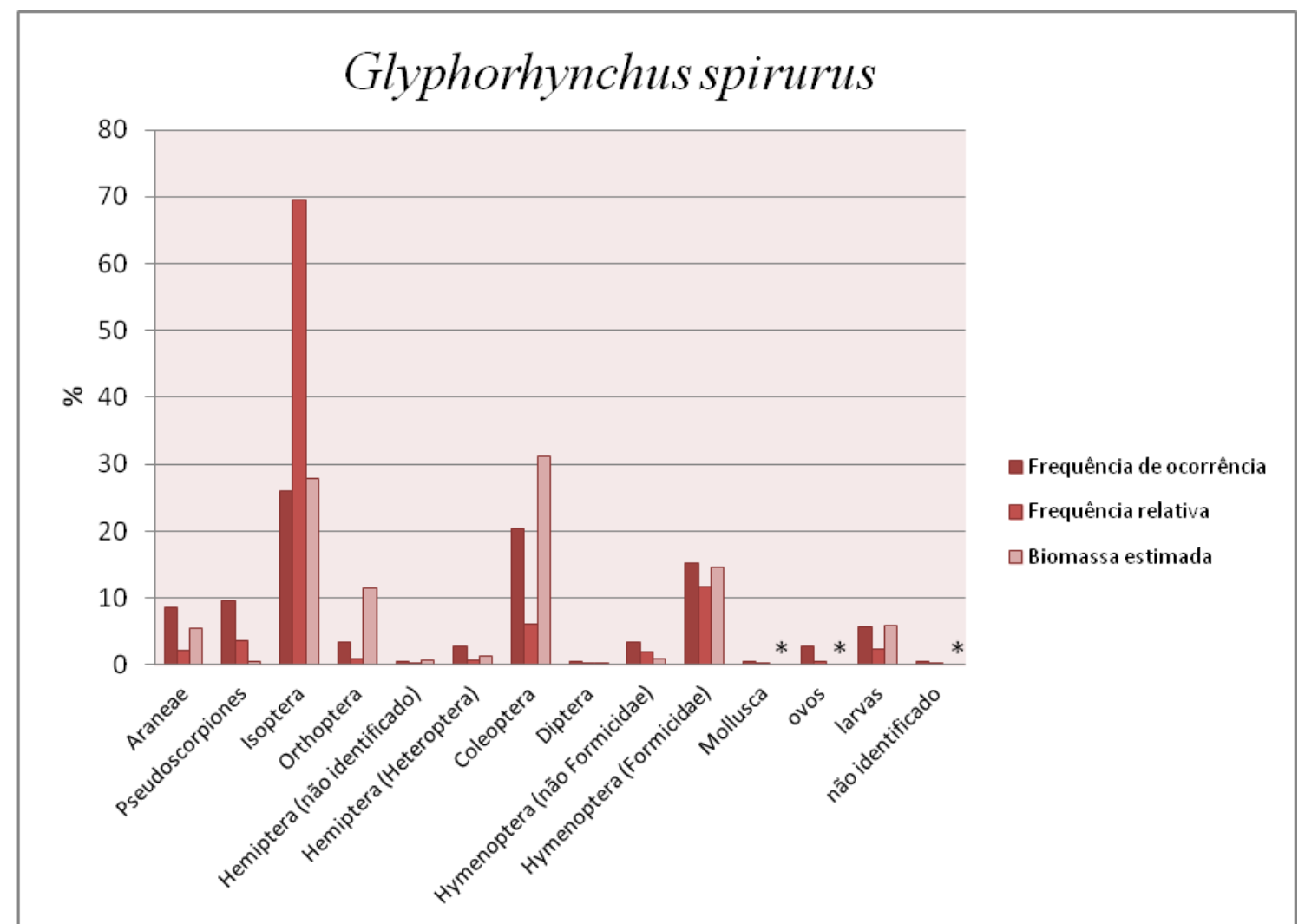

Figura 15: Itens alimentares consumidos por Glyphorhynchus spirurus $(\mathrm{n}=50) . *$ Biomassa estimada ausente.

Orthoptera e Coleoptera foram os itens alimentares com maiores frequência de ocorrência $(17,6 \%$, cada um), nos três espécimes de Xiphocolaptes promeropirrhynchus. Porém, um sapo pertencente à família Hylidae foi ainda identificado (Kupriyanov et al., 2012). Para este arapaçu de médio porte, já fora registrado o consumo de um pequeno sapo, pertencente à mesma família (Hyla myotympanum) (Marantz et al., 2003). Os representantes desta espécie forrageiam em 
uma ampla variedade de hábitats: cavam a madeira morta e a serrapilheira; sobem em troncos, galhos e epífitas, além de procurar alimento em fendas de cascas de árvores, na folhagem viva e morta, em líquens e ninhos de Isoptera. Ocasionalmente, associam-se às formigas de correição. Durante as colunas de formigas forrageiam no sub-bosque (Marantz et al., 2003).

Willis e Oniki (1978) observaram que todas as espécies de Dendrocolaptes seguem regularmente colunas de formigas, mas também podem forragear sozinhas ou em bandos mistos (Marantz et al., 2003). D. certhia, frequentemente, sobe em troncos bicando sua superfície e cavidades (Wetmore, 1972), mas sabe-se que D. hoffmannsi voa para apanhar presas utilizando os troncos como poleiros, contudo não explora os troncos à procura de presas. Os principais itens alimentares [Coleoptera, Orthoptera, Hemiptera (Heteroptera) e Araneae] encontrados em estômagos de D. certhia correspondem aos dados citados por Schubart et al. (1965) e Marantz et al. (2003). Além destes itens, pequenos vertebrados (lagartos) podem ser ocasionalmente consumidos (Marantz et al., 2003). O único representante de D. hoffmannsi analisado consumiu, principalmente, Coleoptera. Porém, Schubart et al. (1965) e Marantz et al. (2003) não descrevem a dieta desta espécie.

Os principais itens consumidos por Xiphorhynchus picus (Coleoptera, Hymenoptera e larvas) concordam com os dados citados na literatura (Schubart et al., 1965 e Marantz et al., 2003). Marantz et al. (2003) citam ainda pequenos vertebrados para esta espécie. Os espécimes de X. spixii (Fig. 16) consumiram em maior abundância ovos e Coleoptera (40\% e 18,8\%, respectivamente), cujas maiores frequências de ocorrências foram Coleoptera (22,2\%), seguido de Araneae e Orthoptera (17,7, cada um), porém Orthoptera foi o item que mais contribuiu com a biomassa $(45,7 \%)$, entre os estômagos analisados. Representado por seis espécimes, X. elegans, consumiu principalmente Coleoptera (45,6\%), entretanto, apesar da baixa frequência relativa, dois pequenos lagartos (G. humeralis) (Kupriyanov et al., 2012) contribuíram com a maior biomassa entre os itens analisados (54,9\%). Já X. obsoletus, representado por apenas um espécime consumiu vários itens [Araneae, Isoptera, Orthoptera, Hemiptera (Heteroptera), Hymenoptera (Formicidae e não Formicidae)], enquanto Schubart et al. (1965) encontraram principalmente Coleoptera e Hymenoptera para esta espécie. O principal item consumido por X. guttatus (Fig. 17) foi Coleoptera $(28,1 \%)$, seguido de 
Araneae, ovos e Orthoptera $(17,4 \% ; 14,5 \%$ e 10,6\%, respectivamente). Orthoptera e Coleoptera contribuíram, juntos, com quase $80 \%$ da biomassa ingerida. Os dados encontrados para esta espécie correspondem com as informações de Schubart et al. (1965) e Marantz et al. (2003). Esta espécie, considerada forrageadora regular de folhas mortas, consumiu proporcionalmente mais Coleoptera do que Orthoptera, diferenciando sua dieta dos demais forrageadores de folhas mortas (Rosenberg, 1997). Ainda um espécime de $X$. guttatus consumiu um anura (indeterminado) (Kupriyanov et al., 2012). Quase todas as espécies de Xiphorhynchus analisadas neste estudo são forrageadoras indiretas de formigas de correição, pois são mais atraídas pelas aves e pelas presas afugentadas do que pela própria coluna de formigas. No entanto, X. guttatus é um seguidor regular de formigas de correição. Em geral, X. picus, X. spixii, X. elegans e X. guttatus associam-se a bandos mistos, mas diferentemente de seus congêneres, $X$. obsoletus fica distante de bandos mistos, podendo se associar transitoriamente àqueles bandos que passam pelo seu hábitat. As espécies deste gênero forrageiam, principalmente, sobre troncos, capturando presas na superfície dos troncos ou galhos.

A espécie Lepidocolaptes albolineatus, representada por dois espécimes, consumiu principalmente Hymenoptera (Formicidae) e Coleoptera. Schubart et al. (1965) também descrevem estes itens como os principais consumidos por esta espécie. Geralmente, são vistos aos pares ou sozinhos em bandos mistos, forrageando em estratos superiores e dosséis, descem apenas ocasionalmente ao sub-bosque e, raramente, vão ao solo. Pegam presas na superficie de cascas de árvores, ou em fendas e, ocasionalmente, de aglomerados de vegetação viva e morta.

Campylorhamphus procurvoides, representada por um espécime, consumiu Araneae, Orthoptera e ovos. Segundo Marantz et al. (2003), a alimentação desta espécie é constituída amplamente por artrópodes, a análise de conteúdo estomacal inclui Coleoptera e Scorpiones. Tal espécie forrageia sobre troncos estreitos a médios, galhos verticais, trepadeiras e bambus de estratos baixos a médios da floresta. A maioria das presas é capturada de troncos e galhos, e ainda com o auxílio do seu longo bico, em talos de bambus mortos, extremidades de galhos quebrados, fendas de cascas de árvores, epífitas, aglomerados de galhos mortos ou trepadeiras (Marantz et al., 2003). 


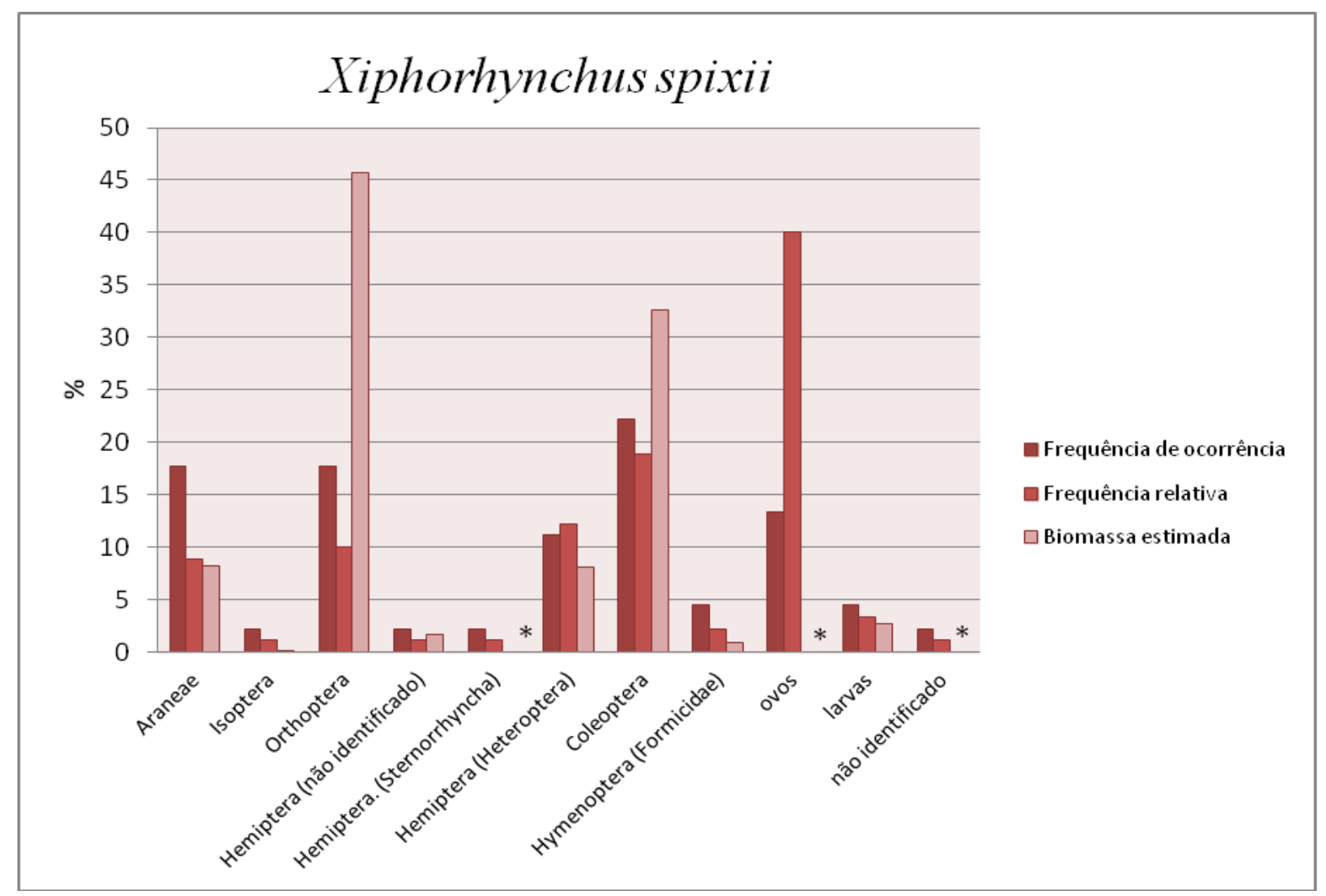

Figura 16: Itens alimentares consumidos por Xiphorhynchus spixii $(\mathrm{n}=10)$. * Biomassa estimada ausente.

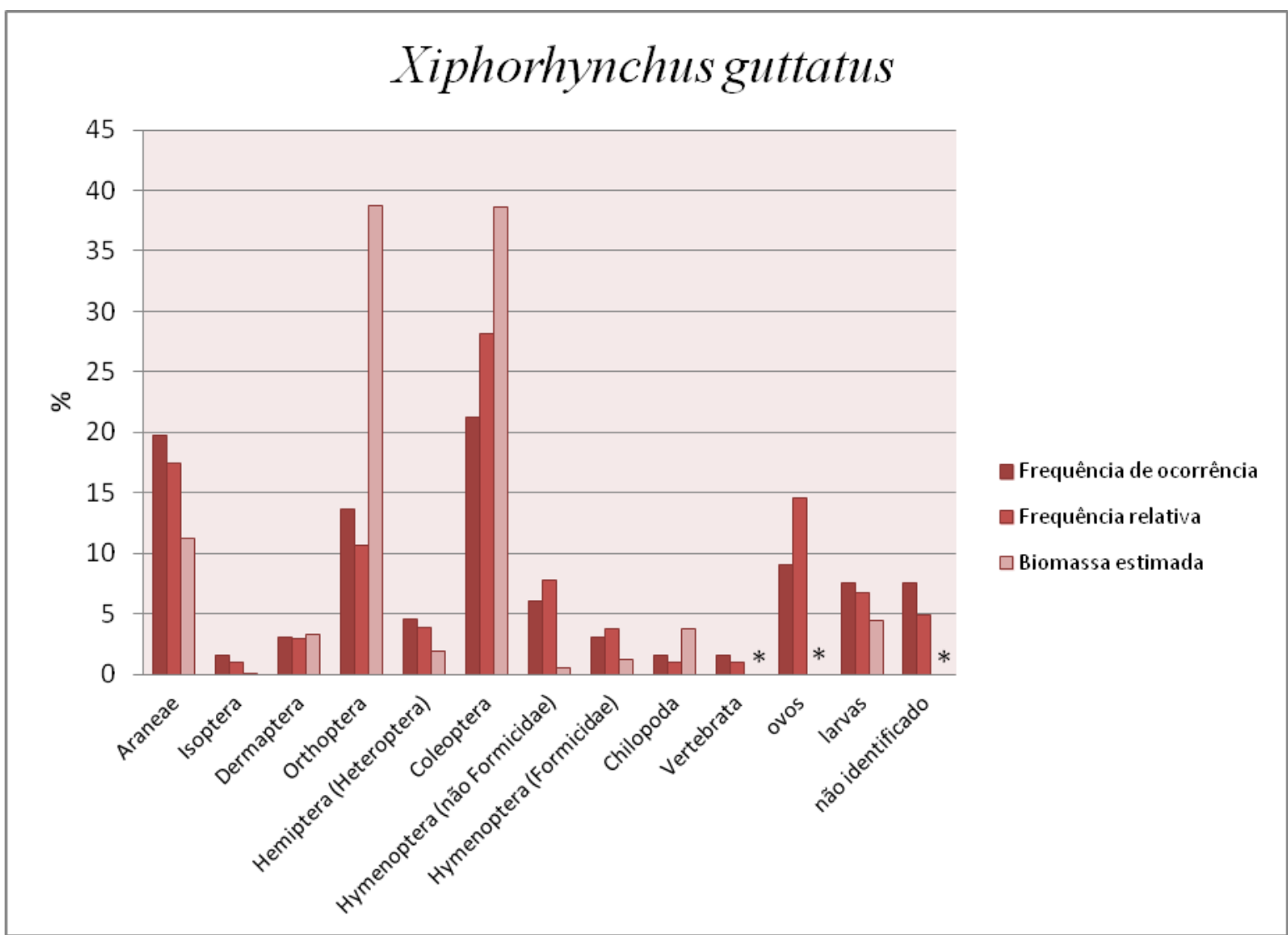

Figura 17: Itens alimentares consumidos por Xiphorhynchus guttatus $(\mathrm{n}=15)$. * Biomassa estimada ausente. 


\subsection{Família Thamnophilidae}

Dentre as espécies de Thamnophilidae analisadas, cerca de 50\% são seguidoras ocasionais de formigas de correição e, ocasionalmente, associam-se a bandos mistos e inspecionam folhas mortas suspensas; $15,6 \%$ seguem regularmente correição de formigas; $21,8 \%$ são membros assíduos de bandos mistos, 6,25\% inspecionam folhas mortas, regularmente e $6,25 \%$ são seguidoras obrigatórias de formigas de correição (Zimmer e Isler, 2003).

A análise de conteúdo estomacal de representantes desta família mostra Coleoptera e Orthoptera com as maiores frequências de ocorrências (22,7\% e 20,2\%, respectivamente) e estes mesmos itens foram responsáveis por mais de $80 \%$ da biomassa consumida pelos tamnofilídeos, sendo que Orthoptera contribuiu com 52,8\% e Coleoptera 29,2\%. Duas espécies de tamnofilídeos - Percnostola leucostigma $(\mathrm{n}=1)$ e Hylophylax poecilinotus $(\mathrm{n}=4)$ - consumiram vertebrados, mas as presas encontradas não foram identificadas. De acordo com Zimmer e Isler (2003), Orthoptera, Blattodea e Phasmida parecem ser itens alimentares preferidos por muitos tamnofilídeos, assim como larva (Lepidoptera), Coleoptera e Araneae. Muitos tamnofilídeos são conhecidos por se alimentarem de pequenos vertebrados, ao menos ocasionalmente. Tais presas consistem principalmente de pequenos lagartos de espécies de Anolis, embora também ocorram lagartixas, sapos e serpentes. Há registro de que pequenos tamnofilídeos também podem consumir lagartos de 70mm de comprimento (Zimmer e Isler, 2003).

Os tamnofilídeos empregam uma ampla variedade de técnicas de forrageamento para garantir suas presas predominantes $\square \square$ os artrópodes. A maioria é arborícola, embora seja comum encontrar tamnofilídeos em estratos baixos, ou estratos médios da floresta. As espécies de tamnofilídeos, seguidoras de formigas de correição (regulares e obrigatórias), evoluíram na especialização deste forrageamento a tal ponto que praticamente todo o seu alimento é obtido dessa maneira (Zimmer e Isler, 2003). De acordo com Chesser (1995) a dieta de quatro tamnofilídeos seguidores obrigatórios, foi notavelmente similar, sendo Orthoptera, Coleoptera, Hymenoptera (principalmente Formicidae) e Araneae, os principais itens consumidos por estas espécies. Rosenberg (1993) observou que a dieta de espécies congêneres de tamnofilídeos, com diferentes 
estratégias de forrageamento, era qualitativamente similar, sendo Orthoptera o item alimentar mais importante.

Entre os espécimes de Cymbilaimus lineatus $(\mathrm{n}=4)$ Orthoptera e Coleoptera tiveram as maiores frequências de ocorrência $(36,3 \%$ e 18,1\%, respectivamente). Os dados encontrados concordam com as informações fornecidas na literatura (Schubart et al., 1965; Zimmer e Isler, 2003). Os pássaros desta espécie forrageiam entre 5 e 25 metros acima do solo, principalmente em trepadeiras e aglomerados de Philodendron, próximos dos troncos; frequentemente, unem-se a bandos mistos de insetívoros, particularmente com tamnofilídeos e furnariídeos, quando estas aves passam pelo seu território; são seguidores ocasionais de formigas de correição.

Thamnophilus aethiops teve como principal item alimentar Coleoptera $(29,4 \%)$, seguido de Orthoptera e Hymenoptera (Formicidae) (17,6\%, cada um). Orthoptera e Coleoptera contribuíram, juntos, com quase 50\% da frequência relativa entre os itens alimentares de Thamnophilus schistaceus (Fig. 18). No entanto, apenas Orthoptera contribuiu com $64,4 \%$ da biomassa adquirida por estas aves. Thamnophilus punctatus, representada por cinco espécimes, teve maior frequência de ocorrência de Coleoptera $(23,5 \%)$ seguido de larvas (17,6\%). Schubart et al. (1965) encontraram Hemiptera, Coleoptera e Orthoptera; Zimmer e Isler (2003) citam larva (Lepidoptera), Coleoptera (Curculionidae), Orthoptera, Mantidae, Auchenorrhyncha e Neuroptera para essa espécie. Thamnophilus stictocephalus e T. amazonicus consumiram, principalmente, Coleoptera (74\%, 58,3\%, respectivamente). Zimmer e Isler (2003) citam larva (Lepidoptera), Orthoptera, Coleoptera e Hemiptera (Auchenorrhyncha) para $T$. stictocephalus e Araneae, Coleoptera, larva (Lepidoptera), Mantidae e Phasmatidae como itens alimentares para T. amazonicus. As espécies de Thamnophilus forrageiam sozinhas ou aos pares em estratos baixos e médios de florestas. Deslocam-se por pequenos saltos e fazem pequenas pausas para procurar presas na superfície de folhas, pecíolos, galhos e lianas, com movimentos rápidos do bico. Ocasionalmente, inspecionam presas escondidas em folhas mortas. No entanto, T. schistaceus e $T$. amazonicus, em geral, exploram aglomerados de lianas que ficam sobre os troncos. Além disso, T. schistaceus captura ainda presas em voo e T. amazonicus, regularmente, forrageia sobre o topo de bambus. Os representantes deste gênero, frequentemente, 
acompanham bandos mistos quando eles passam pelo seu território e, ocasionalmente, seguem colunas de formigas.

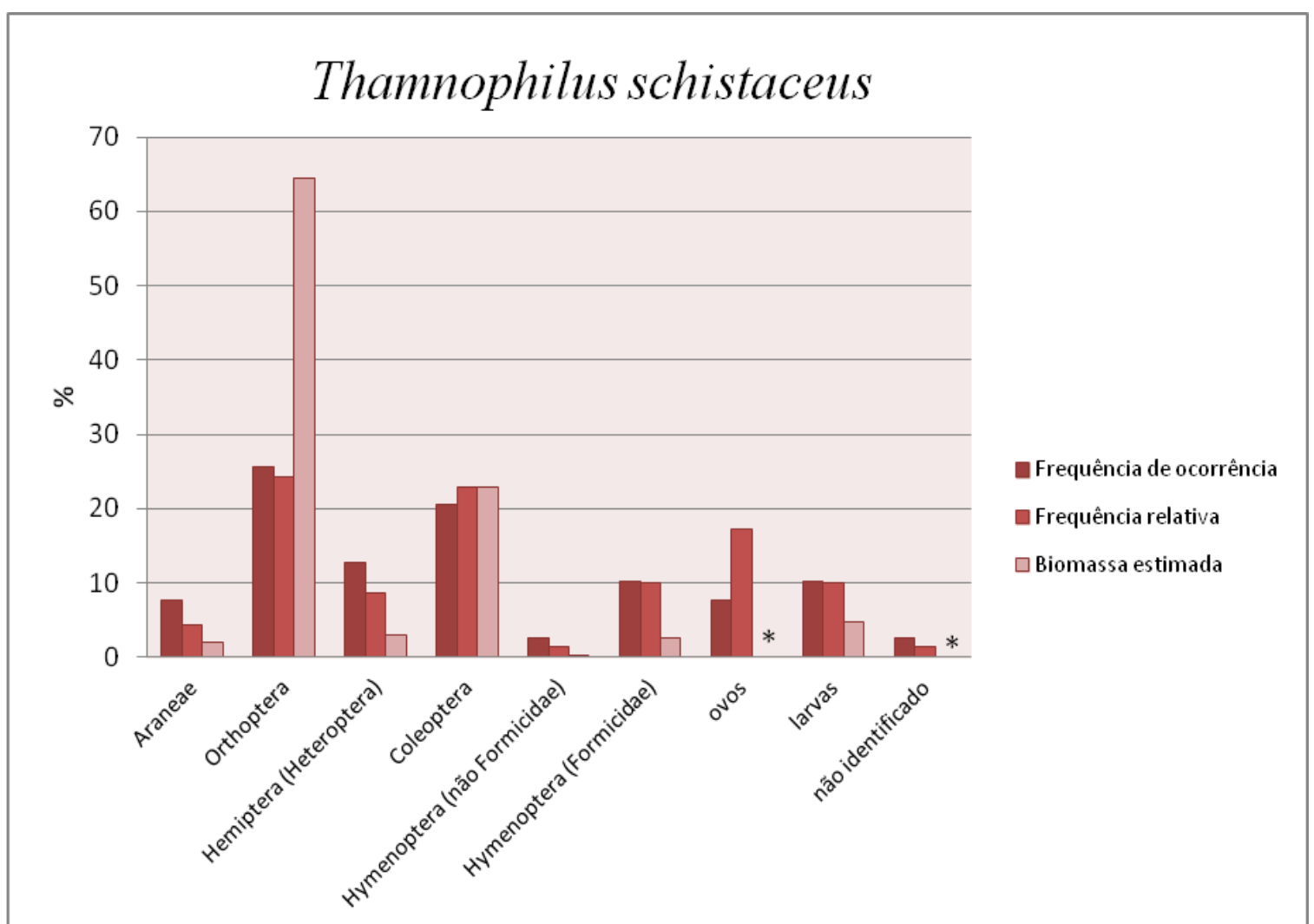

Figura 18: Itens alimentares consumidos por Thamnophilus schistaceus $(\mathrm{n}=15)$. ${ }^{*}$ Biomassa estimada ausente.

Entre as várias categorias alimentares consumidas por espécimes de Thamnomanes saturninus ( $\mathrm{n}=29)$ (Fig. 19), Coleoptera e Orthoptera tiveram as maiores frequências de ocorrência (26,7 e 20,9\%, respectivamente). No entanto, Orthoptera e Coleoptera foram os itens que contribuíram com a maior biomassa consumida $(42,8 \mathrm{e}$ 38,2\%, respectivamente). Zimmer e Isler (2003) citam Orthoptera, Mantidae, Hemiptera e Lepidoptera (larva e adulto), como itens alimentares para T. saturninus. Entre os itens consumidos por Thamnomanes caesius (Fig. 20) Coleoptera, Hemiptera (Heteroptera) e Orthoptera foram os mais frequentes $(25 \%, 20,8 \%$ e $20,8 \%$, respectivamente), porém Orthoptera contribuiu com mais de 50\% da dieta desta espécie, em termos de biomassa. Schubart et al. (1965) encontraram Hemiptera e Coleoptera. Zimmer e Isler (2003) citam Hemiptera (não identificado e Auchenorrhyncha), Coleoptera (Chrysomelidae) e Hymenoptera (Formicidae). Os representantes dessas espécies são membros assíduos de bandos mistos, sendo que $T$. caesius é considerada uma sentinela de tais bandos, vocaliza constantemente, mantendo o grupo coeso: faz alarmes quando aparecem 
predadores e captura artrópodes espantados pelas aves do bando. Essas duas espécies, regularmente, forrageiam juntas inclusive com $T$. ardesiacus, mas $T$. caesius permanece em estratos mais elevados que seus congêneres. Do poleiro, podem capturar presas, em voo, na folhagem e, menos frequentemente, nos troncos e solo. Às vezes forrageiam em associação com arapaçus, furnariídeos, Hylophilus, e traupídeos, e, ocasionalmente, seguem formigas de correição, em geral, por curtos períodos, coincidindo com os movimentos dos bandos mistos (Zimmer e Isler, 2003).

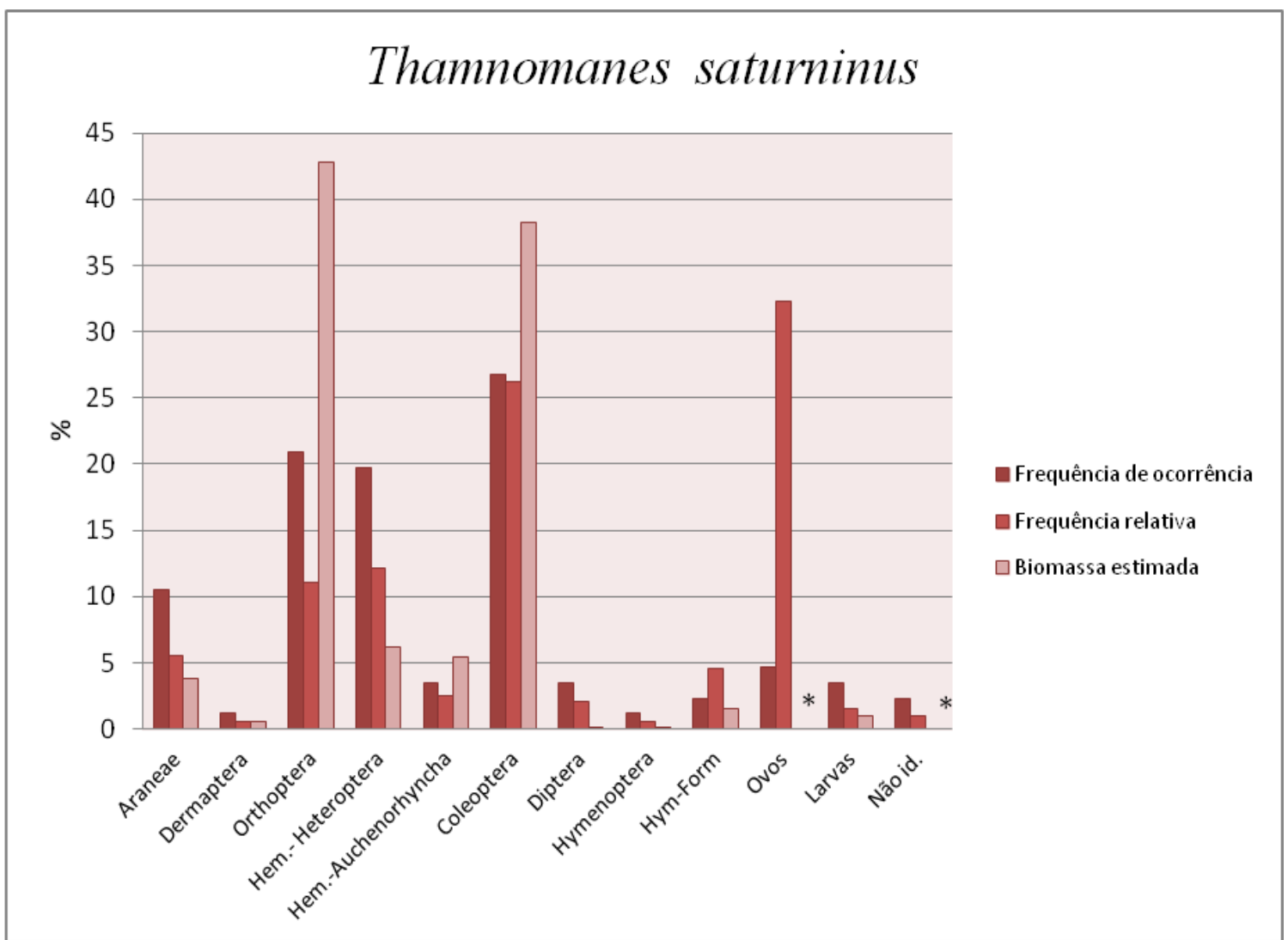

Figura 19: Itens alimentares consumidos por Thamnomanes saturninus $(\mathrm{n}=29) . *$ Biomassa estimada ausente. 


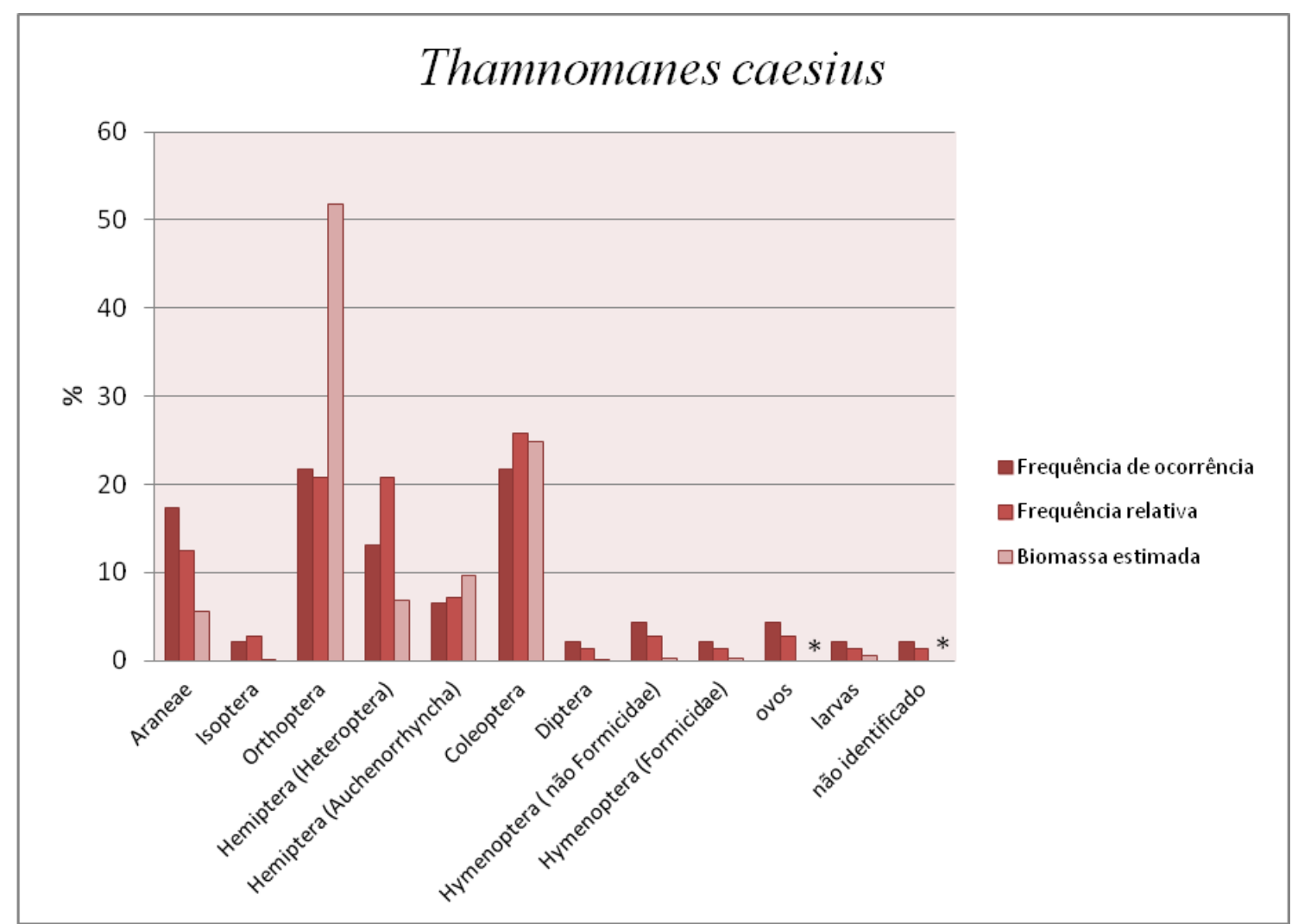

Figura 20: Itens alimentares consumidos por Thamnomanes caesius $(\mathrm{n}=18)$. * Biomassa estimada ausente.

Com apenas um espécime, Myrmotherula brachyura, consumiu Coleoptera, Hemiptera (Heteroptera), Hymenoptera (Formicidae) e Araneae. Para esta espécie Schubart et al. (1965) encontraram Orthoptera, Hemiptera (não identificado e Auchenorrhyncha) e Hymenoptera (Formicidae), já Haverschmidt (1968) encontrou Lepidoptera e Coleoptera. Myrmotherula hauxwelli (Fig. 21) consumiu, principalmente, Araneae (25,3\%), seguido de Coleoptera, ovos e Orthoptera (19\%, 19\%, e 14,2\%, respectivamente). Zimmer e Isler (2003) citam insetos e outros artrópodes e, ocasionalmente, pequenos lagartos ingeridos por esta espécie, enquanto na análise de conteúdo estomacal de nove espécimes de M. hauxwelli, no Peru, Rosenberg (1997) mostra Orthoptera como o item mais comum, seguido por Coleoptera, Araneae, Hymenoptera (Formicidae), larvas (provavelmente Lepidoptera), Hemiptera (Heteroptera), Diptera e Blattodea. Em um experimento de seletividade de presas, usando gaiolas exteriores (Rosenberg, 1993), M. hauxwelli rejeitou Opiliones, mas Lepidoptera e Odonata eram rapidamente capturados e consumidos. Os principais itens consumidos por M. leucophthalma (Fig. 22) foram Coleoptera e Orthoptera (29,4 e 38,2 $\%$, respectivamente). Orthoptera foi o item que contribuiu com a maior biomassa 
(71,6\%). Zimmer e Isler (2003) citam insetos e aranhas para esta espécie. No Peru e na Bolívia (Rosenberg, 1997), a análise de 18 espécimes revelou que os itens mais comuns são Orthoptera e Blattodea. Os itens encontrados em maior frequência para M. axillaris (Fig. 23) foram Araneae, Coleoptera, Orthoptera e ovos (23\%, 17\%, 15,3\% e 15,3\%, respectivamente). No Suriname, Haverschmidt (1968) cita Araneae, Diptera, larva (Lepidoptera), já no Peru e na Bolívia Rosenberg (1993) cita Orthoptera, Coleoptera, larvas e Hymenoptera (Formicidae e não Formicidae). No experimento com gaiolas externas $M$. axillaris rejeitou Hymenoptera (Formicidae), Diptera, Coleoptera e Hemiptera (Heteroptera), mas prontamente consumiu Blattodea, Araneae, Lepidoptera, Odonata e um pequeno lagarto (Rosenberg, 1993). Coleoptera e Araneae foram os itens encontrados no único espécime de $M$. iheringi, enquanto Zimmer e Isler (2003) citam Orthoptera, Phasmatidae, Lepidoptera (larva e adulto) e Araneae. A dieta de $M$. longipennis foi constituída, principalmente, de Coleoptera e Orthoptera, juntos com $70 \%$ de frequência relativa. Haverschmidt (1968), no Suriname, encontrou larva (Lepidoptera), Coleoptera (Chrysomelidae), Hymenoptera (Formicidae), Orthoptera e Araneae, já no Peru e na Bolívia (Rosenberg, 1993) as presas mais comuns foram Orthoptera, seguidas de larvas, Coleoptera, Araneae, Blattodea, Hemiptera (Heteroptera), bem como Hymenoptera (não Formicidae e Formicidae) e Diptera. Representada por apenas um espécime, M. menetriesii consumiu Araneae, Coleoptera e Hymenoptera (Formicidae). Na literatura há a citação do consumo de Orthoptera, Coleoptera e Araneae (Zimmer e Isler, 2003). Rosenberg (1993) observou que a dieta de seis espécies de Myrmotherula $\square \square$ três especialistas de serrapilheira aérea $(M$. leucophthalma, M. haematonota e M. ornata), duas que, habitualmente, forrageiam em folhas vivas ( $M$. axillaris e $M$. longipennis) e uma generalista de substrato ( $M$. hauxwelli) $\square \square$ era qualitativamente similar, sendo Orthoptera o item alimentar mais importante.

As espécies do gênero Myrmotherula, cujo conteúdo estomacal foi analisado, forrageiam sozinhas, aos pares ou em grupos familiares, em geral em estratos baixos e médios, exceto $M$. hauxwelli que permanece até um metro acima do solo, raramente mais elevado. M. brachyura e M. hauxwelli, ocasionalmente, acompanham bandos mistos, quando eles passam pelos seus territórios, enquanto que M. leucophthalma, $M$. axillaris, $M$. iheringi, M. longipennis e $M$. menetriesi são típicos membros de bandos 
mistos de outros insetívoros, principalmente com Thamnomanes, outros tamnofilídeos, furnariídeos e outros insetívoros (Zimmer e Isler, 2003). Avançam pela vegetação por saltos curtos e capturam presas nas superfícies de folhas, caules, galhos, lianas, trepadeiras. No entanto, M. hauxwelli salta lateralmente para galhos verticais e, às vezes, sobem também para Philodendron e outras plantas de folhas grandes próximas de troncos largos. A grande maioria destas aves são especialistas de folhas mortas (Rosenberg, 1997), mas M. brachyura não inspeciona presas na serrapilheira aérea (Zimmer e Isler, 2003). Ao se comparar as dietas de forrageadores de folhas mortas, no Peru e na Bolívia, as espécies de Myrmotherula consumiram mais Blattodea e Araneae do que as espécies de Automolus (Rosenberg, 1997). A composição da dieta de todas as espécies amostradas diferenciaram, significantemente, da disponibilidade de presas, indicando que havia seleção na captura dessas presas. M. hauxwelli ainda é uma espécie seguidora regular de formigas de correição, mas geralmente mantém-se na periferia das colunas, principalmente na presença de espécies seguidoras obrigatórias. Durante as correições costuma empoleirar-se em alturas mais baixas, capturando presas no chão, galhos, trepadeiras e folhagem; $M$. axillaris pode segui-las ocasionalmente (Zimmer e Isler, 2003). 


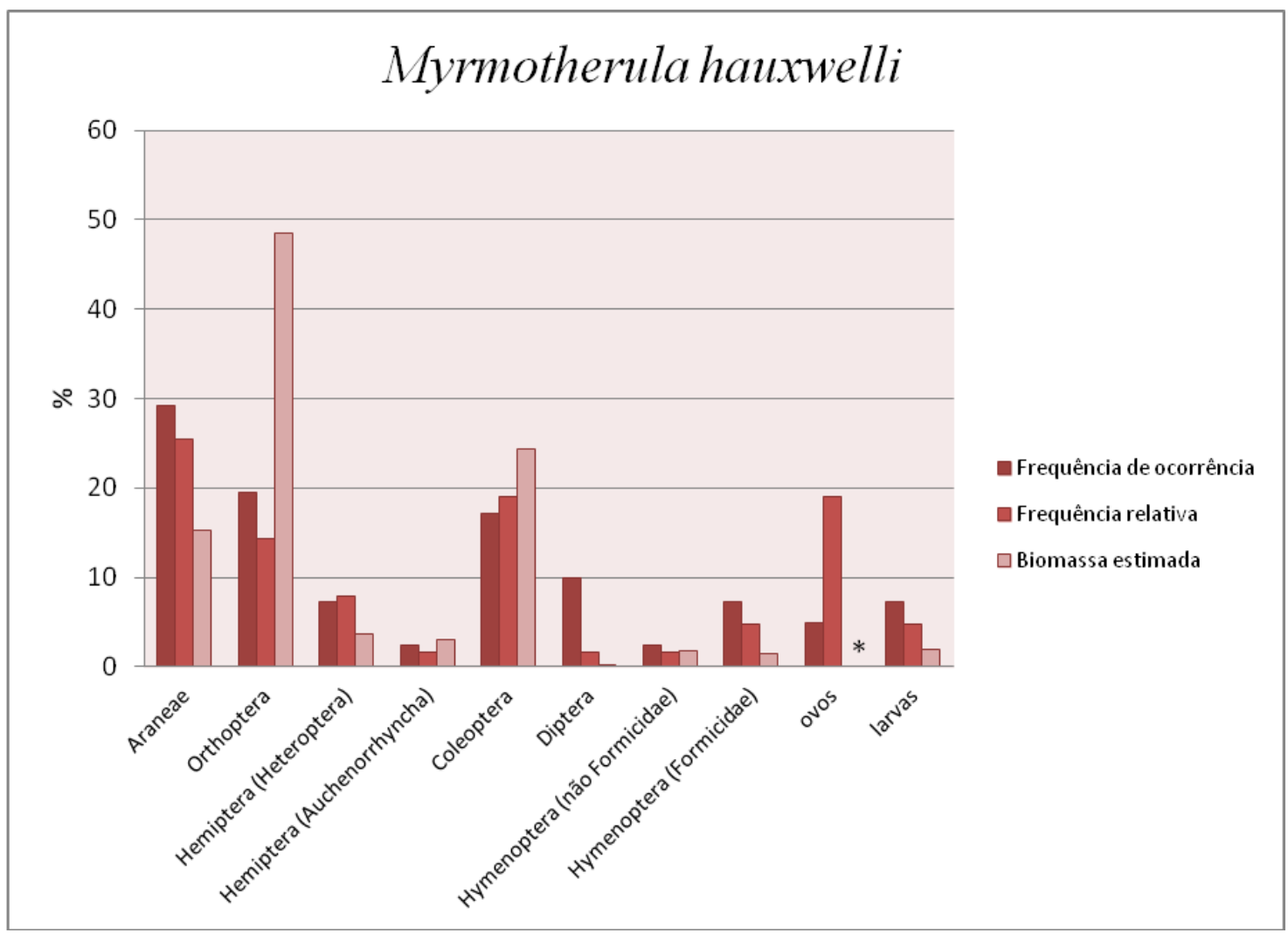

Figura 21: Itens alimentares consumidos por Myrmotherula hauxwelli $(\mathrm{n}=16) .{ }^{*}$ Biomassa estimada ausente.

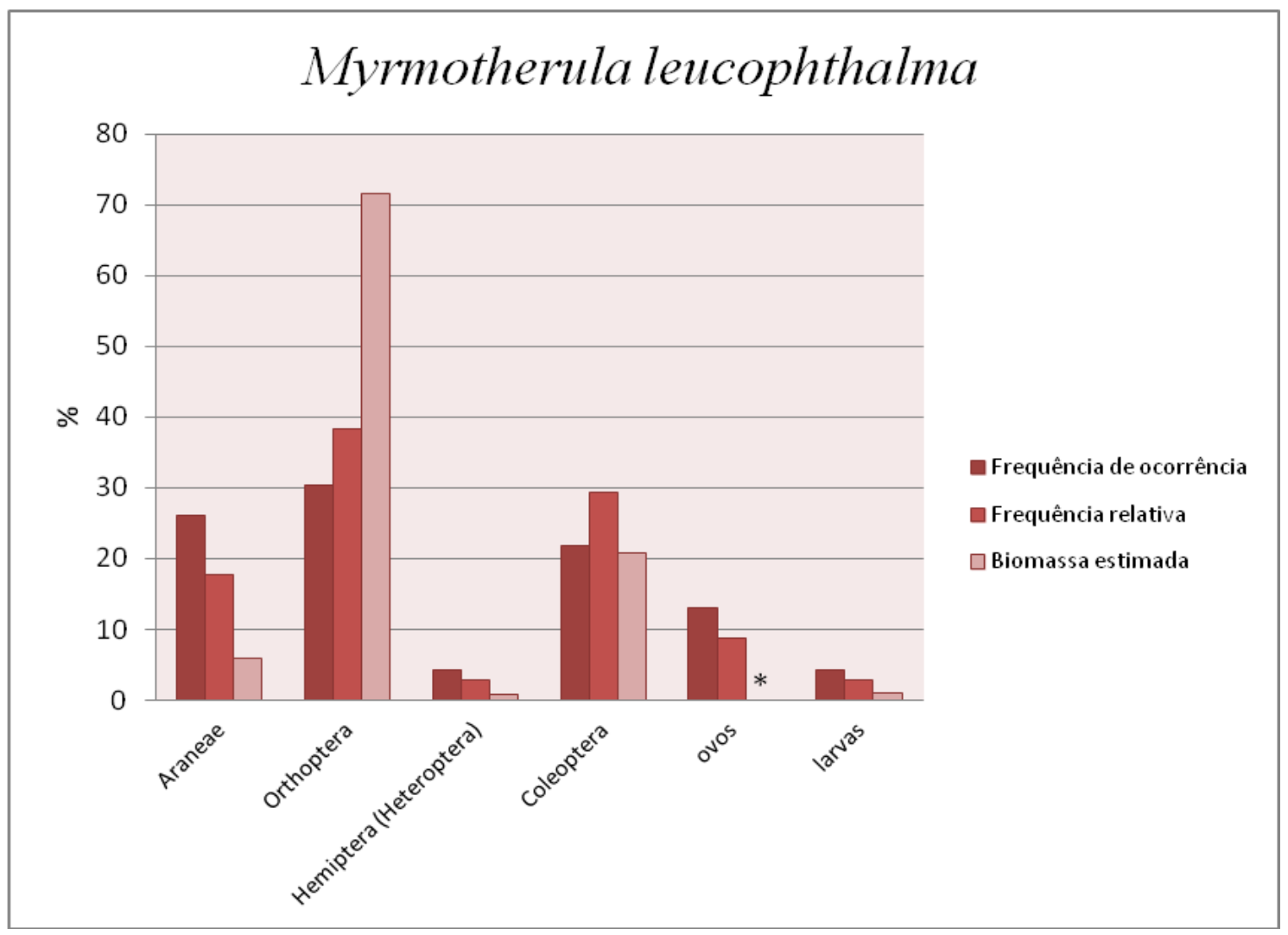

Figura 22: Itens alimentares consumidos por Myrmotherula leucophthalma $(\mathrm{n}=10)$ * Biomassa estimada ausente. 


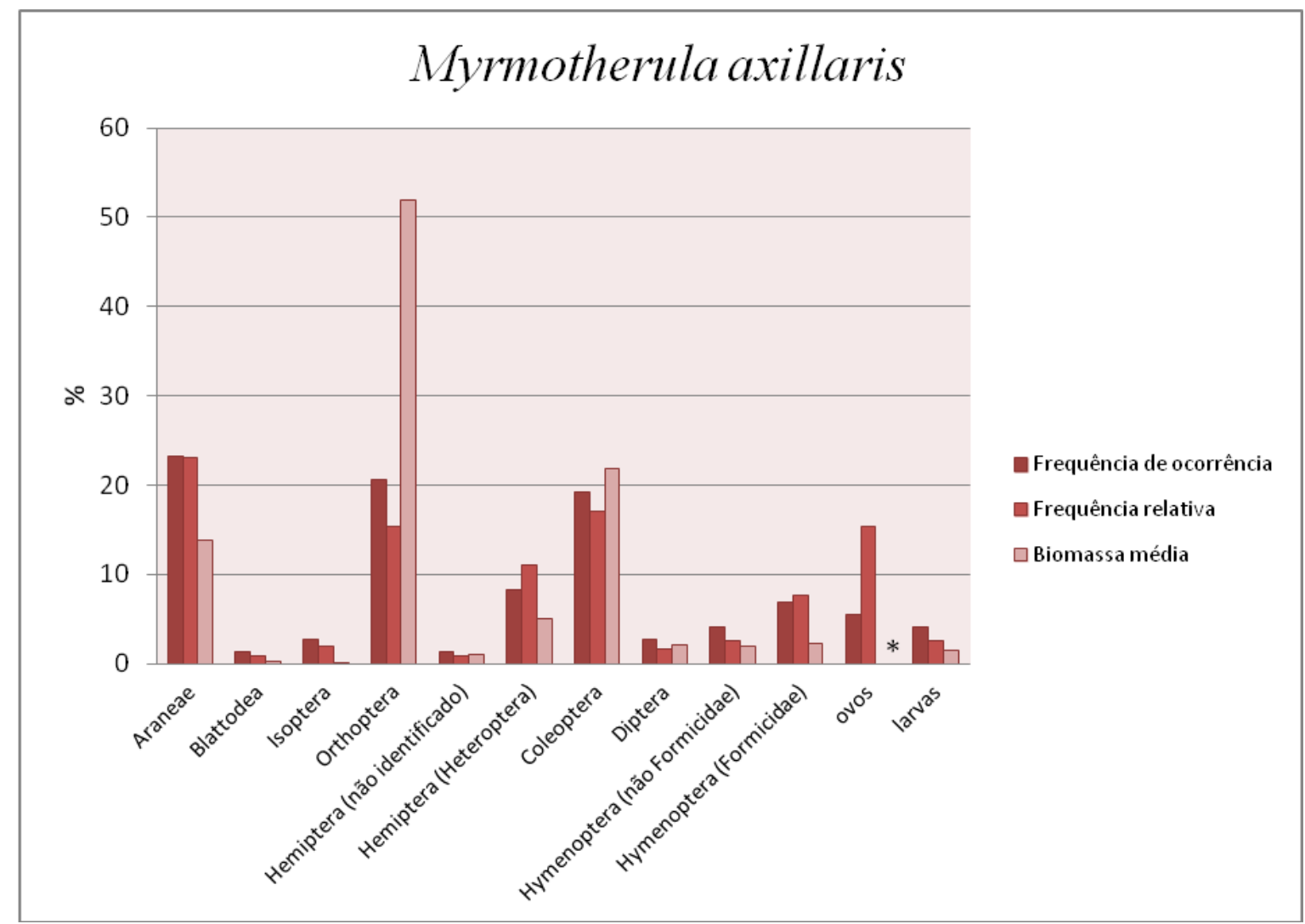

Figura 23: Itens alimentares consumidos por Myrmotherula axillaris $(\mathrm{n}=34) . *$ Biomassa estimada ausente.

Com apenas um representante, Herpsilochmus rufimarginatus consumiu Hymenoptera (Formicidae) e ovos. Schubart et al. (1965) citam Araneae, Orthoptera, Hemiptera e Coleoptera, enquanto que Zimmer e Isler (2003) incluem, como itens da dieta desta espécie, larva (Lepidoptera), Orthoptera, Araneae e um pequeno fruto (Rapanea). Forrageia regularmente a poucos metros do chão. Frequentemente, pode associar-se a bandos mistos de outros insetívoros, quando eles passam pelo seu território. A maioria das presas é capturada em folhas vivas (principalmente, na face superior). Não há registro se seguem formigas de correição (Zimmer e Isler, 2003).

Hemiptera (Heteroptera) e Coleoptera foram os itens com maior frequência de ocorrência entre os espécimes de Microrhopias quixensis. Estes mesmos itens contribuíram com a maior biomassa consumida (29,8\% e 31,7\%, respectivamente). Zimmer e Isler (2003) citam como itens alimentares para esta espécie Orthoptera, Hemiptera, Lepidoptera (adulto e larva) e Araneae. No Suriname, Haverschmidt (1968) encontrou Hemiptera (não identificado e Auchenorrhyncha) e Coleoptera. M. quixensis captura presas na superfície de folhas vivas, pecíolos e galhos; reune-se com bandos 
mistos, quando eles passam pelo seu território, inspecionam folhas mortas suspensas regularmente (Rosenberg, 1997); raramente seguem formigas de correição e nessas ocasiões descem e capturam presas no solo.

O único espécime de Formiciva grisea consumiu Orthoptera e Araneae. Schubart et al. (1965) encontraram, além dos itens citados, Hemiptera, Blattodea, Coleoptera, ovos (Orthoptera), larva (Lepidoptera), enquanto que Haverschmidt (1968), no Suriname, encontrou ainda Hemiptera (Auchenorrhyncha) e ooteca de Blattodea. Zimmer e Isler (2003) citam outros itens para esta espécie, no Brasil (Ceará), tais como Mantidae e Phasmatidae. Hymenoptera (Formicidae), Hemiptera (Heteroptera), Orthoptera e Coleoptera foram itens encontrados para Formicivora rufa, assim como aqueles citados por Schubart et al. (1965). As espécies de Formicivora juntam-se, temporariamente, a bandos mistos de outros insetívoros. Capturam presas na superfície de folhas vivas, caule, galhos e trepadeiras. Formicivora grisea ainda inspeciona bromélias do chão e, ocasionalmente, folhas mortas. Esta espécie segue formigas de correição por curtos períodos (Zimmer e Isler, 2003), mas não é conhecido se $F$. rufa tem o mesmo hábito.

Coleoptera, Orthoptera e ooteca de Blattodea foram itens comuns consumidos por ambas as espécies de Cercomacra. C. nigrescens consumiu ainda Hymenoptera (Formicidae), e C. cinerascens Hemiptera (Heteroptera) e Araneae. Schubart et al. (1965) relatam os mesmos itens encontrados em C. cinerascens, enquanto Zimmer e Isler (2003) citam Araneae, Orthoptera e larva (Lepidoptera). As espécies deste gênero adquirem presas na superfície de folhas vivas ou mortas e de caules, trepadeiras e galhos. Estas aves, ocasionalmente, juntam-se a bandos mistos de outros insetívoros, quando eles passam pelo seu território. C. nigrescens raramente segue formigas de correição, mas C. cinerascens pode segui-las por breves períodos (Zimmer e Isler, 2003).

O espécime de Pyriglena leuconota consumiu Isoptera, Orthoptera e Hymenoptera (Formicidae), enquanto Schubart et al. (1965) encontraram Araneae, Orthoptera, ooteca de Mantidae, larva (Lepidoptera), Hymenoptera (Formicidae) e Hemiptera; Zimmer e Isler (2003) citam Orthoptera como um dos principais itens consumidos e pequenos lagartos regularmente capturados; Gomes et al. (2001) citam 
Coleoptera e Hymenoptera (Formicidae) como itens predominantes na dieta desta espécie. Estes pássaros seguem formigas de correição rotineiramente quando elas estão presentes e, na ausência de seguidores obrigatórios, podem substituir a ave dominante, ocupando o lugar de forrageamento próximo ao centro da coluna de formigas. A maioria das presas é capturada diretamente da superfície de folhas vivas e mortas, do caule, de trepadeiras e galhos; também comumente descem ao solo para capturar presas da serrapilheira (Zimmer e Isler, 2003).

Coleoptera foi a categoria alimentar mais frequente na dieta de Myrmoborus myotherinus (Fig. 24), tanto em termos de frequência relativa $(47,6 \%)$, como em biomassa (54,6\%). Orthoptera foi o segundo item que contribuiu com a biomassa $(28,9 \%)$. Os representantes desta espécie selecionam poleiros horizontais e inclinados, dos quais esses pássaros descem ao solo para apreender presas; também capturam presas da superfície de folhas, caules, galhos. São seguidoras regulares de formigas de correição (Zimmer e Isler, 2003).

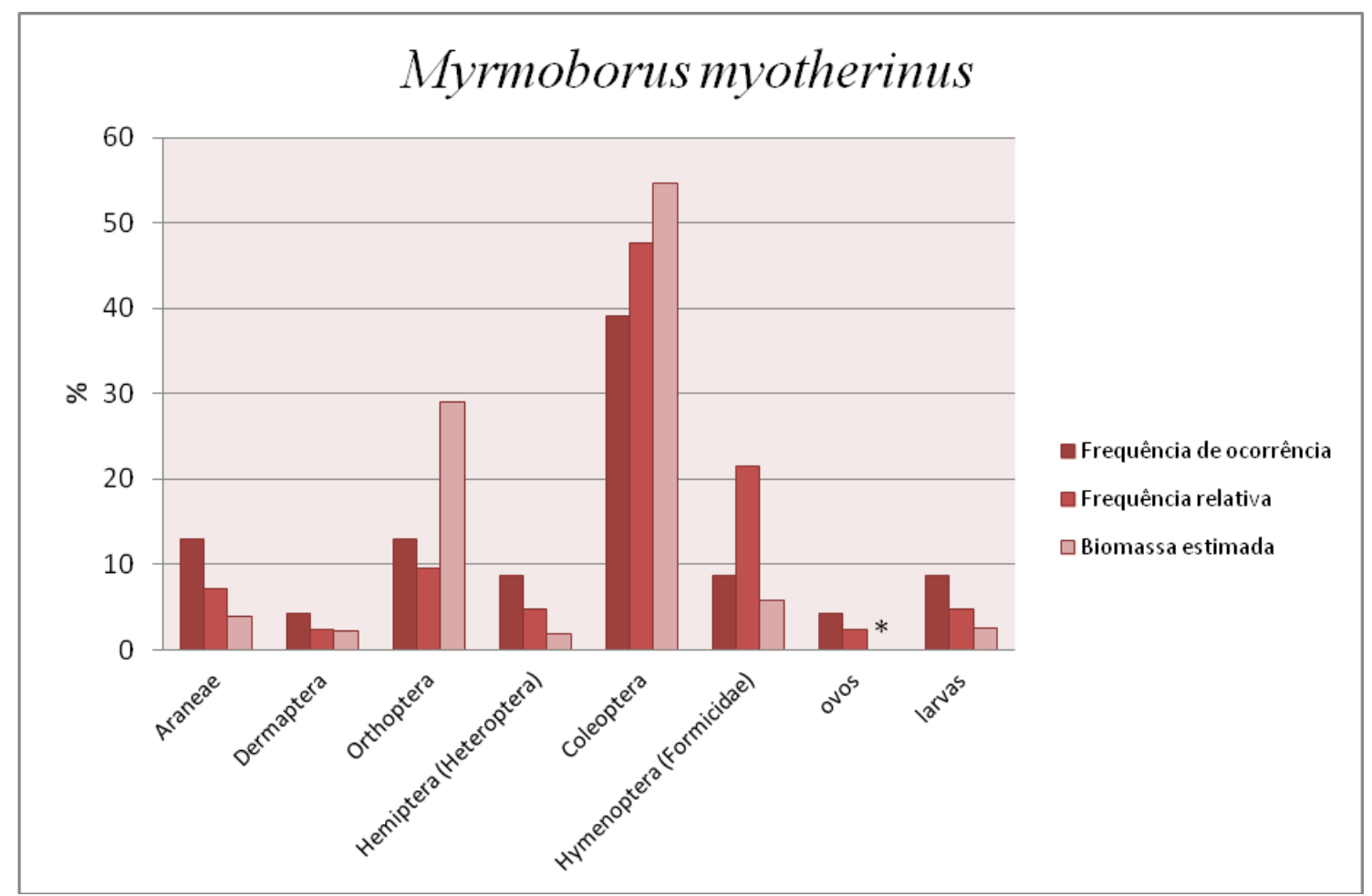

Figura 24: Itens alimentares consumidos por Myrmoborus myotherinus $(\mathrm{n}=10) . *$ Biomassa estimada ausente.

Entre a variedade de itens consumidos por Hypocnemis cantator (Fig. 25) [Diptera, Coleoptera, Hemiptera (não identificado, Heteroptera e Auchenorrhyncha), 
Orthoptera, Hymenoptera (Formicidae), Araneae, ovos e larvas], Coleoptera e Orthoptera contribuíram com as maiores frequências de ocorrência (30\% e 15\%, respectivamente), enquanto que Coleoptera contribuiu com a maior biomassa $(48,8 \%)$, seguido de Orthoptera (29,8\%), na dieta deste tamnofilídeo. Os dados de Schubart et al. (1965) e Haverschmidt (1968) são os mesmos itens encontrados na amostra analisada. Habitualmente, forrageiam em aglomerados densos de trepadeiras, folhagem de estratos baixos, bambus, aglomerados de trepadeiras e epífitas sobre grandes troncos. A maioria das presas é adquirida de folhas vivas (principalmente da face inferior), caules e trepadeiras, mas também inspecionam em folhas mortas suspensas. Ocasionalmente, associam-se a bandos mistos de outros insetívoros. Seguem formigas de correição regularmente (Venezuela, Guiana, Colômbia, Equador, Brasil), mas por curtos períodos de tempo (Zimmer e Isler, 2003).

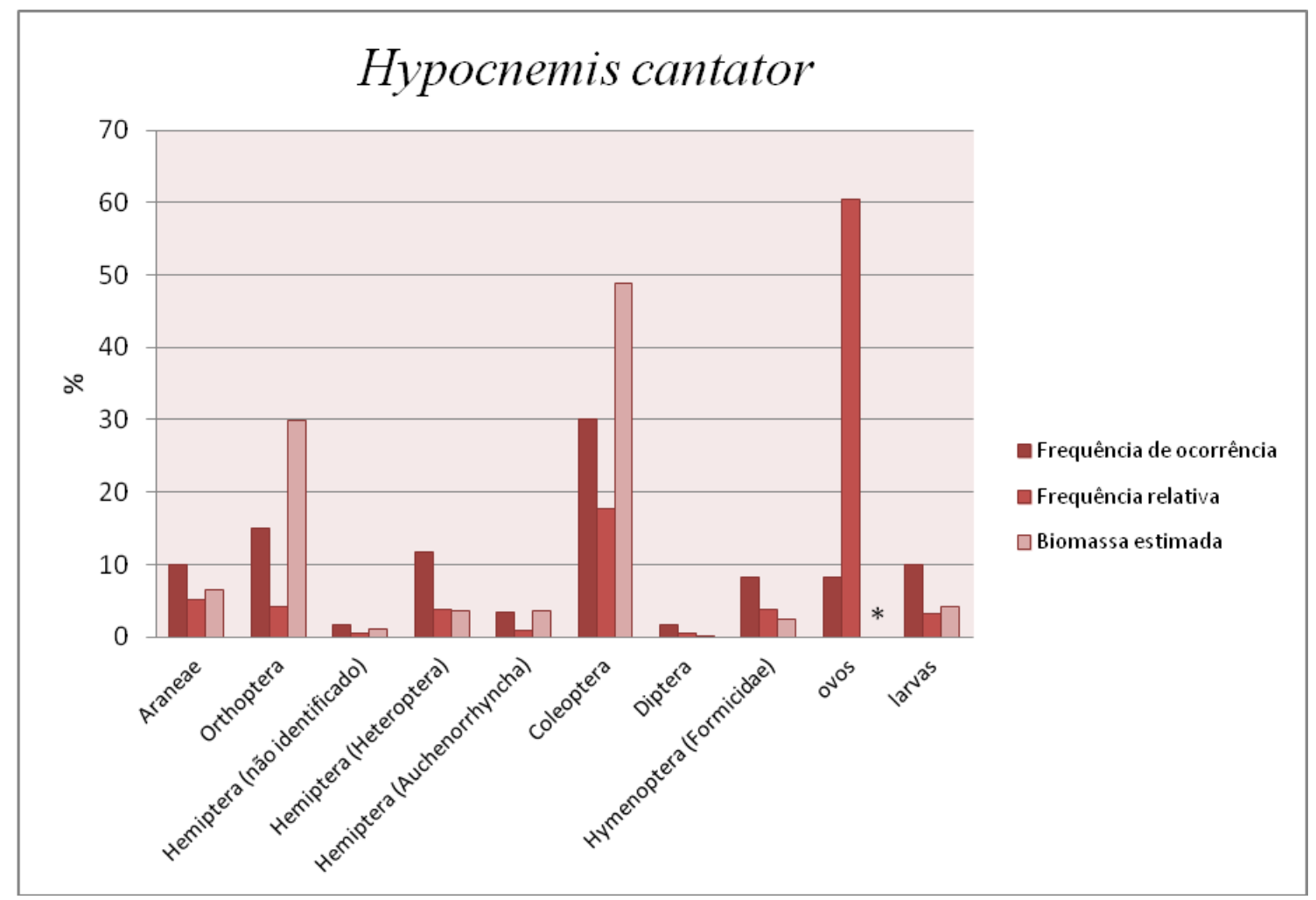

Figura 25: Itens alimentares consumidos por Hypocnemis cantator $(\mathrm{n}=22)$. * Biomassa estimada ausente.

Hypocnemoides maculicauda, representada por quatro espécimes, consumiu principalmente Coleoptera e Hymenoptera (Formicidae). Schubart et al. (1965) citam Coleoptera, Hymenoptera (não Formicidae, Formicidae e Vespoidea), Hemiptera (não identificado), larva (Lepidoptera). Esta espécie procura presas ao longo de troncos e galhos caídos, em raízes e trepadeiras, ao redor da base de árvores, no chão e na 
superficie da serrapilheira. São seguidoras ocasionais de formigas de correição que passam pelo seu hábitat (Zimmer e Isler, 2003).

Mesmo com um número reduzido de espécimes Percnostola leucostigma $(\mathrm{n}=4)$ apresentou uma variedade de itens consumidos [Coleoptera, Hemiptera (Heteroptera), Orthoptera, Hymenoptera (Formicidae), Araneae, Vertebrata e larva]. Coleoptera foi o item com maior frequência de ocorrência (25\%). Não foi possível a identificação dos ossos de vertebrados que foram encontrados no estômago de um espécime, mas há registro na literatura de que esta espécie consome vertebrados (Kurazo e Coltro-Júnior, 2008). As informações encontradas na literatura sobre a dieta de P. leucostigma citam Pseudoscorpiones, Hemiptera (não identificado), Coleoptera, Araneae, Opiliones, Hymenoptera (Formicidae) e larva (Neuroptera) (Schubart et al., 1965); Zimmer e Isler (2003) citam vários insetos e aracnídeos. P. leucostigma forrageia principalmente no chão, ao longo de troncos caídos, ou poleiros baixos, na vegetação densa (samambaias, Heliconia, e outras plantas com folhas largas); capturam presas principalmente da superfície de folhas, caule ou galhos. São aves seguidoras regulares de formigas de correição. Durante as correições de formigas comumente ficam em poleiros baixos e saltam para o solo para apreender presas (Zimmer e Isler, 2003).

Myrmeciza hemimelaena, representada por três indivíduos, consumiu Coleoptera, Orthoptera e Hymenoptera (Formicidae). Zimmer e Isler (2003) citam Orthoptera, Hemiptera e larva (Lepidoptera) como itens da dieta desta espécie. Coleoptera e Orthoptera foram itens encontrados no único espécime de Myrmeciza atrothorax, enquanto Schubart et al. (1965) encontraram representantes de vários outros táxons: Isoptera (Termitidae), Coleoptera (Elateridae e Curculionidae), Diptera (Tipulidae), ovos (Orthoptera) e Hemiptera (Pentatomidae); Zimmer e Isler (2003) citam insetos, aranhas e sapos (oferecidos aos ninhegos); Haverschmidt (1968) encontrou Coleoptera, Orthoptera (Tettigonidae), Neuroptera (larva) e Araneae. As espécies de Myrmeciza capturam presas em folhas, galhos, caules, trepadeiras, grama ou no chão. M. hemimelaena segue, ocasionalmente, formigas de correição, enquanto que esse hábito é raro em M. atrothorax (Zimmer e Isler, 2003).

Hylophylax naevius, representada por sete espécimes, teve Hymenoptera (Formicidae) e Coleoptera entre os itens mais abundantes consumidos. Os dados 
encontrados são os mesmos itens citados por Schubart et al. (1965). Entre os três espécimes de Hylophylax punctulatus foram encontrados Coleoptera, Hymenoptera (Formicidae), Hemiptera (Heteroptera), Orthoptera, Araneae e ovos. Várias categorias alimentares foram consumidas por espécimes de Hylophylax poecilinotus (Fig. 26), no entanto Orthoptera foi o item mais abundante quanto à frequência relativa $(66,2 \%)$ e à biomassa (82,9\%). Segundo Zimmer e Isler (2003) Formicidae (larva e alados), Blattodea, Orthoptera, Araneae, Chilopoda, Hemiptera (Auchenorrhyncha) são itens também consumidos por esta espécie. A amplitude da dieta de $H$. poecilinotus apresentou o menor índice dentre as espécies analisadas, 0,38 , resultado que evidencia que esta espécie apresenta tendência a ser especialista em relação aos recursos alimentares. O alto consumo de poucos itens (Orthoptera e Araneae), e a baixa frequência dos demais itens corroboram com este resultado. No entanto, segundo observações de Willis (1982), esta espécie parece capturar presas oportunisticamente, já que apreendem qualquer pequena presa que pode ser encontrada no chão ou na folhagem baixa, e cita que, em Manaus, larvas (Formicidae) e baratas foram as presas mais frequentemente consumidas. Quatro indivíduos desta espécie consumiram vertebrados, mas não foram identificados, apenas mencionada uma lagartixa; Kurazo e Coltro-Júnior (2008) citam a presença de pequeno vertebrado em conteúdo estomacal de um espécime; Zimmer e Isler (2003) citam que $H$. poecilinotus consome, ocasionalmente, pequenos lagartos. As espécies de Hylophylax capturam presas de folhas, caules, galhos, trepadeiras no chão e até mesmo no ar. Geralmente, não se associam a bandos mistos, mas $H$. poecilinotus pode ser participante regular de bandos mistos em algumas áreas. H. naevius e H. punctulatus seguem, ocasionalmente, formigas de correição, enquanto que $H$. poecilinotus é seguidora regular de tais formigas, mas permanecem restritos ao seu território (Zimmer e Isler, 2003). 


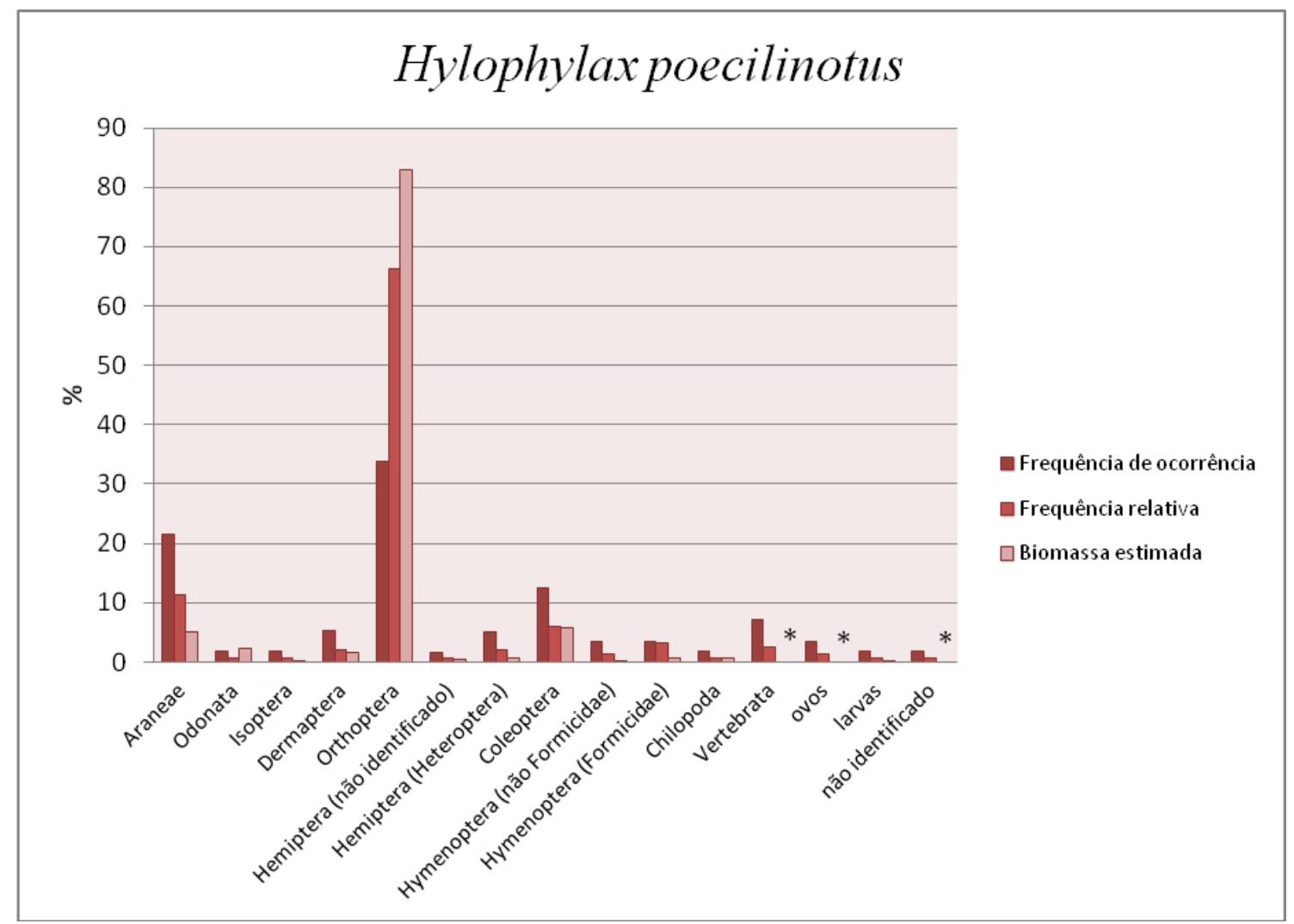

Figura 26: Itens alimentares consumidos por Hylophylax poecilinotus $(\mathrm{n}=24)$. * Biomassa estimada ausente.

Nos estômagos de seis espécimes de Rhegmatorhina gymnops foram encontrados, principalmente, Araneae e Orthoptera, (22,7\% cada um), além de Diptera, Coleoptera, Hemiptera (Heteroptera), Hymenoptera (não Formicidae e Formicidae) e larva (Lepidoptera) consumidos secundariamente. As presas já registradas na literatura incluem Orthoptera, Blattodea, Araneae e Chilopoda (Zimmer e Isler, 2003).

Araneae e Orthoptera $(32,1 \%$, cada um) foram os itens alimentares mais frequentes para Phlegopsis nigromaculata (Fig. 27), sendo que Orthoptera contribuiu com $75 \%$ da biomassa consumida. Os dados citados por Schubart et al. (1965) correspodem aos itens encontrados. Outros registros de presas, no Brasil, incluem Orthoptera, Blattodea, Hemiptera, Coleoptera, Isoptera, larva (Formicidae), Araneae e seus sacos de ovos, Scorpiones, Chilopoda e pequenos lagartos (Vertebrata) (Zimmer e Isler, 2003); Chesser (1995) também cita que esta espécie consumiu Araneae em alta frequência.

Phlegopsis nigromaculata apresentou um alto índice de Levins, 0,70, revelando uma dieta mais ampla, com vários itens consumidos com frequências semelhantes. De 
acordo com Chesser (1995) espécies seguidoras obrigatórias de formigas de correição consomem um número maior de itens alimentares, num determinado intervalo de tempo, se comparado com aves subordinadas a ela, devido ao local privilegiado em que se encontram, no centro das colunas de formigas. No entanto, o consumo mais rápido de presas, poderia significar que há pouca seleção na captura de presas e, provavelmente, essas aves sejam mais generalistas em relação aos recursos alimentares. Zimmer e Isler (2003) afirmam que estes pássaros podem consumir virtualmente todo tipo de presas que podem ser obtidas seguindo formigas de correição, possivelmente, por apresentarem estratégia de forrageamento altamente especializada.

As duas espécies citadas acima, Rhegmatorhina gymnops e Phlegopsis nigromaculata, são consideradas seguidoras obrigatórias de formigas de correição, inspecionam ninhos de formigas de correição e investigam vocalização de coespecíficos e de outros forrageadores obrigatórios à procura de ninhos ativos e, uma vez localizados, eles são seguidos durante a maior parte do dia. Forrageiam em baixas alturas (menos que um metro), principalmente em voos curtos, agarrando-se lateralmente em caules estreitos ou podem ir ao chão para adquirir artrópodes espantados pelas formigas. Ocasionalmente, fazem capturas aéreas, ou na folhagem, trepadeiras, galhos e troncos, às vezes sacodem folhas secas da serrapilheira com o bico para retirar presas escondidas (Zimmer e Isler, 2003). 


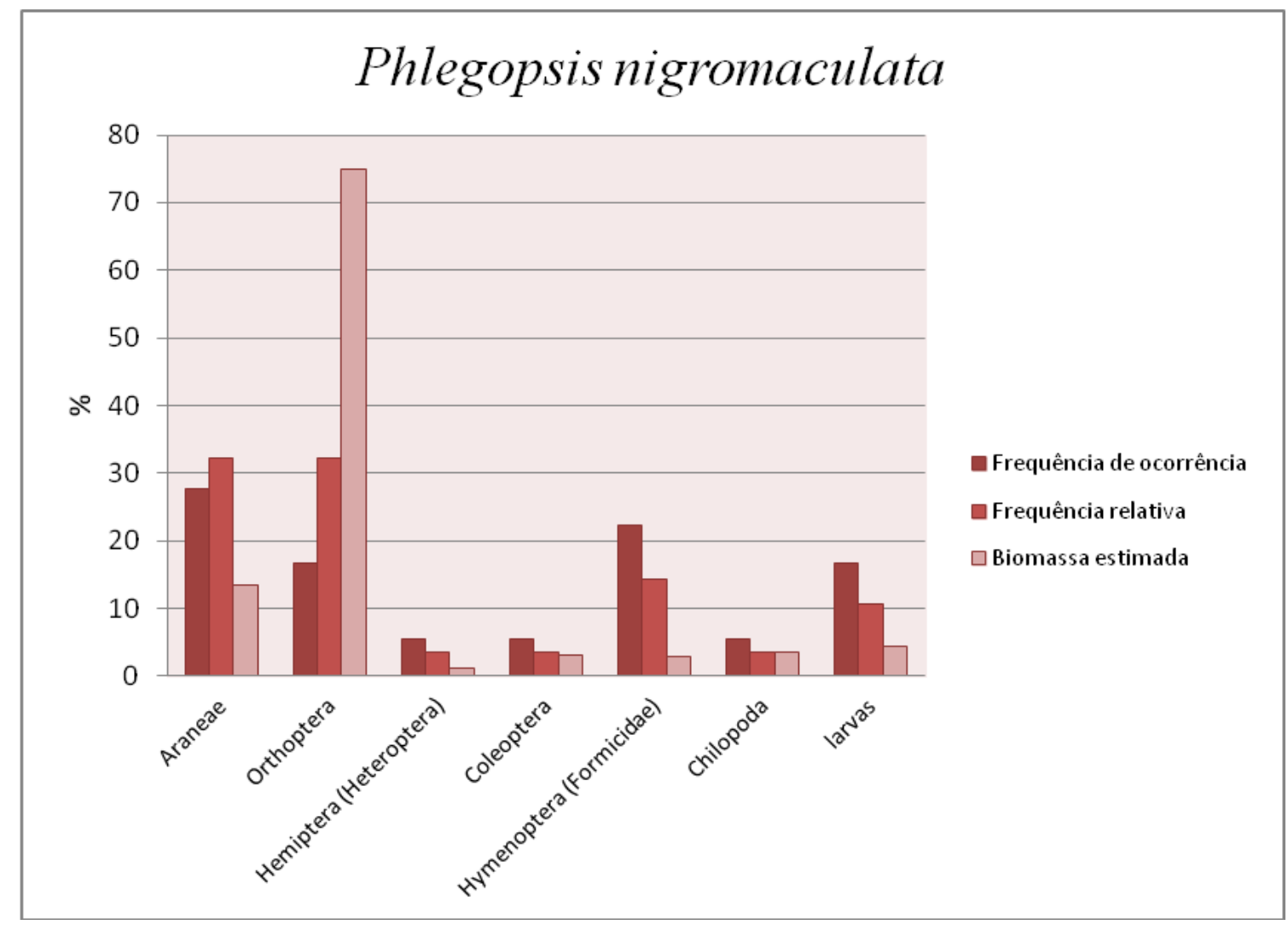

Figura 27: Itens alimentares consumidos por Phlegopsis nigromaculata $(\mathrm{n}=10)$.

\subsection{Família Formicariidae}

Os espécimes representantes de Formicarius colma consumiram, principalmente, Hymenoptera (Formicidae) e Orthoptera, os demais itens [Coleoptera e Hemiptera (Heteroptera)] encontram-se representados em frequências menores. Os dados sobre a alimentação desta espécie concordam com os itens encontrados na literatura (Schubart et al., 1965; Haverschmidt, 1968; Krabe e Schulenberg, 2003a). Além destes itens, Mestre et al. (2002) encontraram larvas de Diptera. Geralmente, os formicariídeos forrageiam sozinhos, caminhando pelo chão, pegando presas da serrapilheira, sacudindo as folhas com o bico. São encontrados, frequentemente, na periferia de enxames de formigas de correição.

\subsection{Família Conopophagidae}

Conopophaga melanogaster consumiu Isoptera e Coleoptera, enquanto que os itens encontrados para $C$. aurita foram Coleoptera e Hymenoptera (não Formicidae). As descrições sobre a alimentação de $C$. aurita e $C$. melanogaster são muito gerais - há apenas citações que se alimentam de pequenos artrópodes (Whitney, 2003). Schubart et 
al. (1965) também citam Hymenoptera (Formicidae) como um dos itens consumidos por $C$. aurita. Esses conopofagídeos forrageiam sobre ou próximo do solo, pegando presas da serrapilheira. 


\section{Conclusões}

1. Verificou-se que Coleoptera e Orthoptera constituem os principais itens consumidos pelas espécies de Furnariida analisadas, tanto em relação à frequência de ocorrência, quanto à maior parte da biomassa ingerida.

2. A predação de vertebrados, por algumas espécies de Dendrocolaptidae e Thamnophilidae, pode ser ocasional e, geralmente, é considerada oportunística, o que pode ser suportada pela baixa frequência de lagartos e sapos consumidos por essas aves.

3. A amplitude trófica apresentou-se sem um padrão geral para o táxon Furnariida. A maioria das espécies apresentou uma diversidade média em relação aos recursos alimentares. Apenas algumas espécies tiveram uma dieta mais ampla, e uma delas teve uma dieta quase restrita, com tendência à especialização.

4. Entre os Furnariidae, Orthoptera e Araneae foram os itens com maior frequência de ocorrência. A presença destes itens na dieta de representantes dessa família pode estar relacionada ao tipo de hábito alimentar da maioria das espécies representadas: forrageio de folhas mortas suspensas.

5. Coleoptera foi a categoria alimentar mais frequente entre os Dendrocolaptidae, coincidindo com o nicho dos arapaçus arborícolas, que capturam presas na superfície de troncos e em fendas de cascas de árvores.

6. Coleoptera e Orthoptera tiveram as maiores frequências de ocorrência entre os Thamnophilidae que apresentam grande variedade de formas de forrageamento. 


\section{Referências Bibliográficas}

Aguiar, N. O.; Bührnheim, P. F. 1990. Pseudoscorpiões foréticos de Stenodontes spinibarbis (Lin., 1758) (Coleoptera) e redescrição de Lechytia chthoniiformis (Balzan, 1890) (Pseudoscorpiones, Chthoniidae) da Ilha de Maracá - Roraima. Acta Amazonica, 21: 425-433.

Aguiar, N. O.; Bührnheim, P. F. 2011. Pseudoscorpionida (Arachnida) em galerias de colônias de Passalidae (Coleoptera, Insecta) em troncos caídos em floresta de terra firme da Amazônia, Brasil. Acta Amazonica, 41(2): 311-320.

Aguirre, A.C. 1973. Contribuição para o estudo do conteúdo gástrico da Zenaida auriculata (Ders Murs). Brasil Florestal, 4(16): 71-75.

Aguirre, A.C. 1974. Contribuição para o estudo do conteúdo gástrico da Zenaida auriculata (Ders murs). Brasil Florestal, 5(18): 61-67.

Aguirre, A.C. 1975. Contribuição para o estudo do conteúdo gástrico da Zenaida auriculata (Ders murs). Brasil Florestal, 6(24): 59-68.

Ames, P.L. 1971. The morphology of the syrinx in passerine birds. Peabody Museum of Natural History Bulletin, 37: 1-194.

Azevedo, F.R.; Ramalho, F.S. 1999. Impacto da temperatura e da defesa da presa na utilização de Tenebrio molitor L. por ninfas do predador Supputius cincticeps (Heteroptera: Pentatomidae). Anais da Sociedade Entomológica do Brasil, 28(1): 111-119.

Belentani, S.C.S. 2001. Ecologia alimentar do lobo-guará, Chrysocyon brachyurus (Mammalia: Canidae) no Parque Florestal Salto e Ponte, município de Prata, M.G. São Paulo, 71 pp. Dissertação (Mestrado). São Paulo, Instituto de Biociências da Universidade de São Paulo.

Bisbal, F.J.; Ojasti, J.D. 1980. Nicho trófico del zorro Cerdocyon thous (Mammalia, Carnivora). Acta Biologica Venezuelica, Caracas, 10 (4): 469-496.

Brandt, A.; Machado, R.B. 1990. Área de alimentação e comportamento alimentar de Anodorhynchus leari. Ararajuba, 1: 57-63. 
Borror, D.J.; Delong, D.M. 1969. Introdução ao estudo dos insetos. São Paulo, Edusp e Edgar Blücher.

Brumfield, R.T.; Tello, J.G.; Cheviron, Z.A.; Carling, M.D.; Crochet, N.; Rosenberg, K.V. 2007. Phylogenetic conservatism and antiquity of a tropical specialization: Army-ant-following in the typical antbirds (Thamnophilidae). Molecular Phylogenetics and Evolution, 45: 1-13.

Brusca, R.C.; Brusca, G.J. 2003. Invertebrates. 2. ed. Sunderland, Massachusetts. Sinauer Associates.

CBRO. 2011. Número de espécies de aves do Brasil (e de alguns grupos e táxons). Versão 25/01/2011. Disponível em http://www.cbro.org.br. Acesso em: $16 / 02 / 2013$.

Chapman, A; Rosenberg, K. 1991. Diets of four sympatric Amazonian woodcreepers (Dendrocolaptidae). Condor, 93: 904-915.

Chesser, R.T. 1995. Comparative diets of obligate ant-following birds at a site in Northern Bolivia. Biotropica, 27(3):382-390.

Chesser, R.T. 2004. Molecular systematics of New World suboscines birds. Molecular Phylogenetics and Evolution, 32: 11-24.

Coates-Estrada, R.; Estrada, A. 1989. Avian attendance and foraging at army-ant swarms in the tropical rain forest of Los Tuxtlas, Veracruz, Mexico. Journal of Tropical Ecology, 5: 281-92.

Costa, C.; Vanin, S.A.; Casari-Chen, S.A. 1988. Larvas de Coleoptera do Brasil. São Paulo, Museu de Zoologia.

CSIRO (Commonwealth Scientific and Industrial Research Organisation). 1991. The insects of Australia: a textbook for students and research works. Division of Enthomology, v. 1-2. 2. ed. Melbourne, Melbourne University Press.

Cueto, V.R.; Casenave, J.L. 2000. Seasonal changes in birds assemblages of coastal woodlands in east-central Argentina. Studies on Neotropical Fauna and Environment, 35: 173-177. 
Delarmelina, A.F.P.; Alves, M.A.S. 2009. Utilização de recursos alimentares por Philydor atricapillus e P. rufum (Aves: Furnariidae) em uma área da Mata Atlântica da Ilha Grande, RJ. Revista Brasileira de Ornitologia, 17(1): 59-64.

Daly, H.V.; Doyen, J.T.; Purcell, A.H. 1998. Introduction to insect biology and diversity. 2. ed. Oxford, Oxford University Press.

Davis, D. E. 1946. A seasonal analysis of mixed flocks of birds in Brazil. Ecology, 27: 168-181.

del Hoyo, J.; Elliot, A.; Christie, D.A. 2003. Handbook of birds of the world. v. 8. Broadbills to Tapaculos. Barcelona, Lynx Edicions.

del Hoyo, J; Elliot, A.; Christie, D.A. 2010. Handbook of the birds of the world. v.15. Weavers to New World Warblers. Barcelona, Lynx Edicions.

Develey, P.F.; Peres, C.A. 2000. Resource seasonality and the structure of the mixed species bird flocks in a coastal Atlantic forest of southeastern Brazil. Journal of Tropical Ecology, 16: 33-53.

Durães, R.; Marini, M.A. 2003. An evaluation of the use of tartar emetic in the study of birds diets in the Atlantic Forest of southeastern Brazil. Journal Field Ornithology, 74(3): 270-280.

Emmons, L.H. 1987. Comparative feeding ecology of felids in a Neotropical rainforest. Behavior, Ecology and Sociobiology, 20: 271-283.

Eisenmann, E. 1961. Favorite foods of Neotropical birds: flying termites and Cecropia catkins. Auk 78(4): 636-638.

Faria, C. M. A.; Rodrigues, M. 2009. Birds and army ants in a fragment of the Atlantic Forest of Brazil. Journal of Field Ornithology, 80: 328-335.

Gill, F.B. 1994. Ornithology, cap. 7, pp. 147-173. New York, W. H. Freeman.

Gomes, V.S.; Alves, V.S.; Ribeiro, J.R.I. 2001. Itens alimentares encontrados em amostras de regurgitação de Pyriglena leucoptera (Vieillot) (Aves, Thamnophilidae) em uma floresta secundária no Estado do Rio de Janeiro. Revista Brasileira de Zoologia, 18(4): 1073-1079. 
Gonzalez, V.H.; Mantilla, B.; Mahnert, V. 2007. A new host record for Dasychernes inquilinus (Arachnida, Pseudoscorpiones, Chernetidae), with an overview of pseudoscorpion - bee relationships. Journal of Arachnology, 35(3): 470-474.

Gradwohl, J.; Greenberg, R. 1982. The effects of a single species of avian predator on the arthopods of aerial leaf-litter. Ecology, 63: 581-583.

Hasui, E; Höfling, E. 1998. Preferência alimentar das aves frugívoras de um fragmento de Floresta Estacional semidecídua secundária, São Paulo, Brasil. Iheringia, 43-64.

Haverschmidt, F. 1968. Birds of Surinam. Oliver e Boyd, Edinburgh and London.

Hempel, A. 1949. Estudo da alimentação natural de aves silvestres do Brasil. Arquivos do Instituto Biológico de São Paulo, 19: 237-268.

Irestedt, M.; Fjeldsa; J.; Johansson, U.S.; Ericson, P.G.P. 2002. Systematic relationships and biogeography of the tracheophone suboscines (Aves: Passeriformes). Molecular Phylogenetics Evolution, 23: 499-512.

Jimbo, S. 1957. A flora na alimentação das aves brasileiras. Papéis Avulsos do Departamento de Zoologia, São Paulo, 13 (8): 99-108.

Jones, S.E.1978. Coexistence in mixed species antwren flocks. Oikos, 29:366-375.

Krabbe, N.K.; Schulenberg, T.S. 2003a. Family Formicariidae (Ground-Antbirds), pp. 682-732. In: del Hoyo, J.; Elliott, A.; Christie, D. (eds). Handbook of the birds of the world, v. 8. Broadbills to Tapaculos. Barcelona, Lynx Edicions.

Krabbe, N.K.; Schulenberg, T.S. 2003b. Family Rhynocryptidae (Tapaculos), pp. 748787. In: del Hoyo, J.; Elliott, A.; Christie, D. (eds). Handbook of the birds of the world, v. 8. Broadbills to Tapaculos. Barcelona, Lynx Edicions.

Krebs, C. J. 1999. Ecological methodology (2. ed.). Menlo Park, CA: Addison-Welsey Educational Publishers.

King, A.S., 1989. Functional anatomy of the syrinx. In: King, A.; Mclelland, J. (eds.) Form and function in birds v. 4, p.105-189. New York, Academic Press. 
Kruuk, H; Parish, T. 1982. Factors affecting population density, group size of the European Badger, Meles meles. Journal of Zoology, London, 196: 31-39.

Kupriyanov, V.M.S.; Daza, J.D.; Bauer, A.M.; Gaban-Lima, R.; Rocha-Brito, G.R.; Höfling, E. 2012. Six species of Amazonian Woodcreepers (Aves: Dendrocolaptidae) preying upon lizards and frogs. Journal of Natural History, 46(47-48): 2985-2997.

Kurazo, M. O. A.; Coltro-Júnior, L. A. 2008. Dietas de algumas espécies de aves das famílias Thamnophilidae, Grallariidae e Formicariidae do Amapá. Revista Brasileira de Ornitologia, 16(4): 376-379.

Lopes, L.E.; Fernandes, A.M.; Marini, M.A. 2003. Consumption of vegetable matter by Furnarioidea. Ararajuba, 11(2): 235-239.

Lopes, L.E.; Fernandes, A.M.; Marini, M.A. 2005. Predation on vertebrates by Neotropical passerine birds. Lundiana, 6(1): 57-66.

Mallet-Rodrigues, F.; Alves, V.S.; Noronha, L.M. 1997. O uso do tártaro emético no estudo da alimentação de aves silvestres no Estado do Rio de Janeiro. Ararajuba, 5(2): 219-228.

Mallet-Rodrigues, F. 2001. Foraging and diet composition of the Black-capped Foliage-gleaner (Phylidor atricapillus). Ornitologia Neotropical, 12: 255-263.

Marantz, C.A.; Aleixo, A.; Bevier, L.R.; Patten, M.A. 2003. Family Dendrocolaptidae (Woodcreepers), pp. 358-447. In: del Hoyo, J.; Elliott, A.; Christie, D. (eds). Handbook of the birds of the world, v. 8. Broadbills to Tapaculos. Barcelona, Lynx Edicions.

Marini, M.A.; Garcia, F.I. 2005. Conservação de aves no Brasil. Megadiversidade, 1(1): 95-102.

Mestre, L.A.M. 2002. Dieta de aves insetívoras terrestres e a disponibilidade de presas em fragmentos florestais amazônicos. São Carlos, 265 p. Dissertação (Mestrado). São Carlos, Universidade Federal de São Carlos. 
Meyer de Schauensee, R. M. 1982. A guide to the birds of South America. Pennsylvania, Academy of Natural Sciences of Philadelphia.

Mills, M.G.L. 1996. Methodological advances in capture, census, and food-habitats studies of large African carnivores, pp. 223-242. In: Gittleman, J. L. Carnivore behavior, ecology and evolution, v. 2. Ithaca, Comstock, Cornell University Press.

Miranda, J.P.; Ricci-Lobão, A.; Rocha, C.F.D. 2010. Influence of structural habitat use on the thermal ecology of Gonatodes humeralis (Squamata: Gekkonidae) from a transitional forest in Maranhão, Brazil. Zoologia (Curitiba). 27(1): 35-39.

Moojen, J.; Carvalho J.C.M.; Lopes H.S. 1941. Observações sobre o conteúdo gástrico das aves brasileiras. Memórias do Instituto Oswaldo Cruz, 36(3): 405-444.

Motta-Junior, J.C.; Talamoni, S.A. 1996. Biomassa de presas consumidas por Tyto alba (Strigiformes: Tytonidae) durante a estação reprodutiva no Distrito Federal. Ararajuba, 4(1): 38-41.

Muchmore, W. 1971. Phoresy by north and central American pseudoscorpions. Proceedings of the Rochester Academy of Science, 12 (2): 79-97.

Munn, C.A. 1985. Permanent canopy and understory flocks in Amazonia: species composition and population density. Ornithological Monographs, 36: 683-712.

Munn, C.A.; Terborgh, J. 1979. Multi-species territoriality in Neotropical foraging flocks. Condor, 81(4): 338-347.

Naranjo, L.G.; Ulloa, P.C. 1997. Diversidad de insectos y aves insectivoras de sotobosque em habitats perturbados de selva lluvosa tropical. Caldasia, 19 (3): 507520.

Nunes, A. L.; Adis, J.; Mello, J. A. S. 2005. Fenologia de Phlugis teres (De Geer, 1927) (Orthoptera, Tettigonidae) e abundância de artrópodos em populações de Eichhornia crassipes (Pontederiaceae) em um lago de Várzea na Amazônia Central. Boletim Museu Paraense Emílio Goeldi, série Ciências Naturais, 1(2): 271285. 
Oren, D.C.; Silva, J. M. C. 1987. Cherrie's spinetail (Synallaxis cherriei gyldenstolpe) (Aves: Furnariidae) in Carajás and Gorotere, Pará, Brazil. Boletim do Museu Parense Emílio Goeldi, série Zoologia, 3(1): 1-9.

Orians, G.H.1969. On the evolution of mating systems in birds and mammals. American Naturalist, 104: 589-603.

Pineschi, R.B. 1990. Aves como dispersoras de sete espécies de Rapanea (Myrsinaceae) no maciço de Itatiaia, estados do Rio de Janeiro e Minas Gerais. Ararajuba, 1: 7378.

Pinkas, L; Oliphant, M.S.; Iverson, I.L.K. 1971. Food habits of albacore, bluefin tuna, and bonito in California waters. Department of Fish and Game. Fish Bulletin, 152: $1-105$.

Pinto, O.M. de O. 1978. Novo catálogo das aves do Brasil. Primeira parte: Aves nãoPasseriformes e Passeriformes não-Oscines, com exclusão da família Tyrannidae. São Paulo, Empresa Gráfica da Revista dos Tribunais.

Poulin, B.; Lefebvre, G. 1996. Dietary relationships of migrant and resident birds from a humid forest in central Panama. Auk, 113(2): 277-287.

Poulin, B.; Lefebvre, G.; Ibanez, R.; Jaramillo, C.; Hernandez, C.; Rand, A.S. 2001. Avian predation upon lizards and frogs in a Neotropical forest understorey. Journal of Tropical Ecology, 17:21-40.

Poulin, B.; Lefebvre, G.; MacNeil, R. 1994a. Diets of land birds from northeastern Venezuela. Condor, 96(2): 354-367.

Poulin, B.; Lefebvre, G.; Mac Neil, R. 1994b. Characteristics of feeding guilds and variation in diets of bird species of three adjacent tropical sites. Biotropica, 26(2):187-197.

Queirolo, Diego. 2001. Seletividade e sazonalidade das presas consumidas pelo loboguará (Chrysocyon brachyurus) no Parque Nacional da Serra da Canastra, Minas Gerais. São Paulo, 84p. Dissertação (Mestrado) - Instituto de Biociências da Universidade de São Paulo. Departamento de Ecologia. 
Remsen, J.V. 2003. Family Furnariidae (Ovenbirds), pp. 162-357. In. del Hoyo, J; Elliot, A; Christie, D.A. (eds). Handbook of birds of the world. v. 8. Broadbills to Tapaculos. Barcelona, Lynx Edicions.

Remsen Jr, J.V.; Parker III, T.A. 1984. Arboreal dead-leaf searching birds of the Neotropics. Condor, 86: 36-4.

Rice, N.H. 2005. Further evidence for paraphyly of the Formicariidae (Passeriformes). Condor, 107: 910-915.

Ridgely, R.S.; Tudor, G. 1994. The birds of South America: the Suboscine Passerines. v. 2. Austin, University of Texas Press.

Roberts, D. L.; Cooper, R.J.; Petit, L. J. 2000. Flock characteristics of ant-following birds in premontane moist forest and coffee agroecosystems. Ecological Applications, 10:1414-1425.

Rocha, O; Peñaranda, E. 1992. Hábitos alimentícios de cuatro espécies de trepatroncos (Aves: Dendrocolaptidae) de La Reserva de La Biosfera "Estacion Biológica Del Beni” (Beni, Bolivia). Ecología en Bolivia, 19: 57-72.

Rosenberg, K.V. 1990. Dead-leaf foraging specialization in tropical forest birds: measuring resources availability and use. Studies in Avian Biology, 13: 360-368.

Rosenberg, K.V. 1993. Diet selection in Amazonian antwrens: consequences of substrate specialization. Auk, 110 (2): 361-375.

Rosenberg, K.V. 1997. Ecology of dead-leaf foraging specialists and their contribution to Amazonian bird diversity. Ornithological Monographs, 48: 673-700.

Rougés, M.; Blake, J.G. 2001. Tasas de captura y dieta de aves del sotobosque en el Parque Biológico Serra de San Javier, Tucúman. Hornero, 16(1): 7-15.

Santos, G. B.; Marques, M.I.; Adis, J.; Ralph de Musis, C. 2003. Artrópodos associados à copa de Attalea phalerata Mart. (Arecaceae), na região do Pantanal de Poconé, Mato Grosso, Brasil. Revista Brasileira de Entomologia, 47(2): 211-224.

Stehr, F.W. 1991. Imature insects, v. 1-2. Dubuque, Iowa, Kendall/Hunt. 
Sibley, C.G.; Ahlquist, J.E.; Moore, Jr.B.L. 1988. A classification of the living birds of the world based on DNA-DNA hybridization studies. Auk, 105: 409-23.

Sibley, C.G.; Ahlquist, J.E.1990. Phylogeny and classification of birds: a study in molecular evolution. New Haven, Yale University Press.

Sibley, C.G.; Monroe Jr., B.L. 1990. Distribution and taxonomy of the birds of the world. New Haven, Yale University Press.

Sick, H. 1997. Ornitologia brasileira. Rio de Janeiro, Nova Fronteira.

Schubart, O.A.; Aguirre, A.C.; Sick, H. 1965. Contribuição para o conhecimento da alimentação das aves brasileiras. Arquivos de Zoologia do Estado de São Paulo, 12: 95-249.

Vasconcelos, M.F.; Lopes, L.E.; Hoffmann, D. 2007. Dieta e comportamento de forrageamento de Oreophylax moreirae (Aves: Furnariidae) na Serra do Caraça, Minas Gerais, Brasil. Revista Brasileira de Ornitologia, 15(3): 439-442.

Vitt, L.J.; Zani, P.A.; Monteiro de Barros, A.A. 1997. Ecological variation among populations of the Gonatodes humeralis in the Amazon Basin. Copeia, 1997 (1): $32-43$.

Vitt, L.J.; Souza, R.A.; Sartorius, S.S.; Ávila-Pires, T.C.S.; Espósito, M.C. 2000. Comparative ecology of sympatric Gonatodes (Squamata: Gekkonidae) in the Western Amazon of Brazil. Copeia, 2000(1): 83-95.

Wetmore, A. 1972. The birds of the Republic of Panamá - Part 3. Passeriformes: Dendrocolaptidae (Woodcreepers) to Oxyruncidae (Sharpbills). Smithsonian Miscellaneous Collections, 150(3):1-631.

Whitney, B.M. 2003. Family Conopophagidae (Gnateaters), pp. 732-748. In: del Hoyo, J.; Elliott, A.; Christie, D. (eds). Handbook of the birds of the world, v. 8. Broadbills to Tapaculos. Barcelona, Lynx Edicions.

Willis, E.O. 1969. On the behavior of five species of Rhegmatorhina, Ant-following Antbirds of the Amazon basin. Wilson Bulletin, 81(4): 362-395. 
Willis, E.O. 1982. The behavior of scale-backed antbirds. Wilson Bulletin, 94(4): 447462.

Willis, E.O.; Oniki, Y. 1978. Birds and army ants. Annual Review of Ecology, Evolution and Systematics, 9: 243-263.

Zimmer, K.J.; Isler, M.L. 2003. Family Thamnophilidae (Typical Antbirds), p. 448-681. In: del Hoyo, J.; Elliott, A.; Christie, D. (eds). Handbook of the birds of the world, v. 8. Broadbills to Tapaculos. Barcelona, Lynx Edicions.

Zonta-de-Carvalho, R.C.; Moscardi, F. 1994. Efeitos de doses de Baculovirus anticarsia no consumo e na utilização de alimento por larvas de Anticarsia gemmatalis Hübner (Lepidoptera: Noctuiidae). Pesquisa agropecuária brasileira, 29(7): 10191025. 


\section{Resumo}

O clado de Passeriformes denominado, atualmente, Furnariida é endêmico da região Neotropical e muito diversificado; ele é representado por cerca de 623 espécies alocadas em 134 gêneros, distribuídas nas seguintes famílias: Furnariidae, Dendrocolaptidae, Thamnophilidae, Formicariidae, Conopophagidae e Rhinocryptidae. As aves deste grupo são, em geral, encontradas em bandos mistos de espécies e/ou podem seguir formigas de correição, fenômenos que são conspícuos entre aves de florestas tropicais. Os representantes de Furnariida são considerados insetívoros, embora possam consumir, ocasionalmente, pequena quantidade de frutos ou sementes e pequenos vertebrados. Este trabalho teve como objetivo descrever a dieta de espécies representantes dos Furnariida que ocorrem em diferentes regiões da Amazônia, além de estimar o número de presas e de biomassa bruta consumida. Para tal, foi analisado o conteúdo estomacal de 476 espécimes de aves Furnariida, dos quais 51 pertencem à família Furnariidae, 139 à Dendrocolaptidae, 280 à Thamnophilidae, 3 à Formicariidae e 3 à Conopophagidae. Foram utilizados dois métodos diferentes para avaliar a contribuição da biomassa de presas consumidas pelos Dendrocolaptidae. O método da biomassa parcial apresentouse muito incerto e, neste estudo, considerou-se a biomassa estimada como o método mais confiável para comparar o número total de itens e sua biomassa correspondente. As principais presas consumidas por estes pássaros foram Coleoptera, Orthoptera e Araneae. No entanto, Orthoptera foi o item que contribuiu com a maior biomassa ingerida, seguido de Coleoptera e Vertebrata. A alta biomassa de Orthoptera no ambiente poderia explicar o maior consumo, ou preferência desses insetívoros por tal item. Os vertebrados foram consumidos por alguns espécimes de Dendrocolaptidae e de Thamnophilidae e a maior parte do material ingerido pelos dendrocolaptídeos corresponde a Gonatodes humeralis, um pequeno lagarto escansorial; já os vertebrados consumidos pelos tamnofilídeos não foram identificados. A predação de vertebrados pode ser ocasional e, em geral, é considerada oportunística. Nas famílias de Furnariida, com número representativo de espécimes, Orthoptera e Araneae tiveram maior frequência de ocorrência em Furnariidae, enquanto Coleoptera e Orthoptera em Thamnophilidae e Coleoptera em Dendrocolaptidae, o que pode estar relacionado aos hábitos de forrageamento das espécies nelas incluídas.

Palavras-chave: Furnariida, aves, conteúdo estomacal, artrópodes, vertebrados 


\section{Abstract}

The clade Furnariida of the Passeriformes is endemic to the Neotropical region, and is very diverse: it is represented by around 623 species in some 134 genera distributed in the following families: Furnariidae, Dendrocolaptidae, Thamnophilidae, Formicariidae, Conopophagidae e Rhinocryptidae. Commonly the birds of this group are found in mixed-species flocks and/or as army-ant-followers, features that are common amongst birds of the tropical forests. Members of the Funariida are considered to be insectivores although they may occasionally eat small quantities of fruit or seeds, or small vertebrates. The objective of this study was to describe the diet of representative species of the Funariida that occur in different Amazonian regions, and also estimate the numbers of prey and total biomass consumed. To do this the stomach contents of 476 specimens of the Furnariida were analyzed, of which, 51 belonged to the family Funariidae, 139 to the Dendrocolaptidae, 280 to the Thamnophilidae, and 3 each to the Formaricariidae and Conopophagidae. Two methods were used to evaluate the contribution of the biomass of the preys consumed by the Dendrocolaptidae. The partial biomass method was found to be very unreliable and so, in this study, the estimated biomass method was found to be the most appropriate to compare the total number of items in the corresponding biomass. The main types of prey eaten by these birds were Coleoptera, Orthoptera and Araneae. Nevertheless, Orthoptera were the group that made the biggest contribution to the ingested biomass, followed by Coleoptera and Vertebrata. The high biomass of Orthoptera in the environment would explain the high consumption and preference for these insects as prey. The vertebrates were consumed by some specimens of Dendrocolaptidae and Thamnophilidae, and in the case of the dendrocolaptids these were all the small scansorial lizard Gonatodes humeralis; those consumed by the thamnophilids were not identified. Predation on vertebrates seems to be occasional and is probably opportunistic. In the families of the Furnariida, represented by numbers of specimens, Orthoptera and Aranae had the highest frequency of occurrence in the Funariidae, with Coleoptera and Orthoptera in the Thamnophilidae, and Coleoptera in the Dendrocolaptidae, which can be related to the foraging habits of the species in these families.

Key words: Furnariida, birds, stomach contents, arthropods, vertebrates 
Anexo 1 - Relação dos espécimes amostrados.

\begin{tabular}{|c|c|c|c|}
\hline Identificação & $\begin{array}{c}\text { Táxon } \\
\text { Família Furnariidae }\end{array}$ & Data da coleta & Procedência \\
\hline AMZ925 & Synallaxis rutilans Temminck, 1823 & $15 / 12 / 2007$ & Santarém - Pará \\
\hline AMZ1008 & Synallaxis rutilans Temminck, 1823 & $17 / 12 / 2007$ & Santarém - Pará \\
\hline GBN048 & Synallaxis rutilans Temminck, 1823 & $29 / 10 / 2007$ & Vilhena - RO \\
\hline SM229 & Synallaxis rutilans Temminck, 1823 & 05/06/2009 & Paranaíta - MT \\
\hline SM330 & Synallaxis cherriei Gyldenstolpe, 1930 & $10 / 06 / 2009$ & Jacareacanga - PA \\
\hline AMZ806 & Synallaxis gujanensis (Gmelin, 1789) & 08/12/2007 & Aveiro-Pará \\
\hline AMZ827 & Certhiaxis cinnamomeus (Gmelin, 1788) & 08/12/2007 & Aveiro-Pará \\
\hline GBN509 & Philydor erythrocercum (Pelzeln, 1859) & $26 / 09 / 2008$ & Paranaíta - MT \\
\hline SM244 & Philydor erythrocercum (Pelzeln, 1859) & $05 / 06 / 2009$ & Paranaíta - MT \\
\hline SM267 & Philydor erythrocercum (Pelzeln, 1859) & 07/06/2009 & Jacareacanga - PA \\
\hline SM306 & Philydor erythropterum (Sclater, 1856) & 09/06/2009 & Jacareacanga - PA \\
\hline AMZ717 & Philydor pyrrhodes (Cabanis, 1848) & $26 / 09 / 2008$ & Paranaíta - MT \\
\hline GBN337 & Automolus ochrolaemus (Tschudi, 1844) & $27 / 06 / 2008$ & Paranaíta - MT \\
\hline GBN350 & Automolus ochrolaemus (Tschudi, 1844) & $28 / 06 / 2008$ & Paranaíta - MT \\
\hline GBN457 & Automolus ochrolaemus (Tschudi, 1844) & 07/03/2008 & Jacareacanga - PA \\
\hline GBN571 & Automolus ochrolaemus (Tschudi, 1844) & $30 / 09 / 2008$ & Paranaíta - MT \\
\hline GBN597 & Automolus ochrolaemus (Tschudi, 1844) & $30 / 09 / 2008$ & Paranaíta - MT \\
\hline GBN607 & Automolus ochrolaemus (Tschudi, 1844) & $30 / 09 / 2008$ & Paranaíta - MT \\
\hline
\end{tabular}




$\begin{array}{ll}\text { GBN694 } & \text { Automolus ochrolaemus (Tschudi, 1844) } \\ \text { SM085 } & \text { Automolus ochrolaemus (Tschudi, 1844) } \\ \text { SM165 } & \text { Automolus ochrolaemus (Tschudi, 1844) } \\ \text { SM177 } & \text { Automolus ochrolaemus (Tschudi, 1844) } \\ \text { SM287 } & \text { Automolus ochrolaemus (Tschudi, 1844) } \\ \text { AMZ877 } & \text { Automolus ochrolaemus (Tschudi, 1844) } \\ \text { AMZ904 } & \text { Automolus ochrolaemus (Tschudi, 1844) } \\ \text { SM134 } & \text { Automolus ochrolaemus (Tschudi, 1844) } \\ \text { SM149 } & \text { Automolus ochrolaemus (Tschudi, 1844) } \\ \text { AMZ725 } & \text { Automolus infuscatus } \text { (Sclater, 1856) } \\ \text { SM302 } & \text { Automolus paraensis Hartert, 1902 } \\ \text { GBN324 } & \text { Sclerurus mexicanus Sclater, 1857 } \\ \text { GBN712 } & \text { Sclerurus rufigularis } \text { Pelzeln, 1868 } \\ \text { SM079 } & \text { Sclerurus rufigularis } \text { Pelzeln, 1868 } \\ \text { SM284 } & \text { Sclerurus rufigularis } \text { Pelzeln, 1868 } \\ \text { GBN303 } & \text { Sclerurus rufigularis } \text { Pelzeln, 1868 } \\ \text { GBN729 } & \text { Xenops tenuirostris Pelzeln, 1859 } \\ \text { GBN200 } & \text { Xenops minutus (Sparrman, 1788) } \\ \text { GBN292 } & \text { Xenops minutus (Sparrman, 1788) } \\ \text { GBN293 } & \text { Xenops minutus (Sparrman, 1788) } \\ \text { GBN294 } & \text { Xenops minutus (Sparrman, 1788) } \\ \text { GBN360 } & \text { Xenops minutus (Sparrman, 1788) } \\ \text { GBN449 } & \text { Xenops minutus (Sparrman, 1788) }\end{array}$

\begin{tabular}{|c|c|}
\hline 04/10/2008 & Paranaíta - MT \\
\hline $18 / 02 / 2009$ & Paranaíta - MT \\
\hline 01/06/2009 & Paranaíta - MT \\
\hline 01/06/2009 & Paranaíta - MT \\
\hline 09/06/2009 & Paranaíta - MT \\
\hline $10 / 12 / 2007$ & Aveiro - Pará \\
\hline $11 / 12 / 2007$ & Aveiro - Pará \\
\hline 24/02/2009 & Jacareacanga - PA \\
\hline 25/02/2009 & Jacareacanga - PA \\
\hline 05/12/2007 & Aveiro-Pará \\
\hline 09/06/2009 & Jacareacanga - PA \\
\hline 27/06/2008 & Paranaíta, MT. \\
\hline 06/10/2008 & Jacareacanga - PA \\
\hline $17 / 02 / 2009$ & Jacareacanga - PA \\
\hline 09/06/2009 & Paranaíta - MT \\
\hline 27/06/2008 & Paranaíta, MT. \\
\hline 06/10/2008 & Jacareacanga - PA \\
\hline 09/11/2007 & Nova Lacerda - MT \\
\hline 25/06/2008 & Paranaíta - MT \\
\hline 25/06/2008 & Paranaíta - MT \\
\hline 25/06/2008 & Paranaíta - MT \\
\hline 28/06/2008 & Jacareacanga - PA \\
\hline 07/03/2008 & Jacareacanga - PA \\
\hline
\end{tabular}




\begin{tabular}{llll} 
GBN559 & Xenops minutus (Sparrman, 1788) & $27 / 09 / 2008$ & Jacareacanga - PA \\
GBN560 & Xenops minutus (Sparrman, 1788) & $27 / 09 / 2008$ & Jacareacanga - PA \\
GBN590 & Xenops minutus (Sparrman, 1788) & $30 / 09 / 2008$ & Paranaíta - MT \\
GBN697 & Xenops minutus (Sparrman, 1788) & $04 / 10 / 2008$ & Paranaíta - MT \\
SM088 & Xenops minutus (Sparrman, 1788) & $18 / 02 / 2009$ & Paranaíta - MT \\
SM123 & Xenops minutus (Sparrman, 1788) & $24 / 02 / 2009$ & Jacareacanga - PA \\
SM322 & Xenops minutus (Sparrman, 1788) & $09 / 06 / 2009$ & Paranaíta - MT \\
SM341 & Xenops minutus (Sparrman, 1788) & $10 / 06 / 2009$ & Paranaíta - MT \\
AMZ872 & Xenops minutus (Sparrman, 1788) & $10 / 12 / 2007$ & Aveiro - Pará \\
AMZ873 & Xenops minutus (Sparrman, 1788) & $10 / 12 / 2007$ & Aveiro - Pará \\
& Família Dendrocolaptidae & & \\
\hline GBN271 & Dendrocincla fuliginosa (Vieillot, 1818) & $25 / 06 / 2008$ & Paranaíta-MT \\
GBN420 & Dendrocincla fuliginosa (Vieillot, 1818) & $07 / 01 / 2008$ & Jacareacanga-PA \\
GBN421 & Dendrocincla fuliginosa (Vieillot, 1818) & $07 / 01 / 2008$ & Jacareacanga-PA \\
GBN452 & Dendrocincla fuliginosa (Vieillot, 1818) & $07 / 03 / 2008$ & Jacareacanga-PA \\
GBN453 & Dendrocincla fuliginosa (Vieillot, 1818) & $07 / 03 / 2008$ & Jacareacanga-PA \\
GBN580 & Dendrocincla fuliginosa (Vieillot, 1818) & $30 / 09 / 2008$ & Paranaíta-MT \\
GBN591 & Dendrocincla fuliginosa (Vieillot, 1818) & $30 / 09 / 2008$ & Paranaíta-MT \\
SM064 & Dendrocincla fuliginosa (Vieillot, 1818) & $17 / 02 / 2009$ & Paranaíta-MT \\
SM116 & Dendrocincla fuliginosa (Vieillot, 1818) & $23 / 02 / 2009$ & Paranaíta-MT \\
SM121 & Dendrocincla fuliginosa (Vieillot, 1818) & $24 / 02 / 2009$ & Jacareacanga-PA \\
SM122 & Dendrocincla fuliginosa (Vieillot, 1818) & $24 / 02 / 2009$ & Jacareacanga-PA \\
SM162 & Dendrocincla fuliginosa (Vieillot, 1818) & $31 / 05 / 2009$ & Paranaíta-MT
\end{tabular}




\begin{tabular}{|c|c|c|c|}
\hline SM235 & Dendrocincla fuliginosa (Vieillot, 1818) & 05/06/2009 & Paranaíta-MT \\
\hline SM254 & Dendrocincla fuliginosa (Vieillot, 1818) & 06/06/2009 & Paranaíta-MT \\
\hline SM353 & Dendrocincla fuliginosa (Vieillot, 1818) & $11 / 06 / 2009$ & Paranaíta-MT \\
\hline AMZ915 & Dendrocincla fuliginosa (Vieillot, 1818) & $12 / 12 / 2007$ & Aveiro - Pará \\
\hline AMZ916 & Dendrocincla fuliginosa (Vieillot, 1818) & $13 / 12 / 2007$ & Aveiro - Pará \\
\hline AMZ949 & Dendrocincla fuliginosa (Vieillot, 1818) & $15 / 12 / 2007$ & Santarém - Pará \\
\hline AMZ950 & Dendrocincla fuliginosa (Vieillot, 1818) & $15 / 12 / 2007$ & Santarém - Pará \\
\hline AMZ969 & Dendrocincla fuliginosa (Vieillot, 1818) & $15 / 12 / 2007$ & Santarém - Pará \\
\hline GBN164 & Dendrocincla merula (Lichtenstein, 1829) & $07 / 11 / 2007$ & Areia Branca - MT \\
\hline GBN165 & Dendrocincla merula (Lichtenstein, 1829) & $07 / 11 / 2007$ & Areia Branca - MT \\
\hline GBN297 & Dendrocincla merula (Lichtenstein, 1829) & $25 / 06 / 2008$ & Paranaíta-MT \\
\hline GBN395 & Dendrocincla merula (Lichtenstein, 1829) & $29 / 06 / 2008$ & Jacareacanga - PA \\
\hline GBN599 & Dendrocincla merula (Lichtenstein, 1829) & $30 / 09 / 2008$ & Paranaíta-MT \\
\hline GBN605 & Dendrocincla merula (Lichtenstein, 1829) & $30 / 09 / 2008$ & Paranaíta-MT \\
\hline SM002 & Dendrocincla merula (Lichtenstein, 1829) & $12 / 02 / 2009$ & Paranaíta-MT \\
\hline SM163 & Dendrocincla merula (Lichtenstein, 1829) & $31 / 05 / 2009$ & Paranaíta-MT \\
\hline SM314 & Dendrocincla merula (Lichtenstein, 1829) & 09/06/2009 & Paranaíta-MT \\
\hline SM320 & Dendrocincla merula (Lichtenstein, 1829) & 09/06/2009 & Paranaíta-MT \\
\hline SM323 & Dendrocincla merula (Lichtenstein, 1829) & 09/06/2009 & Jacareacanga - PA \\
\hline SM343 & Dendrocincla merula (Lichtenstein, 1829) & $10 / 06 / 2009$ & Jacareacanga - PA \\
\hline SM014 & Deconychura longicauda (Pelzeln, 1868) & $12 / 02 / 2009$ & Paranaíta-MT \\
\hline SM037 & Deconychura longicauda (Pelzeln, 1868) & $15 / 02 / 2009$ & Jacareacanga - PA \\
\hline SM197 & Deconychura longicauda (Pelzeln, 1868) & 02/06/2009 & Jacareacanga - PA \\
\hline
\end{tabular}




$\begin{array}{llll}\text { SM236 } & \text { Deconychura longicauda (Pelzeln, 1868) } & 05 / 06 / 2009 & \text { Paranaíta-MT } \\ \text { GBN363 } & \text { Deconychura stictolaema (Pelzeln, 1868) } & 28 / 06 / 2008 & \text { Jacareacanga - PA } \\ \text { SM081 } & \text { Deconychura stictolaema (Pelzeln, 1868) } & 17 / 02 / 2009 & \text { Jacareacanga - PA } \\ \text { AMZ863 } & \text { Sittasomus griseicapillus (Vieillot, 1818) } & 09 / 12 / 2007 & \text { Aveiro-PA } \\ \text { GBN072 } & \text { Glyphorynchus spirurus (Vieillot, 1819) } & 30 / 10 / 2007 & \text { Vilhena-RO } \\ \text { GBN272 } & \text { Glyphorynchus spirurus (Vieillot, 1819) } & 25 / 06 / 2008 & \text { Paranaíta-MT } \\ \text { GBN295 } & \text { Glyphorynchus spirurus (Vieillot, 1819) } & 25 / 06 / 2008 & \text { Paranaíta-MT } \\ \text { GBN296 } & \text { Glyphorynchus spirurus (Vieillot, 1819) } & 25 / 06 / 2008 & \text { Paranaíta-MT } \\ \text { GBN321 } & \text { Glyphorynchus spirurus (Vieillot, 1819) } & 27 / 06 / 2008 & \text { Paranaíta-MT } \\ \text { GBN362 } & \text { Glyphorynchus spirurus (Vieillot, 1819) } & 28 / 06 / 2008 & \text { Jacareacanga-PA } \\ \text { GBN364 } & \text { Glyphorynchus spirurus (Vieillot, 1819) } & 28 / 06 / 2008 & \text { Jacareacanga - PA } \\ \text { GBN393 } & \text { Glyphorynchus spirurus (Vieillot, 1819) } & 29 / 06 / 2008 & \text { Jacareacanga - PA } \\ \text { GBN411 } & \text { Glyphorynchus spirurus (Vieillot, 1819) } & 07 / 01 / 2008 & \text { Jacareacanga - PA } \\ \text { GBN412 } & \text { Glyphorynchus spirurus (Vieillot, 1819) } & 07 / 01 / 2008 & \text { Jacareacanga - PA } \\ \text { GBN417 } & \text { Glyphorynchus spirurus (Vieillot, 1819) } & 07 / 01 / 2008 & \text { Jacareacanga - PA } \\ \text { GBN419 } & \text { Glyphorynchus spirurus (Vieillot, 1819) } & 07 / 01 / 2008 & \text { Jacareacanga - PA } \\ \text { GBN481 } & \text { Glyphorynchus spirurus (Vieillot, 1819) } & 24 / 09 / 2008 & \text { Paranaíta-MT } \\ \text { GBN507 } & \text { Glyphorynchus spirurus (Vieillot, 1819) } & 25 / 09 / 2008 & \text { Paranaíta-MT } \\ \text { GBN552 } & \text { Glyphorynchus spirurus (Vieillot, 1819) } & 27 / 09 / 2008 & \text { Jacareacanga-PA } \\ \text { GBN561 } & \text { Glyphorynchus spirurus (Vieillot, 1819) } & 27 / 09 / 2008 & \text { Jacareacanga - PA } \\ \text { GBN592 } & \text { Glyphorynchus spirurus (Vieillot, 1819) } & 30 / 09 / 2008 & \text { Paranaíta-MT } \\ \text { GBN647 } & \text { Glyphorynchus spirurus (Vieillot, 1819) } & 02 / 10 / 2008 & \text { Jacareacanga - PA } \\ \text { GBN648 } & \text { Glyphorynchus spirurus (Vieillot, 1819) } & 02 / 10 / 2008 & \text { Jacareacanga-PA }\end{array}$




$\begin{array}{llll}\text { GBN650 } & \text { Glyphorynchus spirurus (Vieillot, 1819) } & 02 / 10 / 2008 & \text { Jacareacanga - PA } \\ \text { GBN653 } & \text { Glyphorynchus spirurus (Vieillot, 1819) } & 02 / 10 / 2008 & \text { Jacareacanga - PA } \\ \text { GBN654 } & \text { Glyphorynchus spirurus (Vieillot, 1819) } & 02 / 10 / 2008 & \text { Jacareacanga-PA } \\ \text { GBN655 } & \text { Glyphorynchus spirurus (Vieillot, 1819) } & 02 / 10 / 2008 & \text { Jacareacanga-PA } \\ \text { GBN656 } & \text { Glyphorynchus spirurus (Vieillot, 1819) } & 02 / 10 / 2008 & \text { Jacareacanga-PA } \\ \text { SM029 } & \text { Glyphorynchus spirurus (Vieillot, 1819) } & 13 / 02 / 2009 & \text { Paranaíta-MT } \\ \text { SM046 } & \text { Glyphorynchus spirurus (Vieillot, 1819) } & 15 / 02 / 2009 & \text { Jacareacanga-PA } \\ \text { SM062 } & \text { Glyphorynchus spirurus (Vieillot, 1819) } & 17 / 02 / 2009 & \text { Paranaíta-MT } \\ \text { SM102 } & \text { Glyphorynchus spirurus (Vieillot, 1819) } & 18 / 02 / 2009 & \text { Jacareacanga-PA } \\ \text { SM164 } & \text { Glyphorynchus spirurus (Vieillot, 1819) } & 31 / 05 / 2009 & \text { Paranaíta-MT } \\ \text { SM168 } & \text { Glyphorynchus spirurus (Vieillot, 1819) } & 01 / 06 / 2009 & \text { Paranaíta-MT } \\ \text { SM175 } & \text { Glyphorynchus spirurus (Vieillot, 1819) } & 01 / 06 / 2009 & \text { Paranaíta-MT } \\ \text { SM181 } & \text { Glyphorynchus spirurus (Vieillot, 1819) } & 01 / 06 / 2009 & \text { Paranaíta-MT } \\ \text { SM189 } & \text { Glyphorynchus spirurus (Vieillot, 1819) } & 02 / 06 / 2009 & \text { Jacareacanga-PA } \\ \text { SM195 } & \text { Glyphorynchus spirurus (Vieillot, 1819) } & 02 / 06 / 2009 & \text { Jacareacanga-PA } \\ \text { SM203 } & \text { Glyphorynchus spirurus (Vieillot, 1819) } & 02 / 06 / 2009 & \text { Jacareacanga-PA } \\ \text { SM239 } & \text { Glyphorynchus spirurus (Vieillot, 1819) } & 05 / 06 / 2009 & \text { Paranaíta-MT } \\ \text { SM242 } & \text { Glyphorynchus spirurus (Vieillot, 1819) } & 05 / 06 / 2009 & \text { Paranaíta-MT } \\ \text { SM251 } & \text { Glyphorynchus spirurus (Vieillot, 1819) } & 06 / 06 / 2009 & \text { Paranaíta-MT } \\ \text { SM256 } & \text { Glyphorynchus spirurus (Vieillot, 1819) } & 07 / 06 / 2009 & \text { Jacareacanga-PA } \\ \text { SM277 } & \text { Glyphorynchus spirurus (Vieillot, 1819) } & 09 / 06 / 2009 & \text { Paranaíta-MT } \\ \text { SM288 } & \text { Glyphorynchus spirurus (Vieillot, 1819) } & 09 / 06 / 2009 & \text { Paranaíta-MT } \\ \text { AMZ709 } & \text { Glyphorynchus spirurus (Vieillot, 1819) } & 05 / 12 / 2007 & \text { Aveiro-PA }\end{array}$




\begin{tabular}{|c|c|c|c|}
\hline AMZ710 & Glyphorynchus spirurus (Vieillot, 1819) & $05 / 12 / 2007$ & Aveiro-PA \\
\hline AMZ737 & Glyphorynchus spirurus (Vieillot, 1819) & $06 / 12 / 2007$ & Aveiro-PA \\
\hline AMZ934 & Glyphorynchus spirurus (Vieillot, 1819) & $15 / 12 / 2007$ & Santarém - Pará \\
\hline AMZ935 & Glyphorynchus spirurus (Vieillot, 1819) & $15 / 12 / 2007$ & Santarém - Pará \\
\hline AMZ936 & Glyphorynchus spirurus (Vieillot, 1819) & $15 / 12 / 2007$ & Santarém - Pará \\
\hline AMZ937 & Glyphorynchus spirurus (Vieillot, 1819) & $15 / 12 / 2007$ & Santarém - Pará \\
\hline AMZ938 & Glyphorynchus spirurus (Vieillot, 1819) & $15 / 12 / 2007$ & Santarém - Pará \\
\hline AMZ939 & Glyphorynchus spirurus (Vieillot, 1819) & $15 / 12 / 2007$ & Santarém - Pará \\
\hline SM219 & Xiphocolaptes promeropirhynchus (Lesson, 1840) & 03/06/2009 & Jacareacanga - PA \\
\hline SM220 & Xiphocolaptes promeropirhynchus (Lesson, 1840) & 03/06/2009 & Jacareacanga - PA \\
\hline AMZ878 & Xiphocolaptes promeropirhynchus (Lesson, 1840) & $10 / 12 / 2007$ & Aveiro-PA \\
\hline GBN709 & Dendrocolaptes certhia (Boddaert, 1783) & $05 / 10 / 2008$ & Jacareacanga - PA \\
\hline SM185 & Dendrocolaptes certhia (Boddaert, 1783) & 02/06/2009 & Jacareacanga - PA \\
\hline SM234 & Dendrocolaptes certhia (Boddaert, 1783) & 05/06/2009 & Paranaíta-MT \\
\hline SM316 & Dendrocolaptes certhia (Boddaert, 1783) & 09/06/2009 & Paranaíta-MT \\
\hline SM317 & Dendrocolaptes certhia (Boddaert, 1783) & 09/06/2009 & Paranaíta-MT \\
\hline SM354 & Dendrocolaptes certhia (Boddaert, 1783) & $11 / 06 / 2009$ & Paranaíta-MT \\
\hline AMZ798 & Dendrocolaptes certhia (Boddaert, 1783) & $07 / 12 / 2007$ & Aveiro-PA \\
\hline AMZ799 & Dendrocolaptes certhia (Boddaert, 1783) & $07 / 12 / 2007$ & Aveiro-PA \\
\hline AMZ947 & Dendrocolaptes hoffmannsii Hellmayr, 1909 & $15 / 12 / 2007$ & Santarém - Pará \\
\hline GBN460 & Xiphorhynchus spixii (Lesson, 1830) & 07/03/2008 & Jacareacanga - PA \\
\hline GBN526 & Xiphorhynchus spixii (Lesson, 1830) & $27 / 09 / 2008$ & Jacareacanga - PA \\
\hline SM080 & Xiphorhynchus spixii (Lesson, 1830) & $17 / 02 / 2009$ & Jacareacanga - PA \\
\hline
\end{tabular}




$\begin{array}{llll}\text { SM297 } & \text { Xiphorhynchus spixii (Lesson, 1830) } & 09 / 06 / 2009 & \text { Jacareacanga - PA } \\ \text { SM329 } & \text { Xiphorhynchus spixii (Lesson, 1830) } & 10 / 06 / 2009 & \text { Jacareacanga - PA } \\ \text { SM345 } & \text { Xiphorhynchus spixii (Lesson, 1830) } & 10 / 06 / 2009 & \text { Jacareacanga - PA } \\ \text { AMZ727 } & \text { Xiphorhynchus spixii (Lesson, 1830) } & 05 / 12 / 2007 & \text { Aveiro-PA } \\ \text { AMZ866 } & \text { Xiphorhynchus spixii (Lesson, 1830) } & 10 / 12 / 2007 & \text { Aveiro-PA } \\ \text { AMZ876 } & \text { Xiphorhynchus spixii (Lesson, 1830) } & 10 / 12 / 2007 & \text { Aveiro-PA } \\ \text { AMZ920 } & \text { Xiphorhynchus spixii (Lesson, 1830) } & 12 / 12 / 2007 & \text { Aveiro-PA } \\ \text { GBN052 } & \text { Xiphorhynchus elegans (Pelzeln, 1868) } & 29 / 10 / 2007 & \text { Vilhena-RO } \\ \text { GBN602 } & \text { Xiphorhynchus elegans (Pelzeln, 1868) } & 30 / 09 / 2008 & \text { Paranaíta-MT } \\ \text { GBN609 } & \text { Xiphorhynchus elegans (Pelzeln, 1868) } & 30 / 09 / 2008 & \text { Paranaíta-MT } \\ \text { SM017 } & \text { Xiphorhynchus elegans (Pelzeln, 1868) } & 12 / 02 / 2009 & \text { Paranaíta-MT } \\ \text { SM065 } & \text { Xiphorhynchus elegans (Pelzeln, 1868) } & 17 / 02 / 2009 & \text { Paranaíta-MT } \\ \text { SM107 } & \text { Xiphorhynchus elegans (Pelzeln, 1868) } & 22 / 02 / 2009 & \text { Paranaíta-MT } \\ \text { AMZ1006 } & \text { Xiphorhynchus } \text { obsoletus (Lichtenstein, 1820) } & 17 / 12 / 2007 & \text { Santarém-PA } \\ \text { GBN323 } & \text { Xiphorhynchus guttatus (Lichtenstein, 1820) } & 27 / 06 / 2008 & \text { Paranaíta-MT } \\ \text { GBN373 } & \text { Xiphorhynchus guttatus (Lichtenstein, 1820) } & 29 / 06 / 2008 & \text { Jacareacanga - PA } \\ \text { GBN516 } & \text { Xiphorhynchus guttatus (Lichtenstein, 1820) } & 26 / 09 / 2008 & \text { Paranaíta-MT } \\ \text { GBN541 } & \text { Xiphorhynchus guttatus (Lichtenstein, 1820) } & 27 / 09 / 2008 & \text { Jacareacanga - PA } \\ \text { SM036 } & \text { Xiphorhynchus guttatus (Lichtenstein, 1820) } & 15 / 02 / 2009 & \text { Jacareacanga-PA } \\ \text { SM127 } & \text { Xiphorhynchus guttatus (Lichtenstein, 1820) } & 24 / 02 / 2009 & \text { Jacareacanga - PA } \\ \text { SM187 } & \text { Xiphorhynchus guttatus (Lichtenstein, 1820) } & 02 / 06 / 2009 & \text { Jacareacanga - PA } \\ \text { SM201 } & \text { Xiphorhynchus guttatus (Lichtenstein, 1820) } & 02 / 06 / 2009 & \text { Jacareacanga - PA } \\ \text { SM223 } & \text { Xiphorhynchus guttatus (Lichtenstein, 1820) } & 03 / 06 / 2009 & \text { Jacareacanga-PA }\end{array}$




\begin{tabular}{llll} 
SM271 & Xiphorhynchus guttatus (Lichtenstein, 1820) & $08 / 06 / 2009$ & Jacareacanga - PA \\
AMZ747 & Xiphorhynchus guttatus (Lichtenstein, 1820) & $06 / 12 / 2007$ & Aveiro-PA \\
AMZ748 & Xiphorhynchus guttatus (Lichtenstein, 1820) & $06 / 12 / 2007$ & Aveiro-PA \\
AMZ791 & Xiphorhynchus guttatus (Lichtenstein, 1820) & $07 / 12 / 2007$ & Aveiro-PA \\
AMZ795 & Xiphorhynchus guttatus (Lichtenstein, 1820) & $07 / 12 / 2007$ & Aveiro-PA \\
AMZ893 & Xiphorhynchus guttatus (Lichtenstein, 1820) & $10 / 12 / 2007$ & Aveiro-PA \\
AMZ890 & Xiphorhynchus picus (Gmelin, 1788) & $10 / 12 / 2007$ & Aveiro-PA \\
AMZ891 & Xiphorhynchus picus (Gmelin, 1788) & $10 / 12 / 2007$ & Aveiro-PA \\
AMZ994 & Xiphorhynchus picus (Gmelin, 1788) & $16 / 12 / 2007$ & Santarém - Pará \\
GBN344 & Lepidocolaptes albolineatus (Lafresnaye, 1845) & $27 / 06 / 2008$ & Paranaíta-MT \\
AMZ763 & Lepidocolaptes albolineatus (Lafresnaye, 1845) & $07 / 12 / 2007$ & Aveiro-PA \\
AMZ702 & Campylorhamphus procurvoides (Lafresnaye, 1850) & $06 / 12 / 2007$ & Aveiro-PA \\
& Família Thamnophilidae & & \\
\hline GBN312 & Cymbilaimus lineatus (Leach, 1814) & $27 / 06 / 2008$ & Paranaíta - MT \\
GBN368 & Cymbilaimus lineatus (Leach, 1814) & $29 / 06 / 2008$ & Jacareacanga - PA \\
GBN604 & Cymbilaimus lineatus (Leach, 1814) & $30 / 09 / 2008$ & Paranaíta - MT \\
AMZ840 & Cymbilaimus lineatus (Leach, 1814) & $08 / 12 / 2007$ & Aveiro - Pará \\
GBN095 & Thamnophilus aethiops Sclater, 1858 & $30 / 10 / 2007$ & Vilhena, RO \\
GBN636 & Thamnophilus aethiops Sclater, 1858 & $02 / 10 / 2008$ & Jacareacanga-PA \\
AMZ787 & Thamnophilus aethiops Sclater, 1858 & $07 / 12 / 2007$ & Aveiro - Pará \\
AMZ809 & Thamnophilus aethiops Sclater, 1858 & $08 / 12 / 2007$ & Aveiro - Pará \\
AMZ813 & Thamnophilus aethiops Sclater, 1858 & $08 / 12 / 2007$ & Aveiro - Pará \\
AMZ843 & Thamnophilus aethiops Sclater, 1858 & $08 / 12 / 2007$ & Aveiro - Pará
\end{tabular}




\begin{tabular}{|c|c|c|c|}
\hline AMZ845 & Thamnophilus aethiops Sclater, 1858 & $08 / 12 / 2007$ & Aveiro - Pará \\
\hline GBN469 & Thamnophilus schistaceus d'Orbigny, 1835 & $07 / 04 / 2008$ & Jacareacanga - PA \\
\hline GBN508 & Thamnophilus schistaceus d'Orbigny, 1835 & $26 / 09 / 2008$ & Paranaíta - MT \\
\hline GBN553 & Thamnophilus schistaceus d'Orbigny, 1835 & $27 / 09 / 2008$ & Paranaíta - MT \\
\hline GBN688 & Thamnophilus schistaceus d'Orbigny, 1835 & $04 / 10 / 2008$ & Paranaíta - MT \\
\hline GBN701 & Thamnophilus schistaceus d'Orbigny, 1835 & 05/10/2008 & Paranaíta - MT \\
\hline SM022 & Thamnophilus schistaceus d'Orbigny, 1835 & $13 / 02 / 2009$ & Paranaíta - MT \\
\hline SM047 & Thamnophilus schistaceus d'Orbigny, 1835 & $15 / 02 / 2009$ & Jacareacanga - PA \\
\hline SM091 & Thamnophilus schistaceus d'Orbigny, 1835 & $18 / 02 / 2009$ & Paranaíta - MT \\
\hline AMZ757 & Thamnophilus schistaceus d'Orbigny, 1835 & $06 / 12 / 2007$ & Aveiro - Pará \\
\hline AMZ771 & Thamnophilus schistaceus d'Orbigny, 1835 & $06 / 12 / 2007$ & Aveiro - Pará \\
\hline AMZ846 & Thamnophilus schistaceus d'Orbigny, 1835 & $08 / 12 / 2007$ & Aveiro - Pará \\
\hline AMZ853 & Thamnophilus schistaceus d'Orbigny, 1835 & $09 / 12 / 2007$ & Aveiro - Pará \\
\hline AMZ887 & Thamnophilus schistaceus d'Orbigny, 1835 & $10 / 12 / 2007$ & Aveiro - Pará \\
\hline AMZ808 & Thamnophilus punctatus (Shaw, 1809) & $08 / 12 / 2007$ & Aveiro - Pará \\
\hline AMZ811 & Thamnophilus punctatus (Shaw, 1809) & $08 / 12 / 2007$ & Aveiro - Pará \\
\hline AMZ926 & Thamnophilus punctatus (Shaw, 1809) & $15 / 12 / 2007$ & Santarém - Pará \\
\hline AMZ930 & Thamnophilus punctatus (Shaw, 1809) & $15 / 12 / 2007$ & Santarém - Pará \\
\hline AMZ991 & Thamnophilus punctatus (Shaw, 1809) & $16 / 12 / 2007$ & Santarém - Pará \\
\hline GBN057 & Thamnophilus stictocephalus Pelzeln, 1868 & $29 / 10 / 2007$ & Vilhena - RO \\
\hline GBN064 & Thamnophilus stictocephalus Pelzeln, 1868 & $29 / 10 / 2007$ & Vilhena - RO \\
\hline GBN065 & Thamnophilus stictocephalus Pelzeln, 1868 & $29 / 10 / 2007$ & Vilhena - RO \\
\hline GBN082 & Thamnophilus stictocephalus Pelzeln, 1868 & $30 / 10 / 2007$ & Vilhena - RO \\
\hline
\end{tabular}




\begin{tabular}{|c|c|c|c|}
\hline GBN371 & Thamnophilus stictocephalus Pelzeln, 1868 & $29 / 06 / 2008$ & Jacareacanga - PA \\
\hline GBN487 & Thamnophilus amazonicus Sclater, 1858 & $25 / 09 / 2008$ & Paranaíta - MT \\
\hline SM104 & Thamnophilus amazonicus Sclater, 1858 & $22 / 02 / 2009$ & Paranaíta - MT \\
\hline SM108 & Thamnophilus amazonicus Sclater, 1858 & $22 / 02 / 2009$ & Paranaíta - MT \\
\hline SM227 & Thamnophilus amazonicus Sclater, 1858 & 05/06/2009 & Paranaíta - MT \\
\hline GBN267 & Thamnomanes saturninus (Pelzeln, 1878) & $25 / 06 / 2008$ & Paranaíta - MT \\
\hline GBN455 & Thamnomanes saturninus (Pelzeln, 1878) & 07/03/2008 & Jacareacanga - PA \\
\hline GBN456 & Thamnomanes saturninus (Pelzeln, 1878) & 07/03/2008 & Jacareacanga - PA \\
\hline GBN479 & Thamnomanes saturninus (Pelzeln, 1878) & 07/04/2008 & Jacareacanga - PA \\
\hline GBN521 & Thamnomanes saturninus (Pelzeln, 1878) & $27 / 09 / 2008$ & Jacareacanga - PA \\
\hline GBN527 & Thamnomanes saturninus (Pelzeln, 1878) & $27 / 09 / 2008$ & Jacareacanga - PA \\
\hline GBN593 & Thamnomanes saturninus (Pelzeln, 1878) & $30 / 09 / 2008$ & Paranaíta - MT \\
\hline GBN596 & Thamnomanes saturninus (Pelzeln, 1878) & $30 / 09 / 2008$ & Paranaíta - MT \\
\hline GBN598 & Thamnomanes saturninus (Pelzeln, 1878) & $30 / 09 / 2008$ & Paranaíta - MT \\
\hline GBN606 & Thamnomanes saturninus (Pelzeln, 1878) & $30 / 09 / 2008$ & Paranaíta - MT \\
\hline GBN614 & Thamnomanes saturninus (Pelzeln, 1878) & $30 / 09 / 2008$ & Paranaíta - MT \\
\hline GBN663 & Thamnomanes saturninus (Pelzeln, 1878) & 03/10/2008 & Paranaíta - MT \\
\hline GBN699 & Thamnomanes saturninus (Pelzeln, 1878) & $04 / 10 / 2008$ & Paranaíta - MT \\
\hline GBN718 & Thamnomanes saturninus (Pelzeln, 1878) & $06 / 10 / 2008$ & Jacareacanga - PA \\
\hline GBN719 & Thamnomanes saturninus (Pelzeln, 1878) & $06 / 10 / 2008$ & Jacareacanga - PA \\
\hline GBN722 & Thamnomanes saturninus (Pelzeln, 1878) & $06 / 10 / 2008$ & Jacareacanga - PA \\
\hline GBN724 & Thamnomanes saturninus (Pelzeln, 1878) & $06 / 10 / 2008$ & Jacareacanga - PA \\
\hline SM010 & Thamnomanes saturninus (Pelzeln, 1878) & $12 / 02 / 2009$ & Paranaíta - MT \\
\hline
\end{tabular}




\begin{tabular}{|c|c|c|c|}
\hline SM067 & Thamnomanes saturninus (Pelzeln, 1878) & $17 / 02 / 2009$ & Paranaíta - MT \\
\hline SM068 & Thamnomanes saturninus (Pelzeln, 1878) & $17 / 02 / 2009$ & Paranaíta - MT \\
\hline SM113 & Thamnomanes saturninus (Pelzeln, 1878) & $23 / 02 / 2009$ & Paranaíta - MT \\
\hline SM120 & Thamnomanes saturninus (Pelzeln, 1878) & $24 / 02 / 2009$ & Jacareacanga - PA \\
\hline SM125 & Thamnomanes saturninus (Pelzeln, 1878) & $24 / 02 / 2009$ & Jacareacanga - PA \\
\hline SM237 & Thamnomanes saturninus (Pelzeln, 1878) & 05/06/2009 & Paranaíta - MT \\
\hline SM238 & Thamnomanes saturninus (Pelzeln, 1878) & 05/06/2009 & Paranaíta - MT \\
\hline SM263 & Thamnomanes saturninus (Pelzeln, 1878) & $07 / 06 / 2009$ & Jacareacanga - PA \\
\hline SM301 & Thamnomanes saturninus (Pelzeln, 1878) & $09 / 06 / 2009$ & Jacareacanga - PA \\
\hline SM326 & Thamnomanes saturninus (Pelzeln, 1878) & $09 / 06 / 2009$ & Jacareacanga - PA \\
\hline SM332 & Thamnomanes saturninus (Pelzeln, 1878) & $10 / 06 / 2009$ & Paranaíta - MT \\
\hline SM333 & Thamnomanes saturninus (Pelzeln, 1878) & $10 / 06 / 2009$ & Paranaíta - MT \\
\hline SM357 & Thamnomanes saturninus (Pelzeln, 1878) & $11 / 06 / 2009$ & Jacareacanga - PA \\
\hline GBN050 & Thamnomanes caesius (Temminck, 1820) & $29 / 10 / 2007$ & Vilhena - RO \\
\hline GBN055 & Thamnomanes caesius (Temminck, 1820) & $29 / 10 / 2007$ & Vilhena - RO \\
\hline GBN094 & Thamnomanes caesius (Temminck, 1820) & $30 / 10 / 2007$ & Vilhena - RO \\
\hline GBN388 & Thamnomanes caesius (Temminck, 1820) & $29 / 06 / 2008$ & Jacareacanga - PA \\
\hline GBN462 & Thamnomanes caesius (Temminck, 1820) & $07 / 03 / 2008$ & Jacareacanga - PA \\
\hline GBN522 & Thamnomanes caesius (Temminck, 1820) & $27 / 09 / 2008$ & Jacareacanga - PA \\
\hline GBN595 & Thamnomanes caesius (Temminck, 1820) & $30 / 09 / 2008$ & Paranaíta - MT \\
\hline GBN720 & Thamnomanes caesius (Temminck, 1820) & $06 / 10 / 2008$ & Jacareacanga - PA \\
\hline SM023 & Thamnomanes caesius (Temminck, 1820) & $13 / 02 / 2009$ & Paranaíta - MT \\
\hline SM066 & Thamnomanes caesius (Temminck, 1820) & $17 / 02 / 2009$ & Paranaíta - MT \\
\hline
\end{tabular}




\begin{tabular}{|c|c|c|c|}
\hline SM213 & Thamnomanes caesius (Temminck, 1820) & 03/06/2009 & Jacareacanga - PA \\
\hline SM272 & Thamnomanes caesius (Temminck, 1820) & 08/06/2009 & Jacareacanga - PA \\
\hline SM335 & Thamnomanes caesius (Temminck, 1820) & $10 / 06 / 2009$ & Paranaíta - MT \\
\hline AMZ732 & Thamnomanes caesius (Temminck, 1820) & 05/12/2007 & Aveiro - Pará \\
\hline AMZ738 & Thamnomanes caesius (Temminck, 1820) & $06 / 12 / 2007$ & Aveiro - Pará \\
\hline AMZ754 & Thamnomanes caesius (Temminck, 1820) & $06 / 12 / 2007$ & Aveiro - Pará \\
\hline AMZ780 & Thamnomanes caesius (Temminck, 1820) & $07 / 12 / 2007$ & Aveiro - Pará \\
\hline AMZ800 & Thamnomanes caesius (Temminck, 1820) & $07 / 12 / 2007$ & Aveiro - Pará \\
\hline AMZ861 & Thamnomanes caesius (Temminck, 1820) & $09 / 12 / 2007$ & Aveiro - Pará \\
\hline AMZ907 & Thamnomanes caesius (Temminck, 1820) & $11 / 12 / 2007$ & Aveiro - Pará \\
\hline AMZ764 & Myrmotherula brachyura (Hermann, 1783) & $06 / 12 / 2007$ & Aveiro - Pará \\
\hline GBN250 & Myrmotherula hauxwelli (Sclater, 1857) & $24 / 06 / 2008$ & Paranaíta - MT \\
\hline GBN322 & Myrmotherula hauxwelli (Sclater, 1857) & $27 / 06 / 2008$ & Paranaíta - MT \\
\hline GBN342 & Myrmotherula hauxwelli (Sclater, 1857) & $27 / 06 / 2008$ & Paranaíta - MT \\
\hline GBN377 & Myrmotherula hauxwelli (Sclater, 1857) & $29 / 06 / 2008$ & Jacareacanga - PA \\
\hline GBN445 & Myrmotherula hauxwelli (Sclater, 1857) & 07/03/2008 & Jacareacanga - PA \\
\hline GBN446 & Myrmotherula hauxwelli (Sclater, 1857) & 07/03/2008 & Jacareacanga - PA \\
\hline GBN447 & Myrmotherula hauxwelli (Sclater, 1857) & 07/03/2008 & Jacareacanga - PA \\
\hline GBN448 & Myrmotherula hauxwelli (Sclater, 1857) & 07/03/2008 & Jacareacanga - PA \\
\hline GBN458 & Myrmotherula hauxwelli (Sclater, 1857) & $07 / 03 / 2008$ & Jacareacanga - PA \\
\hline GBN577 & Myrmotherula hauxwelli (Sclater, 1857) & $30 / 09 / 2008$ & Paranaíta - MT \\
\hline GBN578 & Myrmotherula hauxwelli (Sclater, 1857) & $30 / 09 / 2008$ & Paranaíta - MT \\
\hline GBN579 & Myrmotherula hauxwelli (Sclater, 1857) & $30 / 09 / 2008$ & Paranaíta - MT \\
\hline
\end{tabular}




$\begin{array}{ll}\text { GBN645 } & \text { Myrmotherula hauxwelli (Sclater, 1857) } \\ \text { GBN713 } & \text { Myrmotherula hauxwelli (Sclater, 1857) } \\ \text { SM159 } & \text { Myrmotherula hauxwelli (Sclater, 1857) } \\ \text { SM218 } & \text { Myrmotherula hauxwelli (Sclater, 1857) } \\ \text { SM260 } & \text { Myrmotherula hauxwelli (Sclater, 1857) } \\ \text { SM352 } & \text { Myrmotherula hauxwelli (Sclater, 1857) } \\ \text { GBN391 } & \text { Myrmotherula leucophthalma (Pelzeln, 1868) } \\ \text { GBN416 } & \text { Myrmotherula leucophthalma (Pelzeln, 1868) } \\ \text { GBN476 } & \text { Myrmotherula leucophthalma (Pelzeln, 1868) } \\ \text { GBN600 } & \text { Myrmotherula leucophthalma (Pelzeln, 1868) } \\ \text { SM069 } & \text { Myrmotherula leucophthalma (Pelzeln, 1868) } \\ \text { SM214 } & \text { Myrmotherula leucophthalma (Pelzeln, 1868) } \\ \text { SM325 } & \text { Myrmotherula leucophthalma (Pelzeln, 1868) } \\ \text { SM355 } & \text { Myrmotherula leucophthalma (Pelzeln, 1868) } \\ \text { AMZ756 } & \text { Myrmotherula leucophthalma (Pelzeln, 1868) } \\ \text { AMZ819 } & \text { Myrmotherula leucophthalma (Pelzeln, 1868) } \\ \text { AMZ874 } & \text { Myrmotherula leucophthalma (Pelzeln, 1868) } \\ \text { AMZ913 } & \text { Myrmotherula leucophthalma (Pelzeln, 1868) } \\ \text { GBN182 } & \text { Myrmotherula axillaris (Vieillot, 1817) } \\ \text { GBN260 } & \text { Myrmotherula axillaris (Vieillot, 1817) } \\ \text { GBN392 } & \text { Myrmotherula axillaris (Vieillot, 1817) } \\ \text { GBN427 } & \text { Myrmotherula axillaris (Vieillot, 1817) } \\ \text { GBN428 } & \text { Myrmotherula axillaris (Vieillot, 1817) }\end{array}$

$\begin{array}{ll}\text { 02/10/2008 } & \text { Jacareacanga - PA } \\ \text { 06/10/2008 } & \text { Jacareacanga - PA } \\ \text { 31/05/2009 } & \text { Paranaíta - MT } \\ \text { 03/06/2009 } & \text { Jacareacanga - PA } \\ \text { 07/06/2009 } & \text { Jacareacanga - PA } \\ \text { 11/06/2009 } & \text { Paranaíta - MT } \\ \text { 29/06/2008 } & \text { Jacareacanga - PA } \\ \text { 07/01/2008 } & \text { Jacareacanga - PA } \\ \text { 07/04/2008 } & \text { Jacareacanga - PA } \\ \text { 30/09/2008 } & \text { Paranaíta - MT } \\ \text { 17/02/2009 } & \text { Paranaíta - MT } \\ \text { 03/06/2009 } & \text { Jacareacanga - PA } \\ \text { 09/06/2009 } & \text { Jacareacanga - PA } \\ \text { 11/06/2009 } & \text { Jacareacanga - PA } \\ 06 / 12 / 2007 & \text { Aveiro - Pará } \\ 08 / 12 / 2007 & \text { Aveiro - Pará } \\ \text { 10/12/2007 } & \text { Aveiro - Pará } \\ \text { 12/12/2007 } & \text { Aveiro - Pará } \\ 08 / 11 / 2007 & \text { Nova Lacerda - MT } \\ \text { 24/06/2008 } & \text { Paranaíta - MT } \\ \text { 29/06/2008 } & \text { Jacareacanga - PA } \\ 07 / 02 / 2008 & \text { Jacareacanga - PA } \\ 07 / 02 / 2008 & \text { Jacareacanga - PA }\end{array}$


GBNcpt 62

GBN484

GBN486

GBN525

GBN589

GBN657

GBN659

GBN660

GBN661

SM005

SM119

SM129

SM130

SM155

SM161

SM190

SM191

SM198

SM215

AMZ735

AMZ740

AMZ741

AMZ755
Myrmotherula axillaris (Vieillot, 1817) Myrmotherula axillaris (Vieillot, 1817) Myrmotherula axillaris (Vieillot, 1817) Myrmotherula axillaris (Vieillot, 1817) Myrmotherula axillaris (Vieillot, 1817) Myrmotherula axillaris (Vieillot, 1817) Myrmotherula axillaris (Vieillot, 1817) Myrmotherula axillaris (Vieillot, 1817) Myrmotherula axillaris (Vieillot, 1817) Myrmotherula axillaris (Vieillot, 1817) Myrmotherula axillaris (Vieillot, 1817) Myrmotherula axillaris (Vieillot, 1817) Myrmotherula axillaris (Vieillot, 1817) Myrmotherula axillaris (Vieillot, 1817) Myrmotherula axillaris (Vieillot, 1817) Myrmotherula axillaris (Vieillot, 1817) Myrmotherula axillaris (Vieillot, 1817) Myrmotherula axillaris (Vieillot, 1817) Myrmotherula axillaris (Vieillot, 1817) Myrmotherula axillaris (Vieillot, 1817) Myrmotherula axillaris (Vieillot, 1817) Myrmotherula axillaris (Vieillot, 1817) Myrmotherula axillaris (Vieillot, 1817)

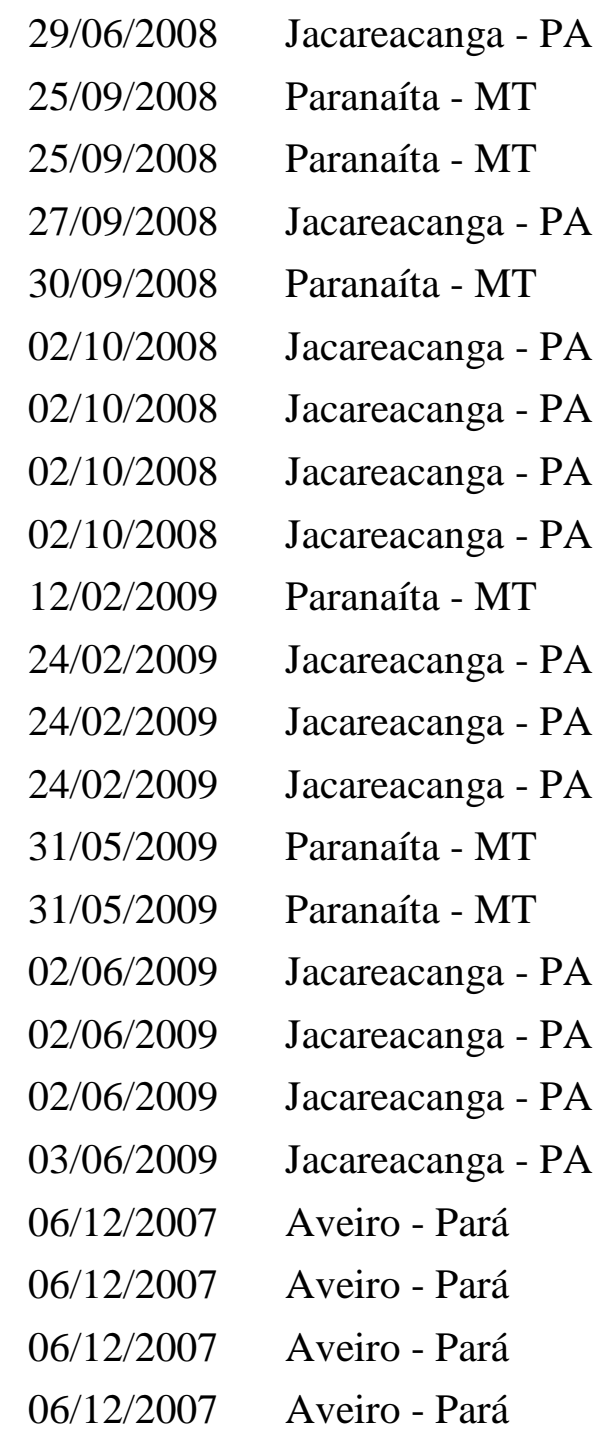




$\begin{array}{llll}\text { AMZ804 } & \text { Myrmotherula axillaris (Vieillot, 1817) } & 07 / 12 / 2007 & \text { Aveiro - Pará } \\ \text { AMZ856 } & \text { Myrmotherula axillaris (Vieillot, 1817) } & 09 / 12 / 2007 & \text { Aveiro - Pará } \\ \text { AMZ886 } & \text { Myrmotherula axillaris (Vieillot, 1817) } & 10 / 12 / 2007 & \text { Aveiro - Pará } \\ \text { AMZ962 } & \text { Myrmotherula axillaris (Vieillot, 1817) } & 15 / 12 / 2007 & \text { Santarém - Pará } \\ \text { AMZ968 } & \text { Myrmotherula axillaris (Vieillot, 1817) } & 15 / 12 / 2007 & \text { Santarém - Pará } \\ \text { AMZ975 } & \text { Myrmotherula axillaris (Vieillot, 1817) } & 15 / 12 / 2007 & \text { Santarém - Pará } \\ \text { AMZ713 } & \text { Myrmotherula iheringi Snethlage, 1914 } & 05 / 12 / 2007 & \text { Aveiro - Pará } \\ \text { GBN611 } & \text { Myrmotherula longipennis Pelzeln, 1868 } & 30 / 09 / 2008 & \text { Paranaíta - MT } \\ \text { GBN710 } & \text { Myrmotherula longipennis Pelzeln, 1868 } & 05 / 10 / 2008 & \text { Jacareacanga - PA } \\ \text { SM016 } & \text { Myrmotherula longipennis Pelzeln, 1868 } & 12 / 02 / 2009 & \text { Paranaíta - MT } \\ \text { SM245 } & \text { Myrmotherula longipennis Pelzeln, 1868 } & 05 / 06 / 2009 & \text { Paranaíta - MT } \\ \text { SM298 } & \text { Myrmotherula longipennis Pelzeln, 1868 } & 09 / 06 / 2009 & \text { Jacareacanga - PA } \\ \text { SM299 } & \text { Myrmotherula longipennis Pelzeln, 1868 } & 09 / 06 / 2009 & \text { Jacareacanga - PA } \\ \text { GBN706 } & \text { Myrmotherula menetriesii (d'Orbigny, 1837) } & 05 / 10 / 2008 & \text { Jacareacanga - PA } \\ \text { GBN122 } & \text { Herpsilochmus rufimarginatus (Temminck, 1822) } & 03 / 11 / 2007 & \text { Jauru- MT } \\ \text { GBN062 } & \text { Microrhopias quixensis (Cornalia, 1849) } & 29 / 10 / 2007 & \text { Vilhena - RO } \\ \text { GBN074 } & \text { Microrhopias quixensis (Cornalia, 1849) } & 30 / 10 / 2007 & \text { Vilhena - RO } \\ \text { GBN406 } & \text { Microrhopias quixensis (Cornalia, 1849) } & 07 / 01 / 2008 & \text { Jacareacanga-PA } \\ \text { GBN566 } & \text { Microrhopias quixensis (Cornalia, 1849) } & 30 / 09 / 2008 & \text { Jacareacanga - PA } \\ \text { AMZ746 } & \text { Microrhopias quixensis (Cornalia, 1849) } & 06 / 12 / 2007 & \text { Aveiro-Pará } \\ \text { AMZ783 } & \text { Microrhopias quixensis (Cornalia, 1849) } & 07 / 12 / 2007 & \text { Aveiro - Pará } \\ \text { AMZ820 } & \text { Microrhopias quixensis (Cornalia, 1849) } & 08 / 12 / 2007 & \text { Aveiro - Pará } \\ \text { AMZ995 } & \text { Microrhopias quixensis (Cornalia, 1849) } & 16 / 12 / 2007 & \text { Santarém - Pará }\end{array}$




$\begin{array}{llll}\text { AMZ996 } & \text { Microrhopias quixensis } \text { (Cornalia, 1849) } & 16 / 12 / 2007 & \text { Santarém - Pará } \\ \text { AMZ854 } & \text { Formicivora grisea } \text { (Boddaert, 1783) } & 09 / 12 / 2003 & \text { Aveiro-Pará } \\ \text { GBN136 } & \text { Formicivora rufa } \text { (Wied, 1831) } & 04 / 11 / 2007 & \text { Jauru - MT } \\ \text { GBN141 } & \text { Formicivora rufa } \text { (Wied, 1831) } & 04 / 11 / 2007 & \text { Jauru - MT } \\ \text { AMZ952 } & \text { Cercomacra nigrescens } \text { (Cabanis \& Heine, 1859) } & 15 / 12 / 2007 & \text { Santarém - Pará } \\ \text { GBN665 } & \text { Cercomacra cinerascens } \text { (Sclater, 1857) } & 03 / 10 / 2008 & \text { Paranaíta - MT } \\ \text { AMZ848 } & \text { Cercomacra cinerascens } \text { (Sclater, 1857) } & 08 / 12 / 2007 & \text { Aveiro-Pará } \\ \text { GBN443 } & \text { Pyriglena leuconota } \text { (Spix, 1824) } & 07 / 03 / 2008 & \text { Jacareacanga - PA } \\ \text { GBN682 } & \text { Myrmoborus myotherinus } \text { (Spix, 1825) } & 04 / 10 / 2008 & \text { Paranaíta - MT } \\ \text { AMZ745 } & \text { Myrmoborus myotherinus } \text { (Spix, 1825) } & 06 / 12 / 2007 & \text { Aveiro - Pará } \\ \text { AMZ767 } & \text { Myrmoborus myotherinus } \text { (Spix, 1825) } & 06 / 12 / 2007 & \text { Aveiro - Pará } \\ \text { AMZ802 } & \text { Myrmoborus myotherinus } \text { (Spix, 1825) } & 07 / 12 / 2007 & \text { Aveiro - Pará } \\ \text { AMZ821 } & \text { Myrmoborus myotherinus } \text { (Spix, 1825) } & 08 / 12 / 2007 & \text { Aveiro - Pará } \\ \text { AMZ942 } & \text { Myrmoborus myotherinus } \text { (Spix, 1825) } & 15 / 12 / 20037 & \text { Santarém - Pará } \\ \text { AMZ943 } & \text { Myrmoborus myotherinus } \text { (Spix, 1825) } & 15 / 12 / 2007 & \text { Santarém - Pará } \\ \text { AMZ944 } & \text { Myrmoborus myotherinus } \text { (Spix, 1825) } & 15 / 12 / 2007 & \text { Santarém - Pará } \\ \text { AMZ967 } & \text { Myrmoborus myotherinus } \text { (Spix, 1825) } & 15 / 12 / 2007 & \text { Santarém - Pará } \\ \text { AMZ977 } & \text { Myrmoborus myotherinus } \text { (Spix, 1825) } & 15 / 12 / 2007 & \text { Santarém - Pará } \\ \text { GBN099 } & \text { Hypocnemis cantator } \text { (Boddaert, 1783) } & 31 / 10 / 2007 & \text { Vilhena- RO } \\ \text { GBN190 } & \text { Hypocnemis cantator } \text { (Boddaert, 1783) } & 08 / 11 / 2007 & \text { Nova Lacerda - MT } \\ \text { GBN380 } & \text { Hypocnemis cantator } \text { (Boddaert, 1783) } & 29 / 06 / 2008 & \text { Jacareacanga - PA } \\ \text { GBN432 } & \text { Hypocnemis cantator } \text { (Boddaert, 1783) } & 07 / 03 / 2008 & \text { Jacareacanga - PA } \\ \text { GBN707 } & \text { Hypocnemis cantator } \text { (Boddaert, 1783) } & 05 / 10 / 2008 & \text { Paranaíta - MT }\end{array}$




\begin{tabular}{|c|c|c|c|}
\hline GBN708 & Hypocnemis cantator (Boddaert, 1783) & $05 / 10 / 2008$ & Paranaíta - MT \\
\hline GBN725 & Hypocnemis cantator (Boddaert, 1783) & $06 / 10 / 2008$ & Jacareacanga - PA \\
\hline SM008 & Hypocnemis cantator (Boddaert, 1783) & $12 / 02 / 2009$ & Paranaíta - MT \\
\hline SM114 & Hypocnemis cantator (Boddaert, 1783) & $23 / 02 / 2009$ & Paranaíta - MT \\
\hline SM153 & Hypocnemis cantator (Boddaert, 1783) & $31 / 05 / 2009$ & Paranaíta - MT \\
\hline SM166 & Hypocnemis cantator (Boddaert, 1783) & $01 / 06 / 2009$ & Paranaíta - MT \\
\hline SM241 & Hypocnemis cantator (Boddaert, 1783) & $05 / 06 / 2009$ & Paranaíta - MT \\
\hline SM248 & Hypocnemis cantator (Boddaert, 1783) & $06 / 06 / 2009$ & Paranaíta - MT \\
\hline SM252 & Hypocnemis cantator (Boddaert, 1783) & $06 / 06 / 2009$ & Paranaíta - MT \\
\hline SM261 & Hypocnemis cantator (Boddaert, 1783) & $07 / 06 / 2009$ & Jacareacanga - PA \\
\hline SM262 & Hypocnemis cantator (Boddaert, 1783) & $07 / 06 / 2009$ & Jacareacanga - PA \\
\hline SM349 & Hypocnemis cantator (Boddaert, 1783) & $10 / 06 / 2009$ & Paranaíta - MT \\
\hline AMZ712 & Hypocnemis cantator (Boddaert, 1783) & $05 / 12 / 2007$ & Aveiro - Pará \\
\hline AMZ726 & Hypocnemis cantator (Boddaert, 1783) & $05 / 12 / 2007$ & Aveiro - Pará \\
\hline AMZ761 & Hypocnemis cantator (Boddaert, 1783) & $06 / 12 / 2007$ & Aveiro - Pará \\
\hline AMZ801 & Hypocnemis cantator (Boddaert, 1783) & $07 / 12 / 2007$ & Aveiro - Pará \\
\hline AMZ879 & Hypocnemis cantator (Boddaert, 1783) & $10 / 12 / 2007$ & Aveiro - Pará \\
\hline AMZ982 & Hypocnemis cantator (Boddaert, 1783) & $16 / 12 / 2007$ & Santarém - Pará \\
\hline GBN538 & Hypocnemoides maculicauda (Pelzeln, 1868) & $27 / 09 / 2008$ & Jacareacanga - PA \\
\hline GBN572 & Hypocnemoides maculicauda (Pelzeln, 1868) & $30 / 09 / 2008$ & Paranaíta - MT \\
\hline GBN667 & Hypocnemoides maculicauda (Pelzeln, 1868) & 03/10/2008 & Jacareacanga - PA \\
\hline SM126 & Hypocnemoides maculicauda (Pelzeln, 1868) & $24 / 02 / 2009$ & Jacareacanga - PA \\
\hline GBN071 & Percnostola leucostigma (Pelzeln, 1868) & $30 / 10 / 2007$ & Vilhena - RO \\
\hline
\end{tabular}




$\begin{array}{llll}\text { SM082 } & \text { Percnostola leucostigma (Pelzeln, 1868) } & 17 / 02 / 2009 & \text { Jacareacanga - PA } \\ \text { AMZ739 } & \text { Percnostola leucostigma (Pelzeln, 1868) } & 06 / 12 / 2003 & \text { Aveiro - Pará } \\ \text { AMZ784 } & \text { Percnostola leucostigma (Pelzeln, 1868) } & 07 / 12 / 2003 & \text { Aveiro - Pará } \\ \text { GBN059 } & \text { Myrmeciza hemimelaena Sclater, 1857 } & 29 / 10 / 2007 & \text { Vilhena - RO } \\ \text { GBN060 } & \text { Myrmeciza hemimelaena Sclater, 1857 } & 29 / 10 / 2007 & \text { Vilhena - RO } \\ \text { GBN078 } & \text { Myrmeciza hemimelaena Sclater, 1857 } & 30 / 10 / 2007 & \text { Vilhena - RO } \\ \text { GBN058 } & \text { Myrmeciza atrothorax (Boddaert, 1783) } & 29 / 10 / 2007 & \text { Vilhena - RO } \\ \text { GBN549 } & \text { Hylophylax naevius (Gmelin, 1789) } & 27 / 09 / 2008 & \text { Jacareacanga - PA } \\ \text { GBN550 } & \text { Hylophylax naevius (Gmelin, 1789) } & 27 / 09 / 2008 & \text { Jacareacanga - PA } \\ \text { GBN711 } & \text { Hylophylax naevius (Gmelin, 1789) } & 06 / 10 / 2008 & \text { Jacareacanga - PA } \\ \text { GBN714 } & \text { Hylophylax naevius (Gmelin, 1789) } & 06 / 10 / 2008 & \text { Jacareacanga - PA } \\ \text { GBN716 } & \text { Hylophylax naevius (Gmelin, 1789) } & 06 / 10 / 2008 & \text { Jacareacanga - PA } \\ \text { SM098 } & \text { Hylophylax naevius (Gmelin, 1789) } & 18 / 02 / 2009 & \text { Jacareacanga - PA } \\ \text { SM327 } & \text { Hylophylax naevius (Gmelin, 1789) } & 10 / 06 / 2009 & \text { Jacareacanga - PA } \\ \text { GBN646 } & \text { Hylophylax punctulatus (Des Murs, 1856) } & 02 / 10 / 2008 & \text { Jacareacanga - PA } \\ \text { SM150 } & \text { Hylophylax punctulatus (Des Murs, 1856) } & 25 / 02 / 2009 & \text { Jacareacanga-PA } \\ \text { SM319 } & \text { Hylophylax punctulatus (Des Murs, 1856) } & 09 / 06 / 2009 & \text { Paranaíta - MT } \\ \text { GBN170 } & \text { Hylophylax poecilinotus (Cabanis 1847) } & 07 / 11 / 2007 & \text { Nova Lacerda - MT } \\ \text { GBN196 } & \text { Hylophylax poecilinotus (Cabanis 1847) } & 09 / 11 / 2007 & \text { Nova Lacerda- MT } \\ \text { GBN268 } & \text { Hylophylax poecilinotus (Cabanis 1847) } & 25 / 06 / 2008 & \text { Paranaíta - MT } \\ \text { GBN275 } & \text { Hylophylax poecilinotus (Cabanis 1847) } & 25 / 06 / 2008 & \text { Paranaíta - MT } \\ \text { GBN305 } & \text { Hylophylax poecilinotus (Cabanis 1847) } & 27 / 06 / 2008 & \text { Paranaíta - MT } \\ \text { GBN320 } & \text { Hylophylax poecilinotus (Cabanis 1847) } & 27 / 06 / 2008 & \text { Paranaíta - MT }\end{array}$




$\begin{array}{llll}\text { GBN357 } & \text { Hylophylax poecilinotus (Cabanis 1847) } & 28 / 06 / 2008 & \text { Jacareacanga - PA } \\ \text { GBN379 } & \text { Hylophylax poecilinotus (Cabanis 1847) } & 29 / 06 / 2008 & \text { Jacareacanga - PA } \\ \text { GBN450 } & \text { Hylophylax poecilinotus (Cabanis 1847) } & 07 / 03 / 2008 & \text { Jacareacanga - PA } \\ \text { GBN474 } & \text { Hylophylax poecilinotus (Cabanis 1847) } & 07 / 04 / 2008 & \text { Jacareacanga - PA } \\ \text { GBN576 } & \text { Hylophylax poecilinotus (Cabanis 1847) } & 30 / 09 / 2008 & \text { Paranaíta - MT } \\ \text { SM083 } & \text { Hylophylax poecilinotus (Cabanis 1847) } & 17 / 02 / 2009 & \text { Jacareacanga - PA } \\ \text { SM115 } & \text { Hylophylax poecilinotus (Cabanis 1847) } & 23 / 02 / 2009 & \text { Paranaíta - MT } \\ \text { SM173 } & \text { Hylophylax poecilinotus (Cabanis 1847) } & 01 / 06 / 2009 & \text { Paranaíta - MT } \\ \text { SM202 } & \text { Hylophylax poecilinotus (Cabanis 1847) } & 02 / 06 / 2009 & \text { Jacareacanga - PA } \\ \text { SM269 } & \text { Hylophylax poecilinotus (Cabanis 1847) } & 07 / 06 / 2009 & \text { Jacareacanga - PA } \\ \text { SM292 } & \text { Hylophylax poecilinotus (Cabanis 1847) } & 09 / 06 / 2009 & \text { Jacareacanga - PA } \\ \text { SM293 } & \text { Hylophylax poecilinotus (Cabanis 1847) } & 09 / 06 / 2009 & \text { Jacareacanga - PA } \\ \text { SM294 } & \text { Hylophylax poecilinotus (Cabanis 1847) } & 09 / 06 / 2009 & \text { Jacareacanga - PA } \\ \text { SM295 } & \text { Hylophylax poecilinotus (Cabanis 1847) } & 09 / 06 / 2009 & \text { Jacareacanga - PA } \\ \text { SM296 } & \text { Hylophylax poecilinotus (Cabanis 1847) } & 09 / 06 / 2009 & \text { Jacareacanga - PA } \\ \text { AMZ867 } & \text { Hylophylax poecilinotus (Cabanis 1847) } & 10 / 12 / 2007 & \text { Aveiro - Pará } \\ \text { AMZ868 } & \text { Hylophylax poecilinotus (Cabanis 1847) } & 10 / 12 / 2007 & \text { Aveiro - Pará } \\ \text { AMZ869 } & \text { Hylophylax poecilinotus (Cabanis 1847) } & 10 / 12 / 2007 & \text { Aveiro - Pará } \\ \text { AMZ905 } & \text { Hylophylax poecilinotus (Cabanis 1847) } & 11 / 12 / 2007 & \text { Aveiro - Pará } \\ \text { GBN574 } & \text { Rhegmatorhina gymnops Ridgway, 1888 } & 30 / 09 / 2008 & \text { Paranaíta - MT } \\ \text { GBN575 } & \text { Rhegmatorhina gymnops Ridgway, 1888 } & 30 / 09 / 2008 & \text { Paranaíta - MT } \\ \text { SM100 } & \text { Rhegmatorhina gymnops Ridgway, 1888 } & 18 / 02 / 2009 & \text { Jacareacanga - PA } \\ \text { SM101 } & \text { Rhegmatorhina gymnops Ridgway, 1888 } & 18 / 02 / 2009 & \text { Jacareacanga - PA }\end{array}$




\begin{tabular}{|c|c|c|c|}
\hline SM278 & Rhegmatorhina gymnops Ridgway, 1888 & 09/06/2009 & Paranaíta - MT \\
\hline SM279 & Rhegmatorhina gymnops Ridgway, 1888 & 09/06/2009 & Paranaíta - MT \\
\hline GBN414 & $\begin{array}{l}\text { Phlegopsis nigromaculata (d'Orbigny \& Lafresnaye, } \\
1837 \text { ) }\end{array}$ & $07 / 01 / 2008$ & Jacareacanga - PA \\
\hline GBN442 & $\begin{array}{l}\text { Phlegopsis nigromaculata (d'Orbigny \& Lafresnaye, } \\
1837 \text { ) }\end{array}$ & 07/03/2008 & Jacareacanga - PA \\
\hline SM060 & $\begin{array}{l}\text { Phlegopsis nigromaculata (d'Orbigny \& Lafresnaye, } \\
\text { 1837) }\end{array}$ & $17 / 02 / 2009$ & Paranaíta - MT \\
\hline SM061 & $\begin{array}{l}\text { Phlegopsis nigromaculata (d'Orbigny \& Lafresnaye, } \\
\text { 1837) }\end{array}$ & $17 / 02 / 2009$ & Paranaíta - MT \\
\hline SM273 & $\begin{array}{l}\text { Phlegopsis nigromaculata (d'Orbigny \& Lafresnaye, } \\
\text { 1837) }\end{array}$ & 08/06/2009 & Jacareacanga - PA \\
\hline AMZ701 & $\begin{array}{l}\text { Phlegopsis nigromaculata (d'Orbigny \& Lafresnaye, } \\
1837 \text { ) }\end{array}$ & $05 / 12 / 2007$ & Aveiro - Pará \\
\hline AMZ704 & $\begin{array}{l}\text { Phlegopsis nigromaculata (d'Orbigny \& Lafresnaye, } \\
\text { 1837) }\end{array}$ & $05 / 12 / 2007$ & Aveiro - Pará \\
\hline AMZ708 & $\begin{array}{l}\text { Phlegopsis nigromaculata (d'Orbigny \& Lafresnaye, } \\
\text { 1837) }\end{array}$ & $05 / 12 / 2007$ & Aveiro - Pará \\
\hline AMZ715 & $\begin{array}{l}\text { Phlegopsis nigromaculata (d'Orbigny \& Lafresnaye, } \\
1837 \text { ) }\end{array}$ & $05 / 12 / 2007$ & Aveiro - Pará \\
\hline AMZ772 & $\begin{array}{l}\text { Phlegopsis nigromaculata (d'Orbigny \& Lafresnaye, } \\
\text { 1837) }\end{array}$ & $06 / 12 / 2007$ & Aveiro - Pará \\
\hline AMZ776 & $\begin{array}{l}\text { Phlegopsis nigromaculata (d'Orbigny \& Lafresnaye, } \\
\text { 1837) }\end{array}$ & $06 / 12 / 2007$ & Aveiro - Pará \\
\hline AMZ931 & $\begin{array}{l}\text { Phlegopsis nigromaculata (d'Orbigny \& Lafresnaye, } \\
\text { 1837) }\end{array}$ & $15 / 12 / 2007$ & Santarém - Pará \\
\hline AMZ945 & $\begin{array}{l}\text { Phlegopsis nigromaculata (d'Orbigny \& Lafresnaye, } \\
1837 \text { ) }\end{array}$ & $15 / 12 / 2007$ & Santarém - Pará \\
\hline AMZ946 & $\begin{array}{l}\text { Phlegopsis nigromaculata (d'Orbigny \& Lafresnaye, } \\
1837 \text { ) }\end{array}$ & $15 / 12 / 2007$ & Santarém - Pará \\
\hline
\end{tabular}




\begin{tabular}{llll} 
AMZ955 & $\begin{array}{l}\text { Phlegopsis nigromaculata (d'Orbigny \& Lafresnaye, } \\
\text { 1837) }\end{array}$ & $15 / 12 / 2007$ & Santarém - Pará \\
& Família Formicariidae & & \\
\hline GBN540 & Formicarius colma Boddaert, 1783 & $27 / 09 / 2008$ & Jacareacanga - PA \\
AMZ888 & Formicarius colma Boddaert, 1783 & $10 / 12 / 2003$ & Aveiro - Pará \\
AMZ889 & Formicarius colma Boddaert, 1783 & $10 / 12 / 2003$ & Aveiro - Pará \\
& Família Conopophagidae & & \\
\hline SM094 & Conopophaga aurita (Gmelin, 1789) & $18 / 02 / 2009$ & Jacareacanga - PA \\
GBN056 & Conopophaga melanogaster Ménétriès, 1835 & $29 / 10 / 2007$ & Vilhena - RO \\
AMZ979 & Conopophaga melanogaster Ménétriès, 1835 & $15 / 12 / 2003$ & Santarém - Pará \\
\hline
\end{tabular}


Anexo 2. Frequência de ocorrência (FO) de itens alimentares consumidos por espécies de Furnariida .

\begin{tabular}{|c|c|c|c|c|c|c|c|}
\hline Itens alimentares & S. rutilans (4) & S. cherriei (1) & S. gujanensis (1) & C. cinnamomeus (1) & P. erytrocercum (3) & P. erytropterum (1) & P. pyrrhodes (1) \\
\hline Araneae & 15,3 & 50 & 20 & 16,6 & 27,2 & 20 & 33,3 \\
\hline Pseudoscorpiones & 0 & 0 & 0 & 0 & 0 & 0 & 0 \\
\hline Archaeognatha & 0 & 0 & 0 & 0 & 0 & 0 & 0 \\
\hline Odonata & 0 & 0 & 0 & 0 & 0 & 0 & 0 \\
\hline Blattodea & 0 & 0 & 0 & 0 & 0 & 0 & 0 \\
\hline Isoptera & 0 & 0 & 0 & 16,6 & 0 & 0 & 0 \\
\hline Dermaptera & 0 & 0 & 0 & 0 & 0 & 0 & 0 \\
\hline Orthoptera & 15,3 & 50 & 0 & 0 & 27,2 & 20 & 33,3 \\
\hline Hemiptera (não identificado) & 0 & 0 & 0 & 0 & 0 & 0 & 0 \\
\hline Hemiptera (Sternorrhyncha) & 0 & 0 & 0 & 0 & 0 & 0 & 0 \\
\hline Hemiptera (Heteroptera) & 15,3 & 0 & 20 & 16,6 & 0 & 20 & 0 \\
\hline Hemiptera (Auchenorrhyncha) & 0 & 0 & 0 & 0 & 0 & 0 & 0 \\
\hline Coleoptera & 23 & 0 & 20 & 16,6 & 18,1 & 0 & 0 \\
\hline Diptera & 0 & 0 & 0 & 16,6 & 0 & 0 & 0 \\
\hline Lepidoptera & 0 & 0 & 0 & 0 & 0 & 0 & 0 \\
\hline Hymenoptera & 0 & 0 & 0 & 0 & 18,1 & 20 & 0 \\
\hline Hymenoptera (Formicidae) & 7,6 & 0 & 20 & 0 & 0 & 0 & 33,3 \\
\hline Chilopoda & 0 & 0 & 0 & 0 & 0 & 0 & 0 \\
\hline Diplopoda & 0 & 0 & 0 & 0 & 0 & 0 & 0 \\
\hline Mollusca & 0 & 0 & 0 & 0 & 0 & 20 & 0 \\
\hline Vertebrata & & 0 & 0 & 0 & 0 & 0 & 0 \\
\hline ovos/ooteca & 7,6 & 0 & 0 & 0 & 0 & 0 & 0 \\
\hline larvas & 15,3 & 0 & 20 & 16,6 & 0 & 0 & 0 \\
\hline não identificado & 0 & 0 & 0 & 0 & 9 & 0 & 0 \\
\hline
\end{tabular}




\begin{tabular}{|c|c|c|c|c|c|c|c|}
\hline Itens alimentares & A. infuscatus (1) & A. paraensis (1) & S. mexicanus (1) & S. rufigularis (3) & X. tenuirostris (1) & D. longicauda (4) & D. stictolaema (2) \\
\hline Araneae & o & 25 & 100 & 33,3 & 0 & 13,3 & 14,3 \\
\hline Pseudos corpiones & 0 & 0 & 0 & 0 & 20 & 6,7 & 0,0 \\
\hline Archaeognatha & 0 & 0 & 0 & 0 & 0 & 0,0 & 0,0 \\
\hline Odonata & 0 & 0 & 0 & 0 & 0 & 0,0 & 0,0 \\
\hline Blattodea & 0 & 0 & 0 & 0 & 0 & 0,0 & 0,0 \\
\hline Isoptera & 0 & 0 & 0 & 33,3 & 20 & 6,7 & 0,0 \\
\hline Dermaptera & 0 & 0 & 0 & 0 & 0 & 0,0 & 0,0 \\
\hline Orthoptera & 0 & 25 & 0 & 0 & 0 & 20,0 & 0,0 \\
\hline Hemiptera (não identificado) & 0 & 0 & 0 & 0 & 0 & 0,0 & 0,0 \\
\hline Hemiptera (Sternorrhyncha) & 0 & 0 & 0 & 0 & 0 & 0,0 & 0,0 \\
\hline Hemiptera (Heteroptera) & 0 & 0 & 0 & 0 & 0 & 6,7 & 14,3 \\
\hline Hemiptera (Auchenorrhyncha) & 0 & 0 & 0 & 0 & 0 & 13,3 & 0,0 \\
\hline Coleoptera & 33,3 & 0 & 0 & 0 & 0 & 26,7 & 28,6 \\
\hline Diptera & 0 & 0 & 0 & 0 & 0 & 6,7 & 0,0 \\
\hline Lepidoptera & 0 & 0 & 0 & 0 & 0 & 0,0 & 0,0 \\
\hline Hymenoptera & 0 & 25 & 0 & 0 & 0 & 0,0 & 14,3 \\
\hline Hymenoptera (Formicidae) & 33,3 & 25 & 0 & 0 & 20 & 0,0 & 0,0 \\
\hline Chilopoda & 0 & 0 & 0 & 0 & 0 & 0,0 & 0,0 \\
\hline Diplopoda & 0 & 0 & 0 & 0 & 0 & 0,0 & 0,0 \\
\hline Mollusca & 0 & 0 & 0 & 0 & 0 & 0,0 & 0,0 \\
\hline Vertebrata & 0 & 0 & 0 & 0 & 0 & 0,0 & 14,3 \\
\hline ovos/ooteca & 33,3 & 0 & 0 & 0 & 20 & 0,0 & 14,3 \\
\hline larvas & 0 & 0 & 0 & 33,3 & 0 & 0,0 & 0,0 \\
\hline não identificado & 0 & 0 & 0 & 0 & 20 & 0,0 & 0,0 \\
\hline
\end{tabular}




\begin{tabular}{|c|c|c|c|c|c|c|c|}
\hline Itens alimentares & S. griseicapillus (1) & X. promeropirrhynch & & D.hoffmannsii (1) & X. picus (3) & X. elegans $(6)$ & X. obsoletus (1) \\
\hline \begin{tabular}{|l|} 
Araneae \\
\end{tabular} & 25,0 & 0,0 & 7,6 & 11,1 & 15,8 & 13,6 & 16,6 \\
\hline \begin{tabular}{|l|} 
Pseudoscorpiones \\
\end{tabular} & 0,0 & 0,0 & 0,0 & 0,0 & 0,0 & 0,0 & 0,0 \\
\hline Archaeognatha & 0,0 & 0,0 & 0,0 & 0,0 & 0,0 & 0,0 & 0,0 \\
\hline Odonata & 0,0 & 0,0 & 0,0 & 0,0 & 0,0 & 0,0 & 0,0 \\
\hline Blattodea & 0,0 & 0,0 & 0,0 & 0,0 & 0,0 & 0,0 & 0,0 \\
\hline Isoptera & 0,0 & 0,0 & 0,0 & 0,0 & 0,0 & 4,5 & 16,6 \\
\hline Dermaptera & 0,0 & 0,0 & 0,0 & 0,0 & 0,0 & 0,0 & 0,0 \\
\hline Orthoptera & 0,0 & 17,6 & 19,2 & 11,1 & 15,8 & 13,6 & 16,6 \\
\hline Hemiptera (não identificado) & 25,0 & 0,0 & 0,0 & 0,0 & 0,0 & 0,0 & 0,0 \\
\hline Hemiptera (Sternorrhyncha) & 0,0 & 0,0 & 0,0 & 0,0 & 0,0 & 0,0 & 0,0 \\
\hline Hemiptera (Heteroptera) & 0,0 & 5,8 & 7,6 & 11,1 & 10,5 & 9,1 & 16,6 \\
\hline Hemiptera (Auchenorrhyncha) & 0,0 & 0,0 & 7,6 & 11,1 & 0,0 & 0,0 & 0,0 \\
\hline Coleoptera & 25,0 & 17,6 & 26,9 & 11,1 & 15,8 & 27,2 & 0,0 \\
\hline Diptera & 0,0 & 0,0 & 0,0 & 11,1 & 5,3 & 0,0 & 0,0 \\
\hline Lepidoptera & 0,0 & 0,0 & 0,0 & 0,0 & 0,0 & 0,0 & 0,0 \\
\hline Hymenoptera & 0,0 & 0,0 & 0,0 & 0,0 & 5,2 & 0,0 & 16,6 \\
\hline Hymenoptera (Formicidae) & 0,0 & 11,7 & 7,6 & 11,1 & 10,5 & 4,5 & 16,6 \\
\hline Chilopoda & 0,0 & 5,8 & 0,0 & 0,0 & 0,0 & 0,0 & 0,0 \\
\hline Diplopoda & 0,0 & 0,0 & 0,0 & 0,0 & 5,3 & 0,0 & 0,0 \\
\hline Mollusca & 0,0 & 5,8 & 3,8 & 0,0 & 0,0 & 0,0 & 0,0 \\
\hline Vertebrata & 0,0 & 5,8 & 0,0 & 0,0 & 0,0 & 4,5 & 0,0 \\
\hline ovos/ooteca & 25,0 & 11,7 & 11,5 & 11,1 & 5,3 & 13,6 & 0,0 \\
\hline larvas & 0,0 & 11,7 & 7,6 & 11,1 & 10,5 & 9,1 & 0,0 \\
\hline não identificado & 0,0 & 5,8 & 0,0 & 0,0 & 0,0 & 0,0 & 0,0 \\
\hline
\end{tabular}




\begin{tabular}{|c|c|c|c|c|c|c|c|}
\hline Itens alimentares & L. albolineatus (2) & C. procurvoides (1) & C. lineatus (4) & T. aethiops (7) & T. punctatus (5) & T. stictocephalus (5) & T. amazonicus (4) \\
\hline \begin{tabular}{|l|} 
Araneae \\
\end{tabular} & 18,2 & 50,0 & 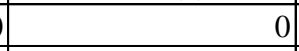 & +2 & 5,8 & 10 & 9,1 \\
\hline \begin{tabular}{|l|} 
Pseudoscorpiones \\
\end{tabular} & 0,0 & 0,0 & 0 & 0 & 0 & 0 & 0 \\
\hline Archaeognatha & 0,0 & 0,0 & 0 & 0 & 0 & 0 & 0 \\
\hline \begin{tabular}{|l|} 
Odonata \\
\end{tabular} & 0,0 & 0,0 & 0 & 0 & 0 & 0 & 0 \\
\hline Blattodea & 0,0 & 0,0 & 0 & 0 & 0 & 0 & 0 \\
\hline Isoptera & 9,1 & 0,0 & 0 & 0 & 0 & 0 & 0 \\
\hline Dermaptera & 0,0 & 0,0 & 0 & 0 & 0 & 0 & 0 \\
\hline Orthoptera & 9,1 & 50,0 & 36,3 & 17,6 & 11,7 & 10 & 18,1 \\
\hline Hemiptera (não identificado) & 0,0 & 0,0 & 0 & 5,8 & 0 & 10 & 0 \\
\hline Hemiptera (Sternorrhyncha) & 0,0 & 0,0 & 0 & 0 & 0 & 0 & 0 \\
\hline Hemiptera (Heteroptera) & 9,1 & 0,0 & 9,1 & 11,7 & 11,7 & 0 & 18,1 \\
\hline Hemiptera (Auchenorrhyncha) & 0,0 & 0,0 & 9,1 & 5,8 & 0 & 10 & 0 \\
\hline Coleoptera & 18,2 & 0,0 & 18,1 & 29,4 & 23,5 & 40 & 36,3 \\
\hline Diptera & 0,0 & 0,0 & 9 & 0 & 5,8 & 10 & 0 \\
\hline Lepidoptera & 0,0 & 0,0 & 0 & 0 & 0 & 0 & 0 \\
\hline Hymenoptera & 0,0 & 0,0 & 0 & 0 & 0 & 0 & 9,1 \\
\hline Hymenoptera (Formicidae) & 18,2 & 0,0 & 0 & 0 & 5,8 & 10 & 0 \\
\hline Chilopoda & 0,0 & 0,0 & 9 & 17,6 & 5,8 & 0 & 0 \\
\hline Diplopoda & 0,0 & 0,0 & 0 & 0 & 0 & 0 & 0 \\
\hline Mollusca & 0,0 & 0,0 & 0 & 0 & 0 & 0 & 0 \\
\hline Vertebrata & 0,0 & 0,0 & 0 & 0 & 0 & 0 & 0 \\
\hline ovos/ooteca & 18,2 & 0,0 & 9 & 11,7 & 11,7 & 0 & 9,1 \\
\hline larvas & 0,0 & 0,0 & 0 & 0 & 17,6 & 0 & 0 \\
\hline não identificado & 0,0 & 0,0 & 0 & 0 & 0 & 0 & 0 \\
\hline
\end{tabular}




\begin{tabular}{|c|c|c|c|c|c|c|c|}
\hline Itens alimentares & M. brachyura (1) & M. iheringi (1) & M. longipennis (6) & M. menetriessi (1) & H. rufimarginatus (1) & M. quixensis (9) & F. grisea (1) \\
\hline Araneae & 25 & 50 & 14,2 & 33,3 & 0 & 10,5 & +2 \\
\hline Pseudoscorpiones & 0 & 0 & 0 & 0 & 0 & 0 & 0 \\
\hline Archaeognatha & 0 & 0 & 0 & 0 & 0 & 0 & 0 \\
\hline Odonata & 0 & 0 & 0 & 0 & 0 & 0 & 0 \\
\hline Blattodea & 0 & 0 & 0 & 0 & 0 & 0 & 0 \\
\hline Isoptera & 0 & 0 & 0 & 0 & 0 & 0 & 0 \\
\hline Dermaptera & 0 & 0 & 0 & 0 & 0 & 0 & 0 \\
\hline Orthoptera & 0 & 0 & 28,5 & 0 & 0 & 5,2 & 50 \\
\hline Hemiptera (não identificado) & 0 & 0 & 0 & 0 & 0 & 0 & 0 \\
\hline Hemiptera (Sternorrhyncha) & 0 & 0 & 0 & 0 & 0 & 0 & 0 \\
\hline Hemiptera (Heteroptera) & 25 & 0 & 14,2 & 0 & 0 & 26,3 & 0 \\
\hline Hemiptera (Auchenorrhyncha) & 0 & 0 & 0 & 0 & 0 & 0 & 0 \\
\hline Coleoptera & 25 & 50 & 28,5 & 33,3 & 0 & 21 & 0 \\
\hline Diptera & 0 & 0 & 0 & 0 & 0 & 5,2 & 0 \\
\hline Lepidoptera & 0 & 0 & 0 & 0 & 0 & 0 & 0 \\
\hline Hymenoptera & 0 & 0 & 7,1 & 0 & 0 & 5,2 & 0 \\
\hline Hymenoptera (Formicidae) & 25 & 0 & 0 & 33,3 & 50 & 10,5 & 0 \\
\hline Chilopoda & 0 & 0 & 0 & 0 & 0 & 0 & 0 \\
\hline Diplopoda & 0 & 0 & 0 & 0 & 0 & 0 & 0 \\
\hline \begin{tabular}{|l|} 
Mollusca \\
\end{tabular} & 0 & 0 & 0 & 0 & 0 & 0 & 0 \\
\hline Vertebrata & 0 & 0 & 0 & 0 & 0 & 0 & 0 \\
\hline ovos/ooteca & 0 & 0 & 0 & 0 & 50 & 5,2 & 0 \\
\hline larvas & 0 & 0 & 7,1 & 0 & 0 & 10,5 & 0 \\
\hline não identificado & 0 & 0 & 0 & 0 & 0 & 0 & 0 \\
\hline
\end{tabular}




\begin{tabular}{|c|c|c|c|c|c|c|c|}
\hline Itens alimentares & F. rufa (2) & C. nigrescens (1) & C. cinerascens (2) & P. leuconota (1) & H. maculicauda (1) & S. leucostigma (4) & M. hemimelaena (3) \\
\hline Araneae & 0 & 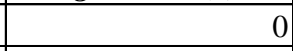 & 14,2 & 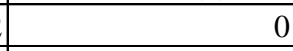 & 20 & 16,6 & 0 \\
\hline \begin{tabular}{|l|} 
Pseudoscorpiones \\
\end{tabular} & 0 & 0 & 0 & 0 & 0 & 0 & 0 \\
\hline Archaeognatha & 0 & 0 & 0 & 0 & 0 & 0 & 0 \\
\hline Odonata & 0 & 0 & 0 & 0 & 0 & 0 & 0 \\
\hline Blattodea & 0 & 0 & 0 & 0 & 0 & 0 & 0 \\
\hline Isoptera & 0 & 0 & 0 & 33,3 & 0 & 0 & 0 \\
\hline Dermaptera & 0 & 0 & 0 & 0 & 0 & 0 & 0 \\
\hline Orthoptera & 33,3 & 25 & 14,2 & 33,3 & 6,6 & 16,6 & 33,3 \\
\hline Hemiptera (não identificado) & 0 & 0 & 0 & 0 & 0 & 0 & 0 \\
\hline Hemiptera (Sternorrhyncha) & 0 & 0 & 0 & 0 & 0 & 0 & 0 \\
\hline Hemiptera (Heteroptera) & 16,6 & 0 & 28,5 & 0 & 6,6 & 8,3 & 0 \\
\hline Hemiptera (Auchenorrhyncha) & 0 & 0 & 0 & 0 & 6,6 & 0 & 0 \\
\hline Coleoptera & 16,6 & 25 & 28,5 & 0 & 26,6 & 25 & 33,3 \\
\hline Diptera & 0 & 0 & 0 & 0 & 6,6 & 0 & 0 \\
\hline \begin{tabular}{|l|} 
Lepidoptera \\
\end{tabular} & 0 & 0 & 0 & 0 & 0 & 0 & 0 \\
\hline Hymenoptera & 0 & 0 & 0 & 0 & 6,6 & 0 & 0 \\
\hline \begin{tabular}{|l|} 
Hymenoptera (Formicidae) \\
\end{tabular} & 33,3 & 25 & 0 & 33,3 & 20 & 16,6 & 22,2 \\
\hline Chilopoda & 0 & 0 & 0 & 0 & 0 & 0 & 0 \\
\hline Diplopoda & 0 & 0 & 0 & 0 & 0 & 0 & 0 \\
\hline \begin{tabular}{|l|} 
Mollusca \\
\end{tabular} & 0 & 0 & 0 & 0 & 0 & 0 & 0 \\
\hline \begin{tabular}{|l|} 
Vertebrata \\
\end{tabular} & 0 & 0 & 0 & 0 & 0 & 8,3 & 0 \\
\hline ovos/ooteca & 0 & 25 & 14,2 & 0 & 0 & 0 & 0 \\
\hline larvas & 0 & 0 & 0 & 0 & 0 & 8,3 & 0 \\
\hline não identificado & 0 & 0 & 0 & 0 & 0 & 0 & 11,1 \\
\hline
\end{tabular}




\begin{tabular}{|c|c|c|c|c|c|c|c|}
\hline Itens alimentares & M. atrothorax (1) & H. naevius (7) & H. punctulatus (3) & R. gymnops (6) & F.colma (3) & C. aurita (1) & C. melanogaster (2) \\
\hline Araneae & 然 & 4,5 & 14,2 & 22,2 & 0 & 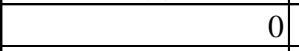 & 0 \\
\hline \begin{tabular}{|l|} 
Pseudoscorpiones \\
\end{tabular} & 0 & 0 & 0 & 0 & 0 & 0 & 0 \\
\hline Archaeognatha & 0 & 0 & 0 & 0 & 0 & 0 & 0 \\
\hline Odonata & 0 & 0 & 0 & 0 & 0 & 0 & 0 \\
\hline Blattodea & 0 & 0 & 0 & 0 & 0 & 0 & 0 \\
\hline Isoptera & 0 & 0 & 0 & 0 & 0 & 0 & 28,5 \\
\hline Dermaptera & 0 & 0 & 0 & 0 & 0 & 0 & 0 \\
\hline Orthoptera & 50 & 13,6 & 14,2 & 16,6 & 14,2 & 0 & 0 \\
\hline Hemiptera (não identificado) & 0 & 0 & 0 & 0 & 0 & 0 & 0 \\
\hline Hemiptera (Sternorrhyncha) & 0 & 0 & 0 & 0 & 0 & 0 & 0 \\
\hline Hemiptera (Heteroptera) & 0 & 9,1 & 14,2 & 16,6 & 14,2 & 0 & 14,2 \\
\hline Hemiptera (Auchenorrhyncha) & 0 & 0 & 0 & 0 & 0 & 0 & 0 \\
\hline Coleoptera & 50 & 22,7 & 28,5 & 11,1 & 14,2 & 50 & 28,5 \\
\hline Diptera & 0 & 0 & 0 & 5,5 & 0 & 0 & 0 \\
\hline \begin{tabular}{|l|} 
Lepidoptera \\
\end{tabular} & 0 & 0 & 0 & 0 & 0 & 0 & 0 \\
\hline Hymenoptera & 0 & 9 & 0 & 11,1 & 0 & 50 & 14,2 \\
\hline \begin{tabular}{|l|} 
Hymenoptera (Formicidae) \\
\end{tabular} & 0 & 22,7 & 14,2 & 11,1 & 42,8 & 0 & 14,2 \\
\hline Chilopoda & 0 & 0 & 0 & 0 & 0 & 0 & 0 \\
\hline Diplopoda & 0 & 0 & 0 & 0 & 0 & 0 & 0 \\
\hline \begin{tabular}{|l|} 
Mollusca \\
\end{tabular} & 0 & 0 & 0 & 0 & 0 & 0 & 0 \\
\hline \begin{tabular}{|l|} 
Vertebrata \\
\end{tabular} & 0 & 0 & 0 & 0 & 0 & 0 & 0 \\
\hline ovos/ooteca & 0 & 0 & 14,2 & 0 & 0 & 0 & 0 \\
\hline larvas & 0 & 9,1 & 0 & 5,5 & 0 & 0 & 0 \\
\hline não identificado & 0 & 9,1 & 0 & 0 & 14,2 & 0 & 0 \\
\hline
\end{tabular}

